\title{
Dorsolateral head muscles of the catfish families Nematogenyidae and Trichomycteridae (Siluriformes: Loricarioidei): comparative anatomy and phylogenetic analysis
}

\author{
Aléssio Datovo and Flávio Alicino Bockmann
}

The skeletal muscles of the dorsolateral region of the head of the Nematogenyidae and representatives of the all major clades of the Trichomycteridae are described and illustrated. A hypothesis on the phylogenetic relationships among these taxa exclusively based on the surveyed musculature is presented. The single most parsimonious cladogram obtained from the phylogenetic analysis of the 36 myological characters gathered and 35 terminal-taxa mostly agrees with the previous hypotheses of trichomycterid intrarelationships. The Copionodontinae and Trichogeninae form a monophyletic lineage that is the sistergroup to all remaining trichomycterids. The monophyly of the clades formed by Glanapteryginae plus Sarcoglanidinae; Stegophilinae plus Tridentinae plus Vandelliinae; and the assemblage comprising all of these five subfamilies (TSVSG clade) is corroborated. Two of our findings are, however, discordant with the previous prevailing hypotheses: the sister-group relationship among Tridentinae and Stegophilinae and the monophyly of the Trichomycterinae lato sensu, i.e., including the genera Scleronema and Ituglanis. In addition, the previously proposed osteological synapomorphies supporting the close affinities of Scleronema and Ituglanis with the TSVSG clade were revised, revealing that they are either invalid or ambiguous. Most of the synapomorphies herein proposed are homoplasy-free, with some of them corroborating the monophyly of weakly-supported groups, such as Stegophilinae.

Os músculos esqueléticos da região dorsolateral da cabeça de Nematogenyidae e de representantes de todos os maiores clados de Trichomycteridae são descritos e ilustrados. Uma hipótese das relações filogenéticas entre estes táxons, baseada exclusivamente na musculatura estudada, é apresentada. O único cladograma mais parcimonioso obtido da análise filogenética dos 36 caracteres miológicos levantados e 35 táxons-terminais concorda com a maior parte das hipóteses anteriores de relações entre os tricomicterídeos. Copionodontinae e Trichogeninae formam uma linhagem monofilética que é grupo-irmã de todos os demais tricomicterídeos. O monofiletismo dos clados formados por Glanapteryginae mais Sarcoglanidinae; Stegophilinae mais Tridentinae mais Vandelliinae; e do agrupamento incluindo estas cinco subfamílias (clado TSVSG) é corroborado. Duas de nossas descobertas são, entretanto, discordantes com relação às hipóteses anteriores mais aceitas: a relação de grupo-irmão entre Tridentinae e Stegophilinae e o monofiletismo de Trichomycterinae lato sensu, i.e., incluindo os gêneros Scleronema e Ituglanis. Além disso, as sinapomorfias osteológicas previamente propostas suportando as relações de afinidade de Scleronema e Ituglanis com o clado TSVSG foram revisadas, revelando serem inválidas ou ambíguas. A maior parte das sinapomorfias aqui propostas são livres de homoplasias, com algumas delas corroborando o monofiletismo de grupos fracamente suportados, tais como o da subfamília Stegophilinae.

Key words: Myology, Ostariophysi, Teleostei.

\section{Introduction}

The Siluriformes is a worldwide, megadiverse group of primarily freshwater fishes with 3370 valid species described to date (Eschmeyer \& Fong, 2010). Historically, most of the anatomical studies on catfishes, either in descriptive approaches or as sources of information for cladistic analyses, relied heavily upon their skeleton, due its known utility, easy access and extensive literature. Alternative body systems and approaches to the study of catfish morphology are rarely addressed, and when undertaken, rarely carried on in an organized fashion. Musculature is certainly the second most investigated morphological complex in fishes. Despite being recognized as phylogenetically informative (e.g. Winterbottom, 1974b, 1993; Yabe, 1985; Stiassny, 1990; Springer \& Johnson, 2004; Hertwig, 2008), sometimes with changes apparently more conspicuous than those of others morphological systems (Winterbottom, 1974b: 1), myology

Laboratório de Ictiologia de Ribeirão Preto, Universidade de São Paulo, FFCLRP, Departamento de Biologia, Programa de Pós-Graduação em Biologia Comparada. Av. dos Bandeirantes, 3900, 14040-901 Ribeirão Preto, SP, Brazil. adatovo@gmail.com, fabockmann@ffclrp.usp.br 
remains poorly explored by systematists. This is likely due to the obstacles intrinsic to the investigation of this body system: dissections are laborious, time-consuming, and, many times, destructive (preventing future verification of conditions in the same material); observations are difficult, and a standardized comparative framework is deficient. In the catfish literature, exceptions are found in the recent contributions by Diogo and collaborators (e.g. Diogo, 2007; Diogo \& Vandewalle, 2003; Diogo et al., 2004, 2006).

In the present study we carried out an investigation on the dorsolateral head myology of two Neotropical catfish lineages that are currently thought to be sister-groups, the Nematogenyidae and Trichomycteridae (de Pinna, 1992, 1998; Diogo, 2005). These taxa are of special interest due to their key positions in the phylogeny of Siluriformes. First of all, they comprise the basal most lineage of the suborder Loricarioidei (sensu Sullivan et al., 2006; interchangeably treated as superfamily Loricarioidea by Schaefer \& Lauder, 1986; de Pinna, 1998), a group which also includes the families Callichthyidae, Scoloplacidae, Astroblepidae, and Loricariidae. Moreover, the Loricarioidei is a group that apparently diverged relatively early in the catfish evolution (cf. Arratia, 1992; de Pinna, 1998; Diogo, 2005), being recently regarded as the basal most group in the Siluriformes (Sullivan et al., 2006; Lundberg et al., 2007). Accordingly, morphological studies in Nematogenyidae and Trichomycteridae, especially of the former (de Pinna, 1998), may be important for an understanding of the evolution of traits in the Loricarioidei in particular and the Siluriformes as a whole.

The Nematogenyidae is endemic to the upper reaches of central Chile (de Pinna, 1998). The single living species of the family, Nematogenys inermis, inhabits the plane sectors with slow-running waters of rivers and streams, being associated with aquatic vegetation as juveniles and occupying deeper areas (pools) when adults (Arratia, 1983). Nematogenys is of singular interest because it is thought to retain several primitive character states within the suborder Loricarioidei (Arratia \& Huaquín, 1995; de Pinna, 1998). It is presently accepted as the sister-group of Trichomycteridae, and this hypothesis is based on several anatomical features (Mo, 1991; de Pinna, 1992; Diogo, 2005; Diogo et al., 2006). External cheek and opercular muscles of Nematogenys inermis were briefly described by Howes (1983a, 1983b) and illustrated by Arratia (1992: fig. 43b) and de Pinna (1998: fig. 7), whereas Schaefer \& Lauder (1986) briefly commented on the adductor mandibulae muscle-complex and hyoid musculature of $N$. inermis. The most complete descriptive treatment of the myology for the Nematogenyidae was provided by Diogo et al. (2006). However, examination of material of $N$. inermis revealed various problematic interpretations of the muscular structures proposed by Diogo (2005) and Diogo et al. (2006), revealing the need of an in depth re-analysis of the myology of this species.

The Trichomycteridae, also a Neotropical group, is one of the most specious catfish families, currently encompassing 241 valid species (Eschmeyer \& Fong, 2010). This family is widely distributed throughout the major river drainages from
Costa Rica to Patagonia (de Pinna \& Wosiacki, 2003). The monophyly of Trichomycteridae is very well supported, with the most conspicuous characters involving its highly specialized opercular-interopercular apparatus (Baskin, 1973; de Pinna, 1992, 1998). This system allows a generalized trichomycterine to climb a steep rocky substrate with fastflowing waters (pers. obs.; de Pinna, 1998) and a parasite vandelliine to anchor in the branchial chambers of its host (Zuanon \& Sazima, 2004a, 2004c; Adriaens et al., 2010).

Trichomycterids encompass one of the greatest ranges of feeding modes and habitats in a single fish family. Adults of Copionodontinae and Trichogeninae explore the water column, with the former resting on the bottom but making constant incursions to the upper water levels, while the latter is markedly nektonic, and both feed mostly on insects (FAB, pers. obs.; Sazima, 2004). Trichomycterines are primarily invertebrate-eaters and dwell on rocky bottoms, where they have remarkable skills to resist and ascend against strong currents (pers. obs.; de Pinna, 1998). Glanapterygines and sarcoglanidines are mostly insectivorous, with the former living inside the leaf litter (FAB, pers. obs.; Nico \& de Pinna, 1996) and the latter inhabiting the most superficial layers of clear loose sand and fine gravel (pers. obs.; Zuanon \& Sazima, 2004b; Zuanon et al., 2006). The glanapterygines Pygidianops and Typhlobelus are also psamophilous (Schaefer et al., 2005), but they occupy the deeper interstices of the sandy habitats (FAB, pers. obs.). Members of the Stegophilinae are usually reported to be scale- or mucus-eaters (Baskin et al., 1980; Winemiller \& Yan, 1989; de Pinna, 1998; Fernández \& Schaefer, 2009), but also include carnivores and even scavengers (pers. obs.; Goulding, 1979, 1980; Lüling, 1984). The Trichomycteridae also includes the vandelliines, whose infamous hematophagous members obtain blood from the gills of other fishes (Kelley \& Atz, 1964; Machado \& Sazima, 1983; de Pinna, 1998). Vandelliines and most stegophilines - the so-called "candirus", "caneros", or "carneros" - rest buried in sand bars, fine gravel, and muddy substrate (pers. obs.; Haseman, 1911; Devincenzi \& Teague, 1942; Roberts, 1972; Baskin et al., 1980; Winemiller \& Yan, 1989; Spotte, 2002). The stegophilines Pareiodon and Pseudostegophilus and the Tridentinae are presumably nektonic (FAB, pers. obs.; $c f$. Roberts, 1972; Ferraris, 1991), although members of the latter subfamily are also said to hide in sand bottoms (Burgess, 1989). Such a stunning diversity of feeding specializations, behaviors, and wide range of habitats are obviously mirrored in their morphology.

The Trichomycteridae is recognized as one of the best known siluriform groups in phylogenetic terms (de Pinna, 1998; de Pinna \& Wosiacki, 2003). Members are currently grouped in eight subfamilies: Copionodontinae, Trichogeninae, Trichomycterinae, Glanapteryginae, Sarcoglanidinae, Tridentinae, Stegophilinae, and Vandelliinae. The genera Ituglanis and Scleronema were proposed as occupying phylogenetic positions that justified subfamilial status (Costa \& Bockmann, 1993; de Pinna, 1998). Since this rank was never formally proposed, we follow de Pinna \& 
Wosiacki (2003) who maintained these genera within the Trichomycterinae by default. Monophyly of all subfamilies of the Trichomycteridae is well-corroborated (Baskin, 1973; de Pinna, 1989a, 1989b, 1992, 1998; de Pinna \& Britski, 1991; Costa \& Bockmann, 1994), with the exception of the Trichomycterinae, whose phyletic status has been object of numerous discussions over recent decades (de Pinna, 1989a; Arratia, 1990, 1998; Costa \& Bockmann, 1993; Bockmann et al., 2004; see "Discussion"). Elucidation of the relationships of the members of the Trichomycterinae is critical to an understanding of the evolution of the family as a whole inasmuch as they form a large gray zone containing about $57 \%$ of the diversity of the group at a basal region of the Trichomycteridae cladogram (cf. de Pinna, 1998).

In spite of the remarkable morphological diversity in the Trichomycteridae, its musculature is one of the less known among all catfish families, both in phylogenetic and descriptive terms. Howes (1983b) briefly described the superficial cheek and opercular muscles of the Trichomycteridae on the basis of observations done on one vandelliine (Branchioica $=$ Paravandellia; cf. de Pinna \& Wosiacki, 2003) and three trichomycterines (Eremophilus and two species of Trichomycterus). Schaefer \& Lauder (1986) provided commentaries on the adductor mandibulae complex and hyoid musculature of the Trichomycteridae based on single species of both Henonemus and Trichomycterus. The most important contribution to the knowledge of the myology of the Trichomycteridae published so far is the study of Adriaens et al. (2010) in which the cranial musculature of Trichomycterus guianensis is described in greater detail. Phylogenetic relationships among the major groups of the family were established on the basis of 72 characters (de Pinna, 1998), most of them from the skeleton (83.3\%). A single myological synapomorphy emerged as informative in that analysis, the presence of the protractor operculi muscle, an element first identified as the "preopercular muscle" by Howes (1983b: 329 and fig. 12b), and which was treated as a synapomorphy for non-Copionodontinae, non-Trichogeninae trichomycterids (de Pinna, 1992, 1998). Diogo (2005) proposed several new putative synapomorphies for the Trichomycteridae, including two derived from observations in the dilatator operculi (however, see Discussion) based on examination of Hatcheria macraei and three species of Trichomycterus. For most trichomycterid subfamilies, virtually nothing is known about their myology. In this scenario, myology may potentially offer new lines of evidence for elucidating these relationships, by testing previous hypotheses and highlighting new ones.

In light of the above situation, the purposes of this study were: (1) to provide phylogenetically-oriented descriptions of the dorsolateral head musculature for the Nematogenyidae and each key group of the Trichomycteridae, in order to standardize the future myological comparisons involving these families; (2) evaluate the relationships between the Nematogenyidae and Trichomycteridae and postulate a phylogenetic hypothesis on the relationships within the latter family, based on characters from the investigated musculature; and (3) compare the obtained hypothesis of relationships with others from the literature and assess the congruency among the different phylogenetic sources of information.

\section{Material and Methods}

\section{Anatomical nomenclature}

Myological nomenclature follows Winterbottom (1974a) except for the dorsal branchial muscles which follows Springer \& Johnson (2004). Based mainly on the discoveries of Gosline (1989), Diogo \& Chardon (2000) proposed a new terminology for the sections of the adductor mandibulae in Ostariophysi. However, several problems with this nomenclature were detected (see "Discussion: Nematogenyidae" and "Discussion: Trichomycterinae”; Datovo \& Vari, in prep.). For that reason, for purpose of the present study, we adopt the traditional nomenclature for the adductor mandibulae (Vetter, 1878; Allis, 1897; Winterbottom, 1974a), identifying the outer portion plesiomorphically inserted onto the lower jaw as the "A2" and the inner portion as "A3". The name protractor operculi, applied to a trichomycterid muscle described by de Pinna (1992) is used. Nomenclature for new muscles or muscle sections is explained throughout the text.

Osteological terminology follows Bockmann et al. (2004), except as noted below. The so-called "tendon-bone supraorbital” [= "antorbital” of Britski \& Ortega (1983) and de Pinna (1989a); “fronto-lacrimal tendon bone” of Baskin (1973) and de Pinna (1989a); "nasal” of Eigenmann (1918)] seems to be an ossification associated with a ligament rather than with a tendon (pers. obs., see below; Adriaens et al., 2010). Hence, this bone is herein designated "sesamoid supraorbital" according to Adriaens et al. (2010). Arratia \& Schultze (1990) demonstrated that the so-called "urohyal" in catfishes does not entirely correspond to the urohyal of other teleosts. For this reason, these authors proposed the name "parurohyal" for that bone in catfishes, a terminology herein followed. The commonly used term "pleural rib" is replaced by "rib" only. "Pleural rib" or "ventral rib" has been traditionally used in opposition to the "dorsal ribs" in gnathostomes (Britz \& Bartsch, 2003). Since Britz \& Bartsch (2003) have demonstrated that gnathostomes have only one type of rib (the "pleural" or "ventral" one), the use of the adjective "pleural" is dispensable (e.g. Britz et al., 2009; Britz \& Johnson, 2010). Furthermore, since fishes lack a true pleural cavity, the use of the term "pleural" may be somewhat confusing (Adriaens, pers. comm.).

Additional morphological terms employed through the text are defined as follows: (1) postorbital process of skull: the small osseous projection on the lateral region of sphenoticfrontal joint, which usually bears a foramen for the infraorbital canal of the cephalic laterosensory system; (2) dorsal process of opercle: the conspicuous osseous outgrowth on the anterodorsal region of the bone; (3) medial crest of opercle: the conspicuous osseous ridge on the medial face of the bone; (4) buccopalatal membrane: the sheet of dense irregular connective tissue that interconnects the autopalatine, upper 
and lower jaws, and forms a membrane over the roof of the anterolateral part of buccal cavity.

\section{Anatomical preparations}

Specimens dissected for musculature were double-stained for cartilage and bone. For this purpose, they underwent the steps 2 and 4 of the protocol of Taylor \& van Dyke (1985) with cartilage stained using their "alternate" Alcian Blue 8GX solution (with 80 parts of $95 \%$ ethanol and 20 parts of glacial acetic acid; Dingerkus \& Uhler, 1977). In order to prevent further demineralization, specimens were then transferred to a sodium borate-based neutralization solution, according to the step 5 of Taylor \& van Dyke (1985), for a shorter period of time of 2-8 hours. Subsequently, they were placed into an ethanol-based solution of Alizarin Red-S for 3-6 hours, in order to stain the bones (Springer \& Johnson, 2000). Potassium hydroxide-based solutions for neutralization and bone stain of Taylor \& van Dyke (1985) were not used because the $\mathrm{KOH}$ seems to macerate tendons and ligaments (Springer \& Johnson, 2000). Specimens were maintained in $60 \%$ to $95 \%$ ethanol, according to the desired hardness of the muscles to facilitate dissections. Typically, more concentrated ethanol solution works better for very small sized specimens, since their muscles become more rigid due the higher dehydration level, making dissections easier. In larger sized specimens, on the other hand, intense dehydration can makes muscle ablation difficult and may damage fine surgical instruments.

Cleared and double-stained skeletal specimens were prepared following Taylor \& van Dyke (1985). Histological sections were stained according to Masson's trichrome staining protocol.

\section{Illustrations}

Drawings were sketched by hand (AD) using a digital pen tablet, based on photographs and direct observation of specimens under stereomicroscope. Colors of structures on drawings are merely illustrative, rather than corresponding of the true coloration of fixed or living specimens. Colors and patterns used to represent each tissue in the drawings are presented in Table 1.

Photographs were taken by a Leica DFC420 digital image capture device attached to a Leica MZ16 stereomicroscope. The photographs herein presented are multifocal montages made with several individual photographs taken from different focal planes of the anatomical structures. This final fully focused montage was made on CombineZP (Hadley, 2009).

\section{Phylogenetic analysis}

Character matrix was assembled in Mesquite 2.7 (Maddison \& Maddison, 2009). Multistate characters were ordered whenever a clear morphoclinal gradient between the more extreme states was identifiable (Maslin, 1952). Ordering states according to morphoclines minimizes the amount of morphological changes between character states thus choosing the most parsimonious hypothesis of transformation (Maslin, 1952; Wilkinson, 1992; de Pinna, 1992; Slowinski, 1993; Wiens, 2001: 693-694). Multistate characters which morphoclines were
Table 1. Color patterns for the different tissues represented in drawings. Classification of cartilages follows Benjamin (1990).

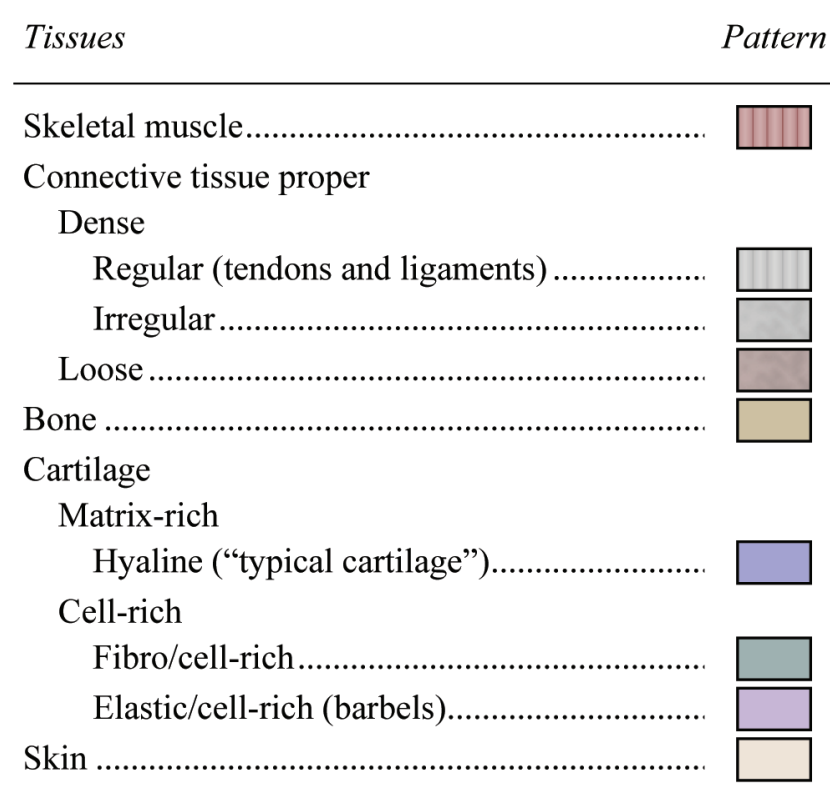

not detected were unordered. Maximum parsimony analysis was performed under TNT 1.1 (Goloboff et al., 2008). A "traditional search" was run with the following settings: 1000 replicates; up to 10000 trees retained in memory; remaining settings follows program defaults (which includes TBR-branch swapping). Obtained trees were rooted in Nematogenys inermis (outgroup), the sole extant member of the Nematogenyidae and the sister-group of Trichomycteridae (de Pinna, 1992, 1998). Bremer support for the clades were calculated through the script bremer.run of TNT with the following settings: swap existing trees up to 10 steps longer; do 10 ratchet iterations in constrained searches; remaining settings follows script defaults. Numbers of steps, consistency indexes, and retention indexes were obtained from Mesquite. The most parsimonious reconstruction for characters with ambiguous optimization (as ACCTRAN or DELTRAN; Swofford \& Maddison, 1987) was not a priori assumed, but rather evaluated case by case (Amorim, 1997; Agnarsson \& Miller, 2008), with the decisions in favor of one or another reconstruction justified into the textual comments of each character.

\section{Material examined}

Museum abbreviations follow Fricke \& Eschmeyer (2009). The number following the catalogue number indicates the total number of specimens in the lot. That number corresponds to that of specimens examined for this study except when indicated. The range of standard lengths (in $\mathrm{mm}$ ) is presented in parentheses whenever available. Terminal-taxa incorporated in the phylogenetic analysis are preceded by an asterisk (*). Abbreviations: cs, cleared and stained specimens; sk, dry skeleton specimens; hs, specimens prepared for histological sections; ms, specimens dissected for muscles; TNU, total number of specimens unavailable. In addition to the material 
listed below, radiographs of the types of all trichomycterids available at the "All Catfish Species Inventory" (Morris et al., 2006) and "Primary Types Imagebase of California Academy of Sciences” (California Academy of Sciences, 2007) websites were also examined.

Albuliformes: Albulidae: Albula vulpes; LIRP 7427, 1: 1ms. Amiiformes: Amiidae: Amia calva; USNM 64338, 4: 1ms (174). Characiformes: Acestrorhynchidae: Acestrorhynchus falcatus; LIRP 5115, 5: 2cs (128.6-135.2), 1ms (147.3). Alestidae: Chalceus erythrurus; LIRP 5955, 2: 1cs (167.4), 1ms (192.0). Phenacogrammus interruptus; LIRP 7441, 4: 2cs (65.0-68.9), 2ms (67.4-69.2). Anostomidae: Leporellus vittatus; LIRP 231, 56: $2 \mathrm{~ms}$. Characidae: Agoniatinae: Agoniates halecinus; MZUSP 34333, 2: 1cs (152.1); MZUSP 53827, 1: 1ms (196.9). Aphyocharacinae: Aphyocharax cf. pusillus; LIRP 4559, 84: 2cs (39.6-42.7), 2ms (44.845.4). Bryconinae: Brycon nattereri; LIRP 3558, 3: 1ms. Brycon orbignyanus; LIRP 6003, 32: 2cs (17.4-24.1), 5ms (22.4-56.7). Characinae: Roeboides cf. prognathus; LIRP 700, 16: 2cs (80.7-889), 2ms (71.9-84.9). Cheirodontinae: Odontostilbe pequira; LIRP 5417, 63: 2ms (36.58-37.08). Glandulocaudinae: Lophiobrycon weitzmani; LIRP 4337, 8: 2cs (25.8-27.0); LIRP 4338, 31: 2ms (27.1-28.4). Mimagoniates microlepis; LIRP 5942, 20: 2cs (44.353.5), 2ms (47.2-49.4). Iguanodectinae: Piabucus melanostomus; LIRP 5936, 19: 2cs (77.3-78.0), 2ms (77.3-87.5). Serrasalminae: Metynnis mola; LIRP 5937, 21: 2cs (44.1-54.0), 2ms (48.3-58.8). Serrasalmus spilopleura; LIRP 4066, 32: 2ms (128.8-130.7). Stethaprioninae: Brachychalcinus cf. copei; LIRP 5939, 14: 2cs (31.5-34.1), 1ms (36.0). Poptella paraguayensis; LIRP 5940, 21: 2cs (38.2-39.8), 2ms (35.5-38.2). Stevardiinae: Planaltina myersi; LIRP 3356, 27: 2cs (30.5-31.4), 2ms (27.9-31.4). Tetragonopterinae: Tetragonopterus argenteus; LIRP 5941, 10: 2cs (63.3-81.7), 2ms (60.6-66.9). Characidae Incertae sedis: Astyanax fasciatus; LIRP 132, 54: 3cs (72.0-75.5), 2ms (10.2-11.1). A. altiparanae; LIRP 2040, 42: 1cs, 2ms. Bryconops alburnoides; LIRP 5116, 7: 2cs (94.0-99.8), 2ms (104.4-106.7). Creagrutus seductus; LIRP 4417, 16: 2ms (38.90-41.63). Hollandichthys multifasciatus; LIRP 5744, 85: 2cs (79.4-86.5), 2ms (76.4-77.6). Salminus hilari; LIRP 670, 3: 1ms. Triportheus paranaensis; LIRP 5935, 44: 2cs (69.2-75.5), 2ms (72.3-86.9). Citharinidae: Citharinus citharus; USNM 72797, 7: 1ms (192). Crenuchidae: Characidium fasciatum; LIRP 220, 107: $2 \mathrm{~ms}$ (53.16-54.20). Ctenoluciidae: Boulengerella maculata; LIRP 5974, 3: 2cs (199.3-200.5), 1ms (266.7). Cynodontidae: Hydrolycus scomberoides; LIRP 5943, 4: 2cs (125.5-139.4), 1ms (143.5). Curimatidae: Curimatopsis sp.; LBP 412, 6: 2cs (58.7-60.4), 2ms (61.6-67.1). Distichodontidae: Xenocharax spilurus; AMNH 230302, 3 of 79: 2ms (95.22-104.29). Erythrinidae: Hoplias malabaricus; LIRP 6032, 5: 2ms (84.48-215); LIRP 5594, 5: 2cs (64.4-66.4). Gasteropelecidae: Thoracocharax cf. stellatus; LIRP 715, 16: 2cs (40.9-44.4), 2ms (42.1-42.5). Hepsetidae: Hepsetus odoe; USNM 309529, 6: 1ms (168). Lebiasinidae: Pyrrhulina australis; LIRP 6049, 416: 2cs (32.7-41.6), 2ms (37.22-38.74). Parodontidae: Parodon hilarii; LIRP 638, 38: 2ms (135.06-138.43). Clupeiformes: Engraulidae: Setipinna taty; USNM 265905, 7: 1ms (103.53). Cypriniformes: Cyprinidae: Barilius senegalensis; USNM 271201, 12: 1ms (92.97). Rasbora cephalotaenia; USNM 330848, 146: 1ms (81.20). Elopiformes: Elopidae: Elops saurus; USNM 289648, 9: 1ms (202). Megalopidae: Megalops cyprinoides; USNM 102685, 12: 1ms (106.10). Esociformes: Esocidae: Esox americanus; USNM 237253, 12: 1ms (158). Gonorynchiformes: Chanidae: Chanos chanos; USNM 173572, 5: 1ms (147).
Gymnotiformes: Gymnotidae: Gymnotus paraguensis; LIRP 6010, 44: 1cs (188), 2ms (193-394). Hypopomidae: Brachyhypopomus pinnicaudatus; LIRP 6055, 11: 1cs, (112), 2ms (130-133). Sternopygidae: Eigenmannia virescens; LIRP 395, 12: 1cs (124.94), 2ms (175-180). Hiodontiformes: Hiodontidae: Hiodon tergistus; USNM 167970, 10: 1ms (77.40). Lepisosteiformes: Lepisosteidae: Lepisosteus platostomus; USNM 54983, 8: 1ms (205). Polypteriformes: Polypteridae: Polypterus senegalus; USNM 229760, 9: 1ms (107.62). Polypterus sp.; LIRP 7426, 2: 1ms (66.08). Siluriformes: Amphiliidae: Amphilius jacksoni; MZUSP 48636, 5: 1ms. Ariidae: Genidens genidens; LIRP 953, 21: 1cs (86.79), 2ms (92.45-94.01). Auchenipteridae: Auchenipterinae: Ageneiosus sp.; LIRP 7430, 5: 1cs (93.08), 1ms (111.76). Centromochlinae: Centromochlus sp.; LIRP 7433, 9: 1ms (31.37). Cetopsidae: Cetopsinae: Cetopsis candiru; LIRP 7423, 1: 1ms. Helogeninae: Helogenes marmoratus; MZUSP 64109, 3: 1ms. Callichthyidae: Callichthyinae: Callichthys callichthys; LIRP 2542, 19: 1cs (67.01), 2ms (71.27-74.42). Corydoradinae: Corydoras aff. aeneus; LIRP 1668, 57: 2cs (32.1-42.5), 1ms (39.1). C. difluviatilis; LIRP 3549, 38: 1cs (38.83), 2ms (38.5-39.52). Diplomystidae: Diplomystes camposensis; LBP 3106, 5: $1 \mathrm{~ms} /$ subsequently prepared as sk (180.11). D. mesembrinus; LBP 449, 2: 1ms (102.9). Heptapteridae: Cetopsorhamdia iheringi; LIRP 2805, 45: 2ms (64.36-74.62). Imparfinis schubarti; LIRP 3035, 7: 2ms (82.11-82.55). Pimelodella australis; LIRP 424, 17: 2ms (82.44-90.06). Phenacorhamdia hoehnei; LIRP 2871, 4: 1ms (60.04). Rhamdia quelen; LIRP 2462, 15: 2ms (112.69-124.55). Loricariidae: Hypostominae: Ancistrus sp.; LIRP 508, 14: 1cs (84.4), 2ms (81.95-82.55). Hypostomus ancistroides; LIRP 2675, 49: 2cs; LIRP 6208, 21: 2ms (52.9160.97). H. nigromaculatus; LIRP 1585, 46: 3cs. Neoplecostominae: Neoplecostomus paranensis; LIRP 127, 80: 2cs (38.2-60.7), 1ms (62.1). Pareiorhaphis cameroni; LIRP 6131, 14: 2cs (52.86-68.57), 2ms (72.21-81.69). Nematogenyidae: *Nematogenys inermis; LBP 1002, 2: 1ms (76.4); MZUSP 88522, 20: $1 \mathrm{~ms} /$ subsequently prepared as sk. Pimelodidae: Iheringichthys labrosus; LIRP 6353, 19: 2ms (149-163). Pimelodus maculatus; LIRP 6313, 16: $2 \mathrm{~ms}$ (185-214). Pseudopimelodidae: Microglanis sp.; LIRP 109, 36: $2 \mathrm{~ms}$ (71.16-75.5). Scoloplacidae: Scoloplax baskini; LIRP 7429, 9. Scoloplax empousa; LIRP 4380, 30: 1cs, 3ms. Scoloplax sp.; LIRP 4370, 2. Trichomycteridae: Copionodontinae: *Copionodon pecten; LIRP 1012, 30: 2cs (43.8-48.1), 3ms (49.5-51.70); LIRP 1013, 12. Glanapteryginae: Glanapteryx anguilla; MZUSP 36530, 2 of 21 (33.7-63.2): 2cs (44.2-59.4). *Listrura camposi; MZUSP 95189, 3: 2ms (40.55-42.51). L. nematopteryx; MZUSP 37138, 2 of TNU: 2 of TNUcs. L. picinguabae; MZUSP 94974, 1 of TNU; ZUEC 6208, 1 of 16: 1cs. *L. tetraradiata; MNRJ 19064, 1 of TNU: 1cs of TNU; MNRJ 31534, 2 of 17 paratypes: 1ms (39.04). Sarcoglanidinae: Ammoglanis diaphanus; LIRP 7402; 5: 1cs (16.2), 1ms (15.4); MZUSP 86249, 1 of TNU; MZUSP 86270, 1 of TNU. A. pulex; MZUSP 42471, 1 of 26 paratypes (11.9-13.8): 1 of 5cs. Malacoglanis gelatinosus; FMNH 98520, 1 of 2: 1cs. Microcambeva barbata; MZUSP 79825,2 of TNU: 1 of TNUcs; MZUSP 79827,1 of TNU. *M. ribeirae; MZUSP 65764, 64: 1cs (39.1), 1ms (41.8). *Sarcoglanis simplex; LIRP 7394, 1; LIRP 7396, 1; LIRP 7437, 21 : 2cs (14.33-16.74), 2ms (16.33-16.90). *Stauroglanis gouldingi; LIRP 5286, 10: 1cs (21.7), 2ms (24.0-26.3); MZUSP 79826, 1 of UTN; MZUSP 86957, 1 of UTN. Stegophilinae: *Haemomaster venezuelae; LIRP 7438, 5: 1cs (35.56), 1ms (36.92); LIRP 7400, 2. *Homodiaetus anisitsi; LIRP 421, 2; LIRP 439, 10; LIRP 7434, 7: 2ms (33.14-43.48). Ochmacanthus batrachostoma; LIRP 4556, 3. *Ochmacanthus flabelliferus; LIRP 4556, 3; LIRP 7398, 1; LIRP 7439, 3: 1cs (29.76), 1ms (33.03); LIRP 7440, 1. *Parastegophilus 
paulensis; LISDEBE 1312, 3: 2ms (46.5-49.3). *Pareiodon microps; LIRP 7422, 3: 1cs (104.5), 2ms (108.1-112.87). *Pseudostegophilus nemurus; LIRP 7428, 1: 1ms (96.3). Trichogeninae: *Trichogenes longipinnis; LIRP 1023, 3; LIRP 1058, 4; LIRP 1059, 12: 1cs (47.4), 2ms (60.8-75.5). Trichomycterinae: *Bullockia maldonadoi; LBP 3112, 39: 1ms (50.45); LIRP 5947: 3: 1cs (45.83). *Hatcheria macraei; ILPLA 1807, 3 of 8: 1ms (181); LBP 451, 1: 1ms (63.97); MLP 5622, 1 of 3; MLP 5668, 1 of 3; MLP 7903, 1 of 2; MZUSP 35687, 2 of TNU: 2cs (42.30-43.98). Ituglanis bambui; MZUSP 79860, holotype; MZUSP 79862; 4 paratypes: 1cs; MZUSP 79864; 4 paratypes: 2cs. I. cf. amazonicus; LIRP 7424, 3: 1ms (57.2); MZUSP 86820, 1. I. eichorniarum; MCP 36243, 1; MCP 36244, 1; MNRJ 780; 2 paralectotypes. I. epikarsticus; MZUSP 79869, holotype; MZUSP 79870, 1 paratype; MZUSP 79871, 1 paratype: 1cs; MZUSP 79872, 1 paratype: 1cs; *I. cf. gracilior; MCP 36257, 13: 1cs (38.2); MCP 36258, 17; MZUSP 86821, 12: 1cs (39.0), 1ms (53.19). I. herberti; MNRJ 1429, 3 paralectotypes; MNRJ 28466, 1 paralectotype; NUP 2238; 1; NUP 2241, 3: 1cs; NUP 2242, 2. I. macunaima; LIRP 5642, 6 paratypes: 1cs (29.1); MZUSP 86237, 7 paratypes: 1cs (25.5); MZUSP 86251, 2 paratypes: 1cs (25.5); MZUSP 86272, 1 paratype; MZUSP 88452; holotype. I. nebulosus; MZUSP 69574; 1 paratype: 1cs (35.1). I. parahybae; MCP 7784, 1; MCP 18026, 1; MCP 18032, 1; MZUSP 71852, 3; MZUSP 79810, 1. I. parkoi; MCP 36240, 1; MCP 36248, 1; MNRJ 3849, holotype. I. passensis; MCP 27436, 3; MZUSP 80097, 3. *I. proops; MNRJ 781, 3 paralectotypes; MZUSP 36502, 7; MZUSP 60255, 20 of 95: 2cs (57.1-77.0), 1ms (70.2). I. ramiroi; MZUSP 79865, holotype; MZUSP 79867, 3 paratypes: 3cs (25.431.3); MZUSP 79868, 1 paratype. I. sp. 1 (Tocantins/upper Paraná); MCP 15930, 37: 2cs (34.7-53.3); MCP 23073, 5: 1cs (56.2); NUP 1103, 4. *Scleronema angustirostre; MCP 21436, 17: 1cs (35.2), $1 \mathrm{~ms}$ (42.4). S. cf. minutum; MCP 19108, 2. Trichomycterus albinotatus; LIRP 4333, 4 (23.9-36.1): 1cs (31.7). T. alternatus; LIRP 266, 1; LIRP 28, 1. T. alterus; MLP 250: 3 of 21. *T. areolatus; LBP 997, 17: 3cs (45.21-91.46), 2ms (60.5-63.5). T. auroguttatus; LIRP 4334, 4 (37.9-92.3): 1cs (59.3). *T. brasiliensis; LIRP 1968, 15: 2cs (68.0-83.8), 2ms (76.4-95.6). T. aff. brasiliensis; LIRP 818, 21: 2cs (40.1-57.0), 1ms (43.6). *T. candidus; LIRP 815, 2; LIRP 1098, 1; LIRP 7425, 12: 1ms (54.63); LIRP 7431, 1; LIRP 7435, 5. *T. chiltoni; LBP 1001, 10: 2ms (83.38-104.25); LBP 1003, 13: 2cs (47.06-50.32). *T. corduvensis; MLP 8221, 1 of 3; MLP 8222, 3 of 20: 1ms (53.53); *T. davisi; LIRP 2798, 18: 2cs (56.7-65.2), 1ms (79.3); LIRP 2799, 34: 3cs (61.0-75.2), 1 hs (63.8), 2ms (17.1-82.2). T. diabolus; LIRP 1128, 21 paratypes; LIRP 3456, 9 paratypes: 2cs. *T. cf. iheringi; LIRP 1027, 1; LIRP 1055, 5: 1cs (77.1); LIRP 3182, 8: 1ms (72.2); LIRP 3183, 2; LIRP 3185, 1. *T. immaculatus; LIRP 285, 28: 2cs (76.2-74.0), 1ms (83.7). T. cf. itatiayae; LIRP 5086, 1: 1 CS (43.3); LIRP 5087, 3. *T. maracaya; LIRP 4381, 4 paratypes (26.7-51.3): 1cs (43.9), 1ms (40.0). T. mirissumba; LIRP 4335, 2 (55.4-56.3): 1cs (56.3). T. paolence; LIRP 5713, 1. T. pauciradiatus; MNRJ 17057, 17: 3cs (27.38-45.90). T. reinhardti; LIRP 1062, 3: 1cs (30.5). T. sp. 1(São Francisco); LIRP 645, 34: 2 cs (48.0-60.0), 1ms (72.2). *T. stawiarski; LIRP 5088, 10 (33.2-60.2): 1cs (50.1), 1ms (45.0). ${ }^{*} T$. zonatus; LIRP 596, 8: 1ms (28.7); Tridentinae: *Tridentopsis pearsoni; MZUSP 38671, 3 (16.6-18.9): 1cs (16.6), 1ms (18.3). Vandelliinae: *Paracanthopoma parva; LIRP 7399, 16: 2cs (9.60-16.43), 2ms (18.91-22.72); LIRP 7410, 3; LIRP 7411, 9; LIRP 7413, 1. *Paravandellia oxyptera; LIRP 4557, 8: 1ms (22.8). P. sp. 1; LIRP 736, 1; LIRP 5407, 1. Vandellia cf. sanguinea; LIRP 7408, 7: 2cs (23.28-28.00). *V. cirrhosa; LIRP 7401, 6: 1cs (47.06), 1ms (49.94). *V. sanguinea; LIRP 7409, 3; LIRP 7414,
52: 3cs (30.89-68.53), 1ms (77.14). V. sp. 1; LIRP 598, 12: 1cs (60.0), 1ms (64.4). Vandellia sp. 2; LIRP 7391, 7: 2cs (71.42-86.90). Trichomycteridae Incertae sedis: “Trichomycterus” hasemani; LIRP 7392, 2; LIRP 7406, 8; LIRP 7395, 16: 3cs (12.38-13.60); LIRP 7405, 5; LIRP 7404, 3; LIRP 7393, 30: 3cs (13.38-13.63); LIRP 7407, 4; LIRP 7397, 49: 4cs (12.94-13.78), 3ms (14.00-15.27); LIRP 7403, 16; LIRP 814, 1; MCP 23070, 5: 1Cs (11.7).

\section{Anatomical descriptions of the cheek muscles Nematogenyidae}

Adductor mandibulae with two main facial subdivisions: one lateral - A2 - and another medial - A3 (Figs. 1, 2). Separation between these sections is complete only along their posterodorsal origin, where the levator arcus palatini lies between the dorsal portions of the A2 and A3. Anteriorly, these two main subdivisions are largely continuous with each other (Fig. 2). The A2 section originates primarily from the posteroventral region of the suspensorium on the hyomandibula and preopercle. A few fibers may also attach tendinously to the postorbital process of the skull and suprapreopercle. Subdivisions A2' (ventral) and A2" (dorsal) are barely distinguishable from each other near their insertion (this distinction is more evident in the larger specimen). The A2' has a primarily musculous insertion onto the posterolateral region of the coronoid process of the lower jaw on both angulo-articular and dentary (Fig. 1). The fibers of the A2" deflect abruptly ventrally near to the coronoid process to insert predominantly onto the medial face of the lower jaw, mainly via a strong tendon that attaches to the posterior rim of the coronoid process of the dentary (Fig. 2). Sections A2' and A2" seem superficially distinguishable due to the different orientation of their fibers (Fig. 1). Nonetheless, no effective separation is possible between these two groups of fibers since they intermix more deeply within the muscle. Therefore, a direct correlation between these two superficially distinct groups of fibers and the sections A2' and A2" is problematic. The A3 section is also separable into ventral (A3') and dorsal (A3") portions along their origins (Fig. 2). The A3' is more deeply associated with the A2, originating anterolaterally to the levator arcus palatini from the hyomandibula, metapterygoid, and quadrate. The lateral most fibers of this portion are exposed on the lateral surface of the adductor mandibulae just below the A2, and insert onto the lateral aspects of the dentary and angulo-articular. The A3" originates medial to the levator arcus palatini from the hyomandibula and sphenotic. Anteriorly, A3" and A3' fuse to each other and insert mainly onto the medial face of the anguloarticular and coronomeckelian bone (Fig. 2). Section A $\omega$ is absent (Fig. 2).

The levator arcus palatini is nearly conically-shaped and positioned between the dorsal portions of the sections A2 and A3 of the adductor mandibulae. It arises from ventral region of postorbital process of skull (Fig. 1) and inserts onto the central region of the lateral face of the hyomandibula.

The extensor tentaculi is undifferentiated from the adductor arcus palatini (Fig. 1; see "Discussion: Nematogenyidae”). The origin of that compound muscle is 


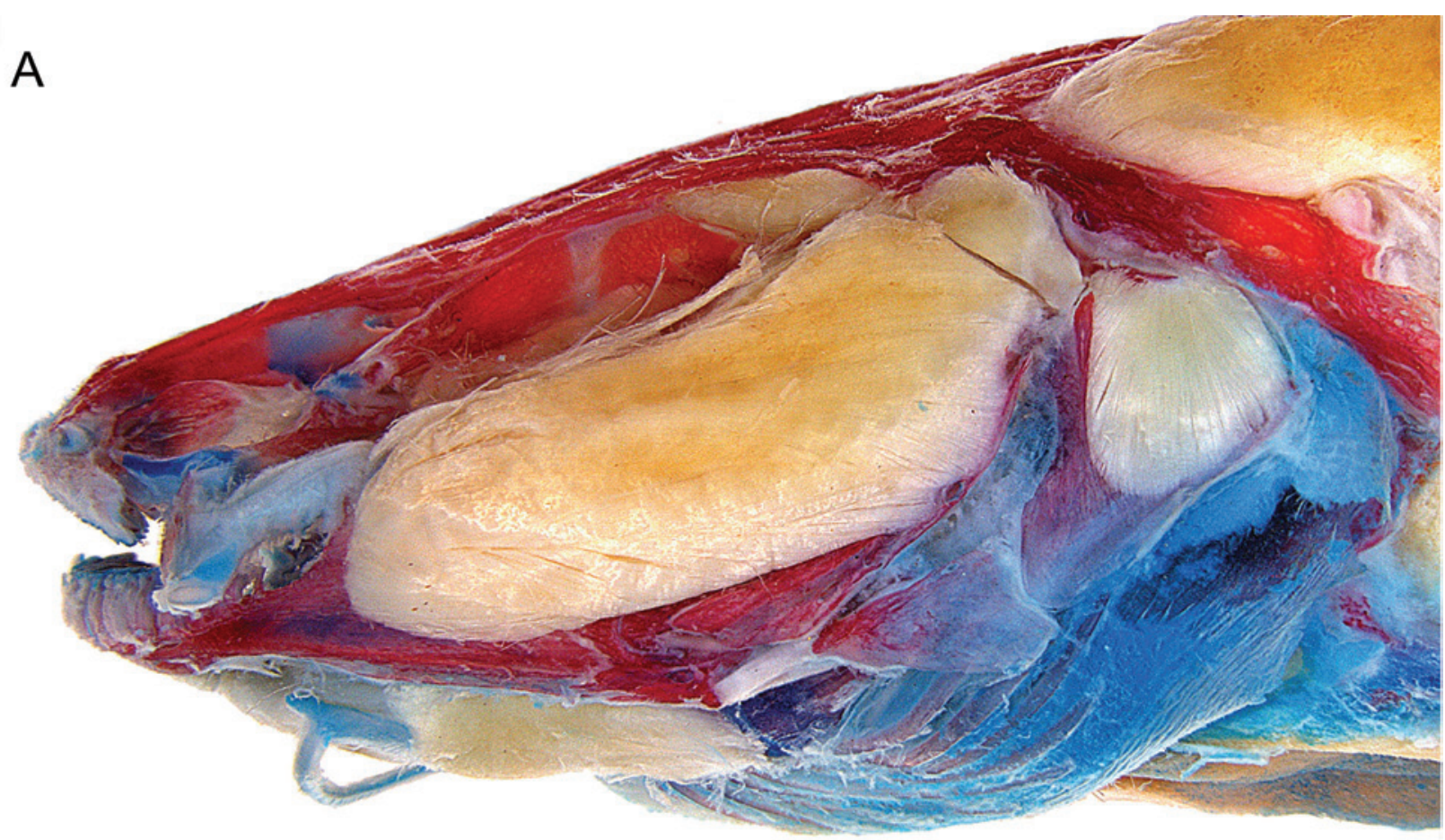

B

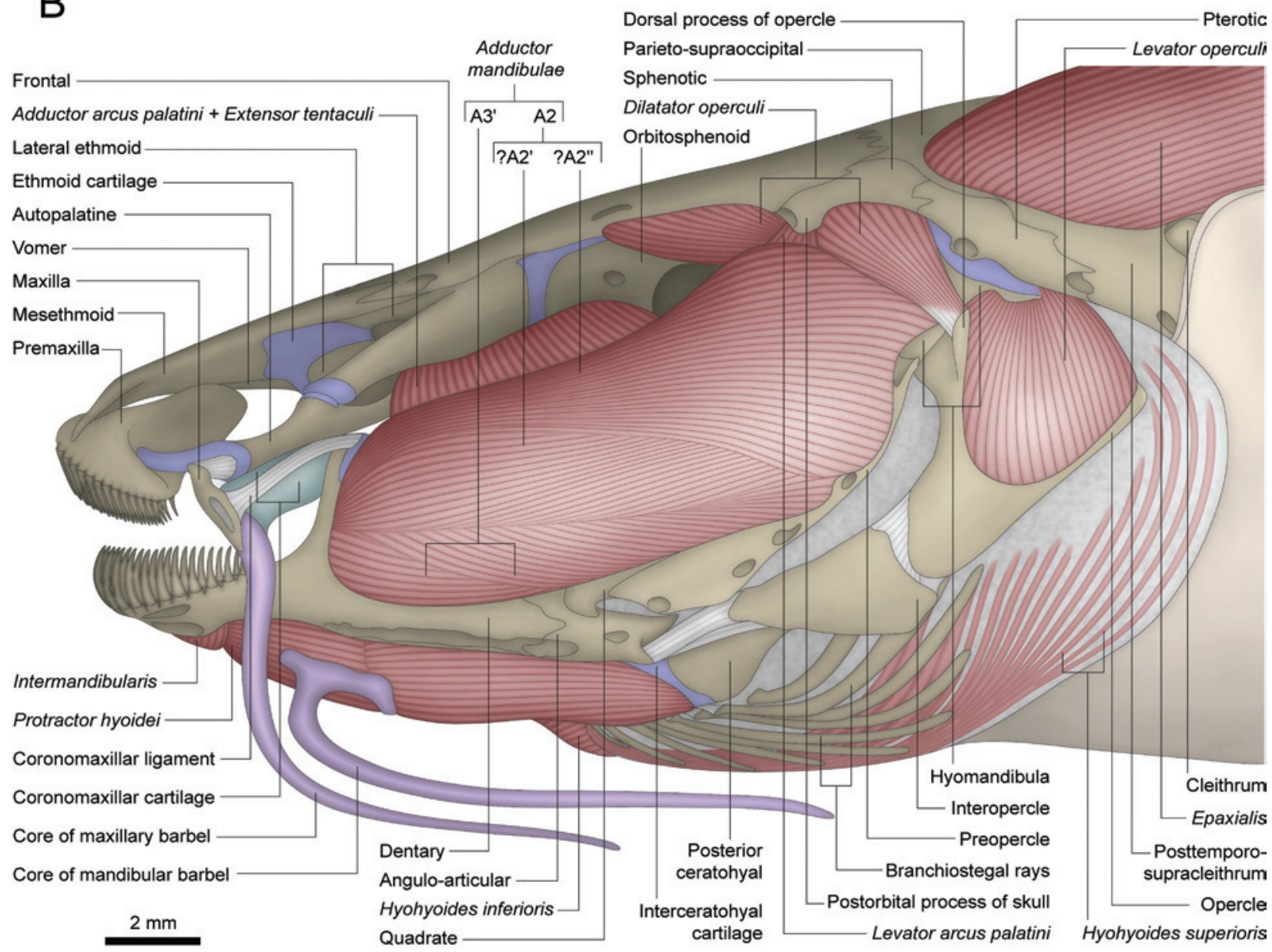

Fig. 1. Left lateral view of head of Nematogenys inermis (Nematogenyidae), LBP 1002 (76.4 mm SL); (A) Photograph (maxillary barbel cut), (B) drawing. Antorbital and suprapreopercle removed. 
tendinous along the anterior most portions but musculous posteriorly. The fibers arise from the ventrolateral region of the neurocranium on the pterosphenoid, parasphenoid, orbitosphenoid, lateral ethmoid, and vomer. Posteriorly, this muscle inserts only on the medial face of the suspensorium (anterior region of the hyomandibula and posterodorsal region of the metapterygoid). Anteriorly the muscle gradually insert onto the lateral surface of the suspensorium (anterodorsal region of metapterygoid, endopterygoid) and autopalatine (posterior portion).

The adductor hyomandibulae and protractor operculi are absent (Fig. 1).

Dilatator operculi with one single section (Fig. 1) originating from the dorsolateral region of the orbitosphenoid and lateral margin of the frontal. The muscle passes medial to the levator arcus palatini and suprapreopercle, but lateral to the adductor mandibulae. Insertion is tendinous onto the tip of dorsal process of the opercle.

The levator operculi originates from the posterolateral region of the hyomandibula (Fig. 1) and lateroventral region of the pterotic. Insertion is onto the posterodorsal region of the lateral face of the opercle (see also pertinent comments about this muscle under "Discussion").

The adductor operculi is fully covered laterally by the levator operculi. The origin is from the ventral region of the pterotic with an insertion onto the dorsal face of the medial crest of the opercle.

\section{Trichomycteridae \\ Copionodontinae}

Adductor mandibulae with sections A2 and A3 well separated from each other posteriorly, especially by the levator arcus palatini (Figs. 3, 4). The A2 section is undivided with its origin from the posteroventral region of the suspensorium on the hyomandibula, quadrate, and preopercle (Fig. 3). The A3 is fully divided into A3' and A3" (Figs. 4, 5). The A3' originates medial to the levator arcus palatini, from the anterodorsal portion of the suspensorium, specifically the hyomandibula, quadrate, and metapterygoid. Somewhat anterior to the levator arcus palatini, the A2 and A3' sections fuse such that they are not separable in the region of insertion. This common insertion occurs solely onto the large posterior face of coronoid process of anguloarticular. The A3" from the anterodorsal part of the hyomandibula and the ligamentous tissue sheet which unites the bones of the suspensorium. It inserts primarily onto the distal part of the maxilla (Figs. 3, 4) with some deeper fibers loosely attaching to the tip of the coronoid process. Because of this insertion onto the maxilla, the A3" could be considered a retractor tentaculi muscle (see Character 7). Section A $\omega$ is absent (Fig. 5).

Levator arcus palatini (Fig. 3) comparable to that in the Nematogenyidae.

Adductor arcus palatini situated fully medial to the suspensorium and separated from the extensor tentaculi (Figs. 3, 6). Origin is from the ventrolateral region of the neurocranium on the orbitosphenoid and pterosphenoid. Insertion is onto the dorsal regions of the hyomandibula, metapterygoid, and connective tissue sheet which joins the skeletal elements of the suspensorium. The anterior part of this muscle, which inserts mainly onto the metapterygoid, is slightly laterally deflected, originating more dorsally over the orbitosphenoid (Fig. 3).

The extensor tentaculi originates mainly from the ventrolateral region of the lateral ethmoid (Fig. 3) with adjacent parts of orbitosphenoid sometimes involved. Insertion is onto the dorsal face of the posterolateral region of the autopalatine.

Adductor hyomandibulae present with its origin on the deep ventral fossa of the pterotic and insertion on the posterior region of the medial face of the hyomandibula (Fig. 6).

The protractor operculi is absent (Fig. 3).

Dilatator operculi with two main recognizable sections: a primary (basically corresponding to the single section of the dilatator operculi of the Nematogenyidae and other Siluriformes; see Character 25) and a secondary section found only in trichomycterids (see Characters 30, 32; Fig. 3). These sections are somewhat continuous with each other in the area of their insertion but are separate at their origins. The primary section passes medial to the levator arcus palatini and lateral to the adductor mandibulae. It originates from the orbital region of the neurocranium, on the ventrolateral portions of the sphenotic and orbitosphenoid. Its fibers converge onto an elongate tendon that is embedded into the deeper fibers of the secondary section and attaches to the posterodorsal margin of the opercle. The secondary section is situated fully lateral to all neighboring muscles, originating from the otic region of the skull roof on the sphenotic and pterotic, and inserting onto the dorsal region of the opercle. At the insertion, a tenuous distinction in the secondary section can be perceived. The ventral portion extends more ventrally over the lateral surface of the opercle, while the dorsal part extends over the medial face of the bone.

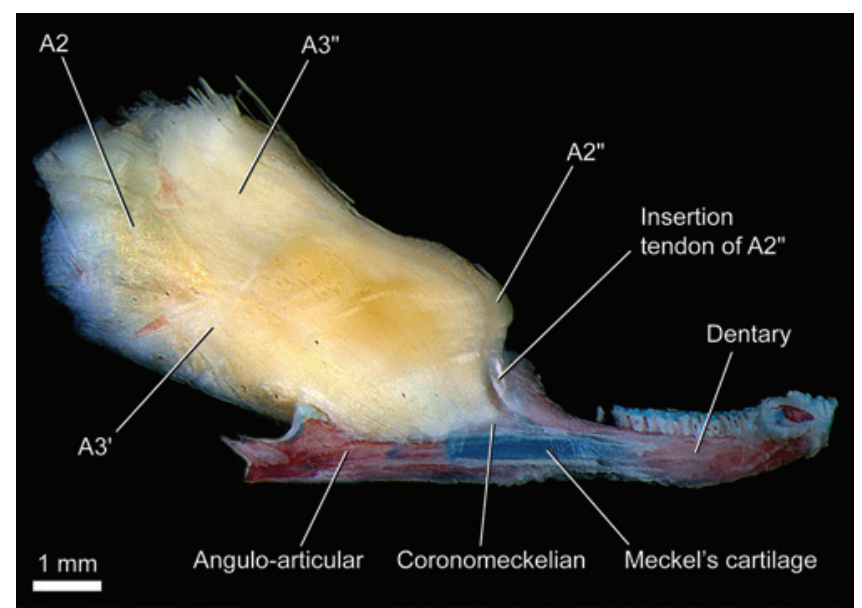

Fig. 2. Medial view of left adductor mandibulae and attached lower jaw of Nematogenys inermis (Nematogenyidae), LBP 1002 (76.4 mm SL). 
The levator operculi originates from the lateral region of the pterotic and posterodorsal part of the hyomandibula (Fig. 3). Insertion is onto the dorsomedial region of the opercle.

The adductor operculi is located fully medial to the levator operculi. Origin is from the ventral region of the pterotic between the origins of the levator operculi (lateral) and adductor hyomandibulae (medial) (Fig. 6). Insertion is onto the dorsal face of the medial crest of the opercle.

\section{Trichogeninae}

Adductor mandibulae with the two main facial subdivisions as encountered in the Nematogenyidae and Copionodontinae - A2 and A3 (Figs. 7, 8). Separation between these sections is, however, much more distinct, despite some remaining intermingling of muscle fibers (see below). The A2 is clearly subdivided into A2' and A2" (Fig. 7). The A2' section originates from the ventral region of the suspensorium on the hyomandibula, preopercle, and quadrate, and inserts primarily onto the posterolateral region of the coronoid process of the angulo-articular. Fibers of the A2" originate from the posterodorsal region of the hyomandibula and converge onto a long tendon that inserts onto the medial face of the anguloarticular (Fig. 8). The entire A3 lies anterior to the levator arcus palatini, and is also distinctly subdivided into two almost fully separated portions (Fig. 8). The A3' originates from the anteroventral portion of the suspensorium on hyomandibula, quadrate, and metapterygoid. Most of its fibers attach to a conspicuous tendon that inserts onto the coronomeckelian bone, albeit with some of its ventrolateral most fibers attaching to the insertion tendon of the A2" (Fig. 8). The A3" has its origin on the hyomandibula and metapterygoid and its insertion across the posteromedial rim of the coronoid process of the dentary (Fig. 8). Section A $\omega$ is absent (Fig. 8).

The levator arcus palatini (Fig. 7) is as in the Nematogenyidae and Copionodontinae, except for being positioned posterior to the A3 section of the adductor mandibulae, rather than lateral to some part of that section.

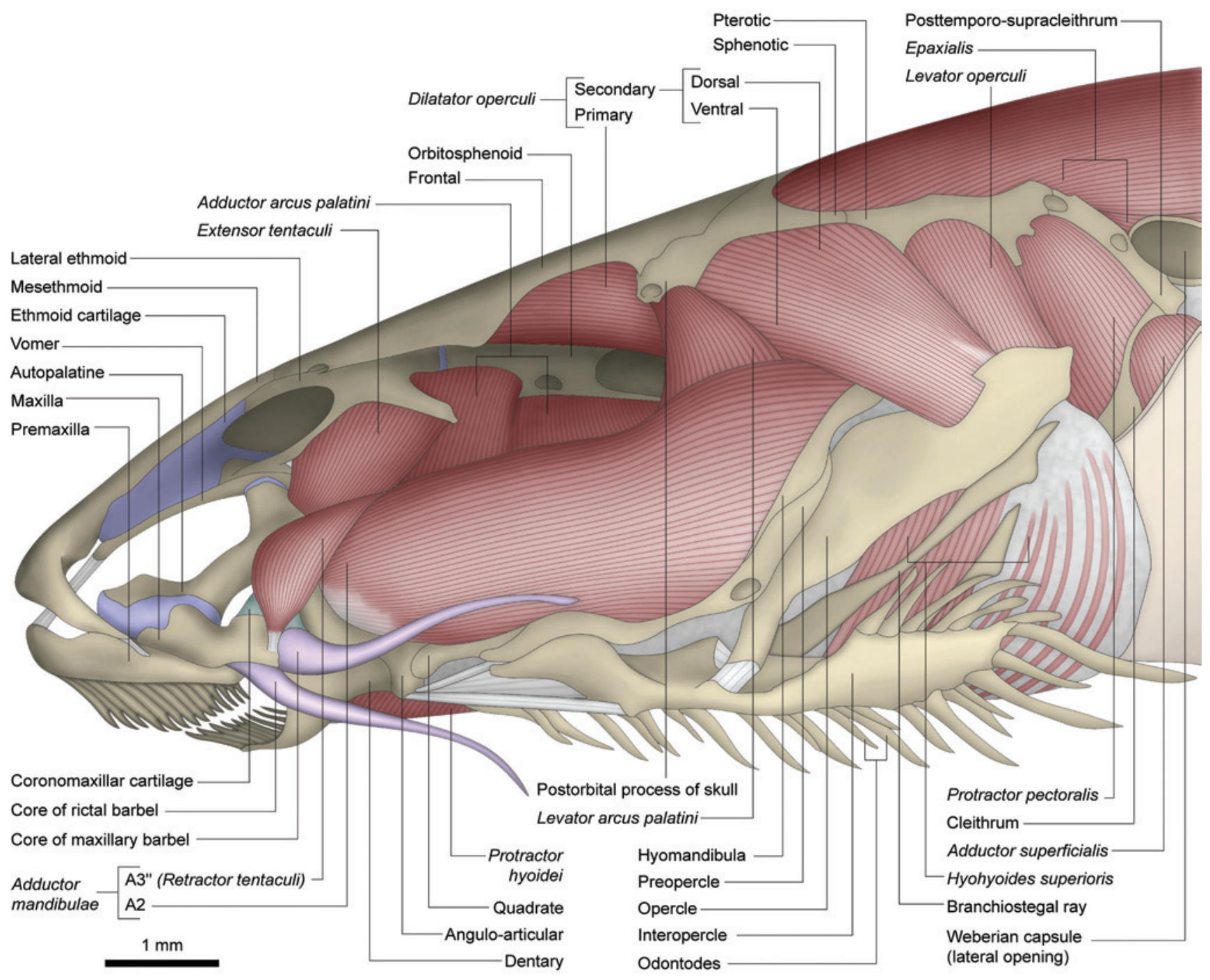

Fig. 3. Left lateral view of head of Copionodon pecten (Copionodontinae), LIRP 1012 (49.5 mm SL). Antorbital and core of nasal barbels removed. 
The adductor arcus palatini is fully separated from the extensor tentaculi (Fig. 7). Its origin is from the ventrolateral region of the neurocranium including the lateral ethmoid, orbitosphenoid, pterosphenoid, and parasphenoid. The insertion is on the dorsal portions of the medial face of the hyomandibula and metapterygoid with a small group of fibers also attaching on the lateral face of the metapterygoid.

Extensor tentaculi with origin mainly from the ventral face of the lateral process of the lateral ethmoid (Fig. 7). Insertion of the muscle is on the posterolateral region of the autopalatine and anterior part of the metapterygoid.

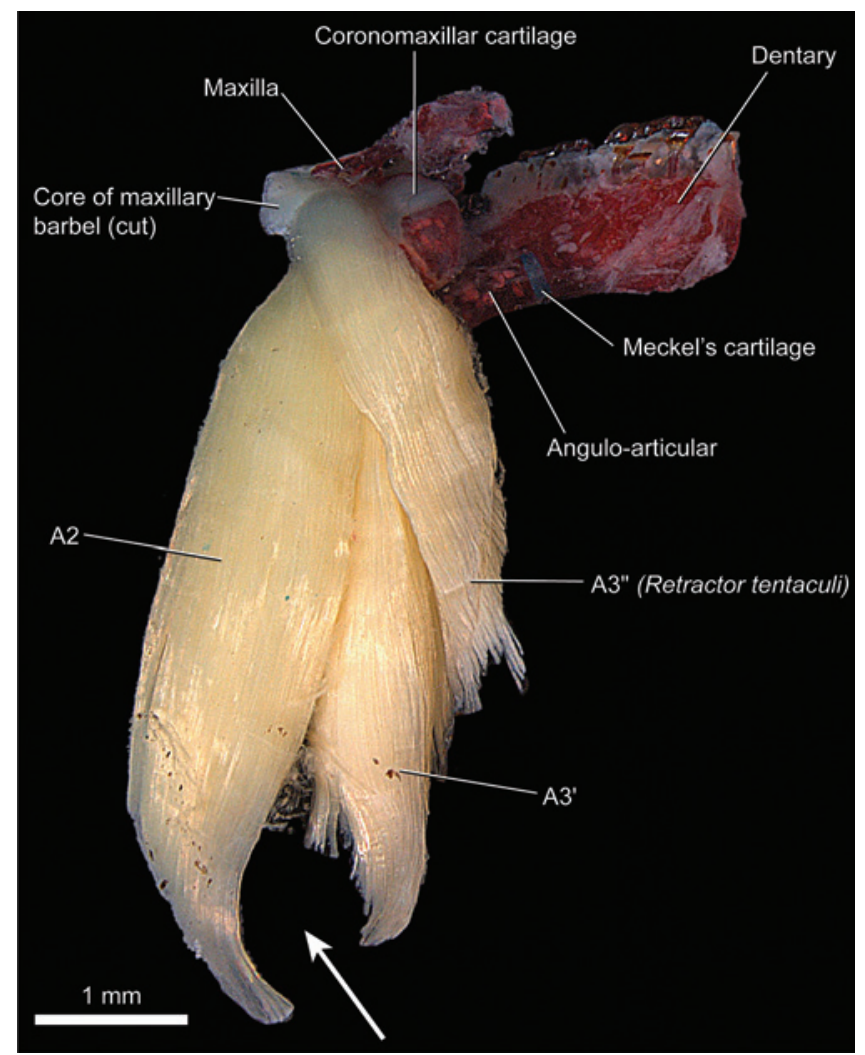

Fig. 4. Dorsal view of left adductor mandibulae and attached lower jaw and maxilla of Copionodon pecten (Copionodontinae), LIRP 1012 (51.7 mm SL). Arrow indicates space occupied by levator arcus palatini.

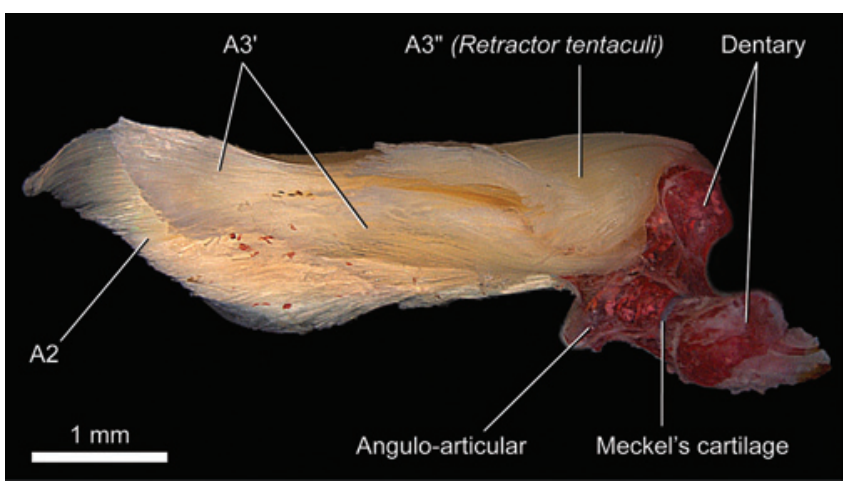

Fig. 5. Medial view of left adductor mandibulae and attached lower jaw of Copionodon pecten (Copionodontinae), LIRP 1012 (51.7 mm SL).
Adductor hyomandibulae with same condition as in the Copionodontinae.

The protractor operculi is absent (Fig. 7).

Dilatator operculi with primary and secondary sections fully separated at their origins but partially continuous with each other in the area of their insertions (Fig. 7). The primary section occupies the same position as in the Copionodontinae and Nematogenyidae (i.e. medial to the levator arcus palatini and lateral to the adductor mandibulae). Origin is from the ventral face of the wide lateral shelf of the sphenotic. Insertion is via an elongate tendon that is embedded into the deeper fibers of the secondary section of the dilatator operculi and attaches to the anterior part of the dorsal process of the opercle. The secondary section originates from the dorsolateral portion of the sphenotic and inserts onto the dorsal process of the opercle. In the area of insertion of the secondary section of one specimen, a slight distinct orientation of the superficial fibers seems to indicate an incipient division into dorsal and ventral portions.

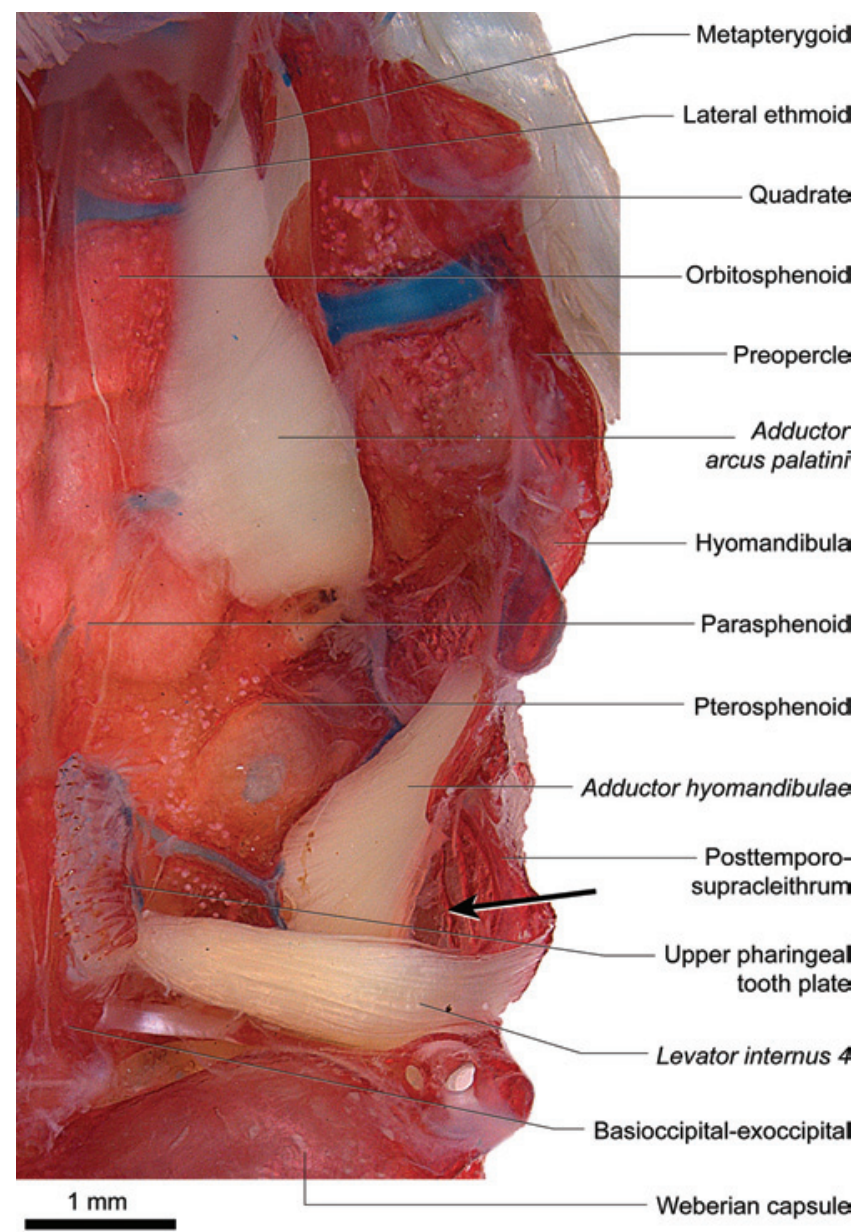

Fig. 6. Ventral view of left half of neurocranial floor and suspensorium of Copionodon pecten (Copionodontinae), LIRP 1012 (49.5 mm SL). Internal suspensorial muscles and upper pharyngeal tooth plate with attached levator internus 4 retained; remaining elements of branchial arches removed. Arrow indicates site of origin of adductor operculi. 
Levator operculi originating from lateroventral region of pterotic and inserting onto the dorsomedial region of the opercle (Fig. 7) (see also comments about this muscle under the "Discussion: Nematogenyidae").

Adductor operculi posteromedial to levator operculi (Fig. 7). Sites of origin and insertion of the muscle comparable to in the Copionodontinae.

\section{Trichomycterinae}

Adductor mandibulae with two main subdivisions - A2 and A3 - partially continuous with each other (Figs. 9-12). The degree of fusion between A2 and A3 is similar or, in many cases, greater than that occurring in Nematogenys. The A2 originates from the ventrolateral region of the suspensorium on the hyomandibula, preopercle and quadrate. In some cases the A2 lacks any obvious subdivision (Fig. 9), whereas in others it is barely subdivided into A2' and A2" portions near to the area of insertion (e.g. Scleronema angustirostris, Trichomycterus areolatus, T. cf. iheringi, some T. brasiliensis; some T. davisi, T. maracaya, T. stawiarski, and T. zonatus)
(Figs. 10, 11). The A2' inserts, often tendinously (Figs. 9-11), onto the posterolateral region of the coronoid process of the angulo-articular. In Trichomycterus cf. iheringi the fibers of the lateral surface of the A2' are arranged into a tripennate configuration (Figs. 10,11), thus resembling the condition reported by Adriaens et al. (2010) for T. guianensis (see "Discussion: Trichomycterinae"). As in the Nematogenyidae, the A2" is also tenuously discernible from the A2' by its deflection ventrad (Fig. 11) near to its insertion onto the posteromedial rim of the coronoid process of the dentary (Fig. 12). The A3 originates from the anterodorsal region of the suspensorium, always from the hyomandibula and usually also from the quadrate and metapterygoid (Fig. 10). Insertion is onto the medial face of the angulo-articular (Fig. 12). Although the A3 section never exhibit complete subdivisions, a ventral (A3') and a dorsal (A3") portion may be distinguished especially at their origins (Fig. 12). As in the Nematogenyidae, the origin of the A3" of most trichomycterines extends posteriorly on the hyomandibula so as to lying medial to the levator arcus palatini (Figs. 10, 12). In other trichomycterines (Bullockia, Hatcheria,

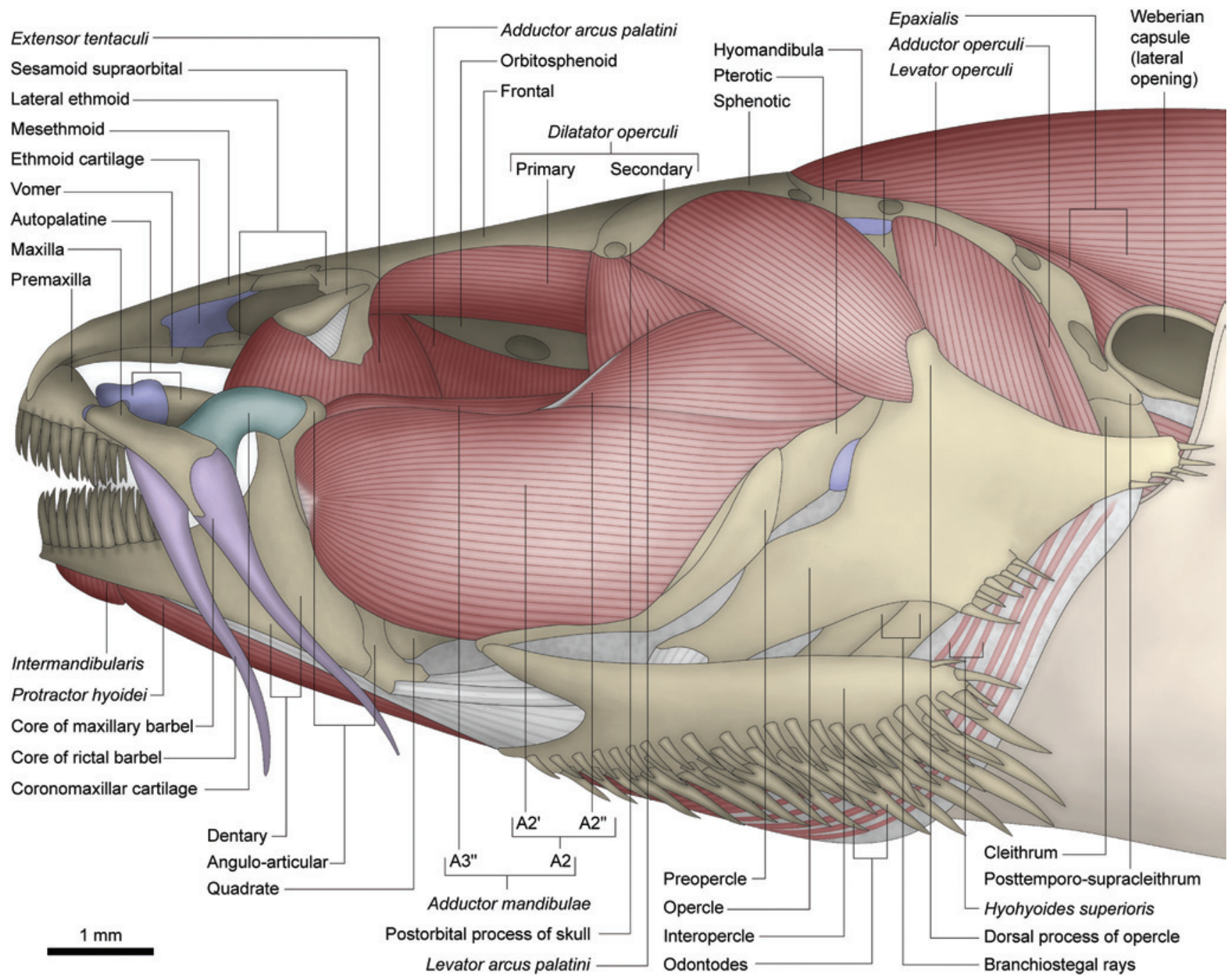

Fig. 7. Left lateral view of head of Trichogenes longipinnis (Trichogeninae), LIRP 1059 (75.5 mm SL). Antorbital and core of nasal barbels removed. 


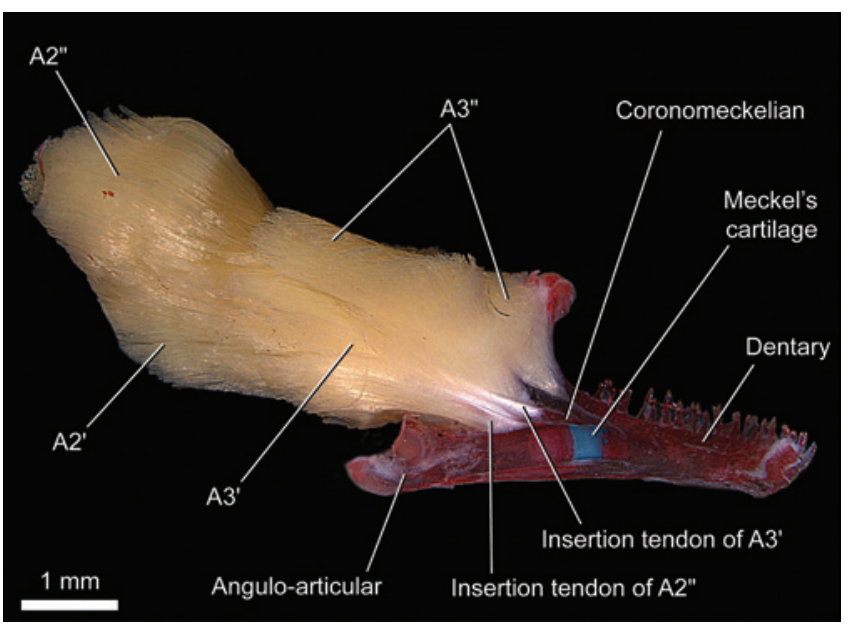

Fig. 8. Medial view of left adductor mandibulae and attached lower jaw of Trichogenes longipinnis (Trichogeninae), LIRP 1059 (60.8 mm SL).
Trichomycterus areolatus, T. chiltoni, T. immaculatus, and $T$. zonatus) that origin is not posteriorly expanded, so that the A3" originates only anterior to the levator arcus palatini (a condition similar to that of trichogenines and some sarcoglanidines). The A3' always originates anteroventrally to the levator arcus palatini and is more associated with the A2 (Fig. 10). Fibers of A3', however, are never exposed on the lateral surface of the adductor mandibulae as occurs in the Nematogenyidae. Section A $\omega$ is absent (Fig. 12).

The major interspecific variations in the adductor mandibulae encountered among the members of the Trichomycterinae involve the degree of hypertrophy of the A2 section and the overall differentiation of the sections that compose that muscle. Some trichomycterines (Ituglanis cf. amazonicus, Trichomycterus brasiliensis, T. davisi, and, in a lesser degree, $T$. cf. iheringi) have a distinctly enlarged A2, with the result that in many cases their eyes cannot be seen from a lateral view (eyes facing upwards). This feature

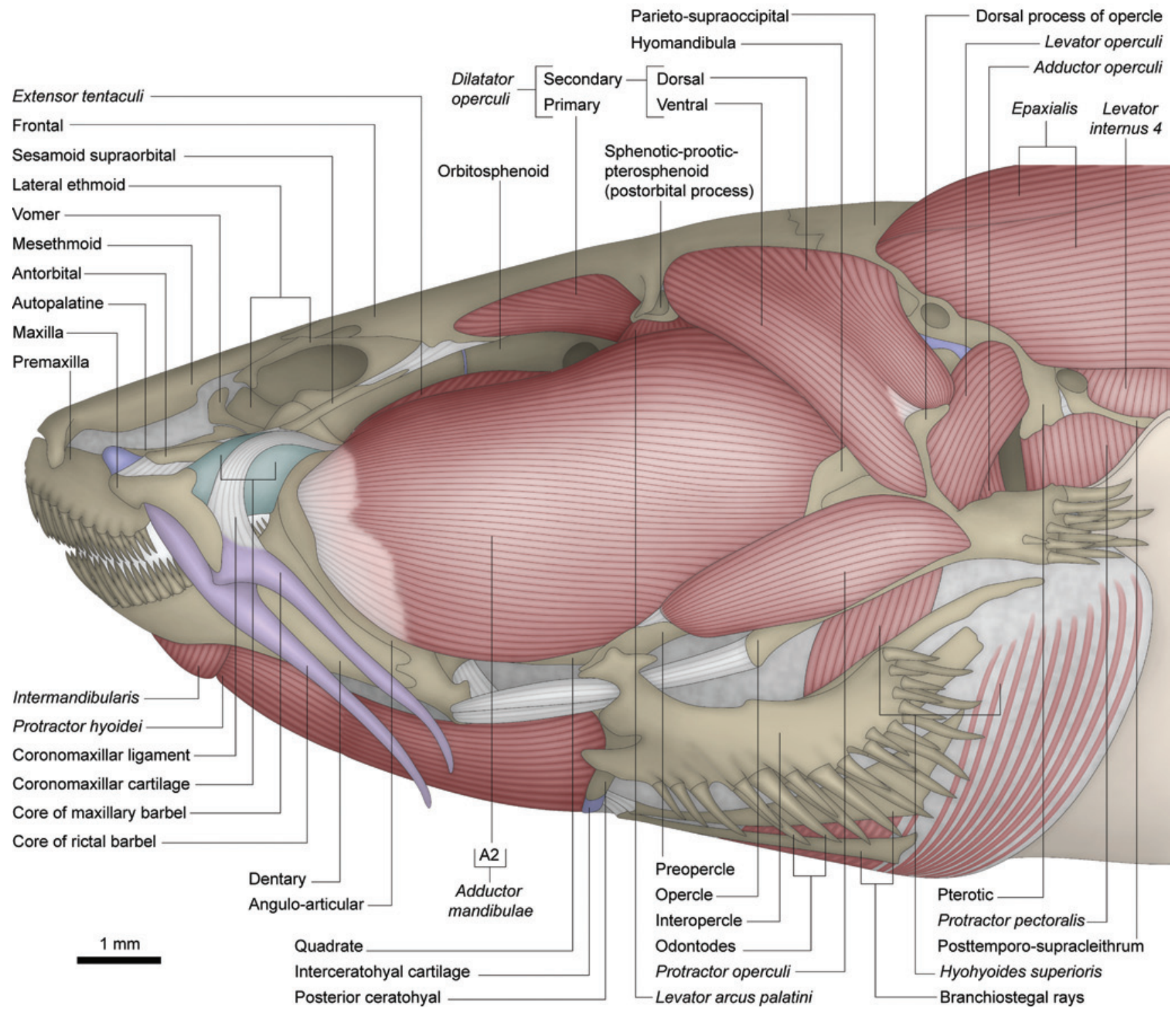

Fig. 9. Left lateral view of head of Trichomycterus brasiliensis (Trichomycterinae), LIRP 1968 (76.4 mm SL). Core of nasal barbels removed. 
apparently shows a positive allometry during ontogeny in these species. Other trichomycterines, including some that also exhibit a hypertrophied A2, possess the subdivisions of the A2 (into A2" and A2') more obviously differentiated from each other than in other species. Among the examined trichomycterines, there is a plenty of intermediate conditions between the less and the most extreme states of development of the A2, as well as variable degrees of differentiation of its subdivisions. This variation renders difficult to delimit discreet states to be incorporated into a phylogenetic analysis.

Levator arcus palatini with the same general configuration as in the Nematogenyidae, Copionodontinae and Trichogeninae. In most species this muscle is positioned between the dorsal portions of the A2 and A3 sections of the adductor mandibulae (Fig. 10) (like in Nematogenyidae and Copionodontinae) while in others, it lies posterior to the A3 section (like in Trichogeninae).

The adductor arcus palatini originates from the ventrolateral region of the neurocranium on the orbitosphenoid, parasphenoid and sphenotic-prooticpterosphenoid (Figs. 9, 13). Some fibers of this muscle may also arise from the connective membrane that joins the bones of the suspensorium (Fig. 13). Insertion is onto the medial surfaces of the metapterygoid, quadrate, and hyomandibula.

Extensor tentaculi usually originating only from the ventrolateral regions of the lateral ethmoid and orbitosphenoid (Figs. 9, 10). In Trichomycterus davisi and T. stawiarski this muscle is considerably enlarged compared to that in other trichomycterids, with the presence of a ventral bundle which also originates from the anterodorsal region of the suspensorium on the metapterygoid and, rarely, the hyomandibula. Insertion is onto the posterolateral region of the autopalatine.

Adductor hyomandibulae is absent (Fig. 13).

Protractor operculi with origin on the midlateral region of the preopercle (just dorsal to its articulation with the interopercle) and on a tiny tendon shared with the A2 section of the adductor mandibulae (Figs. 9, 10, 14). Insertion is onto

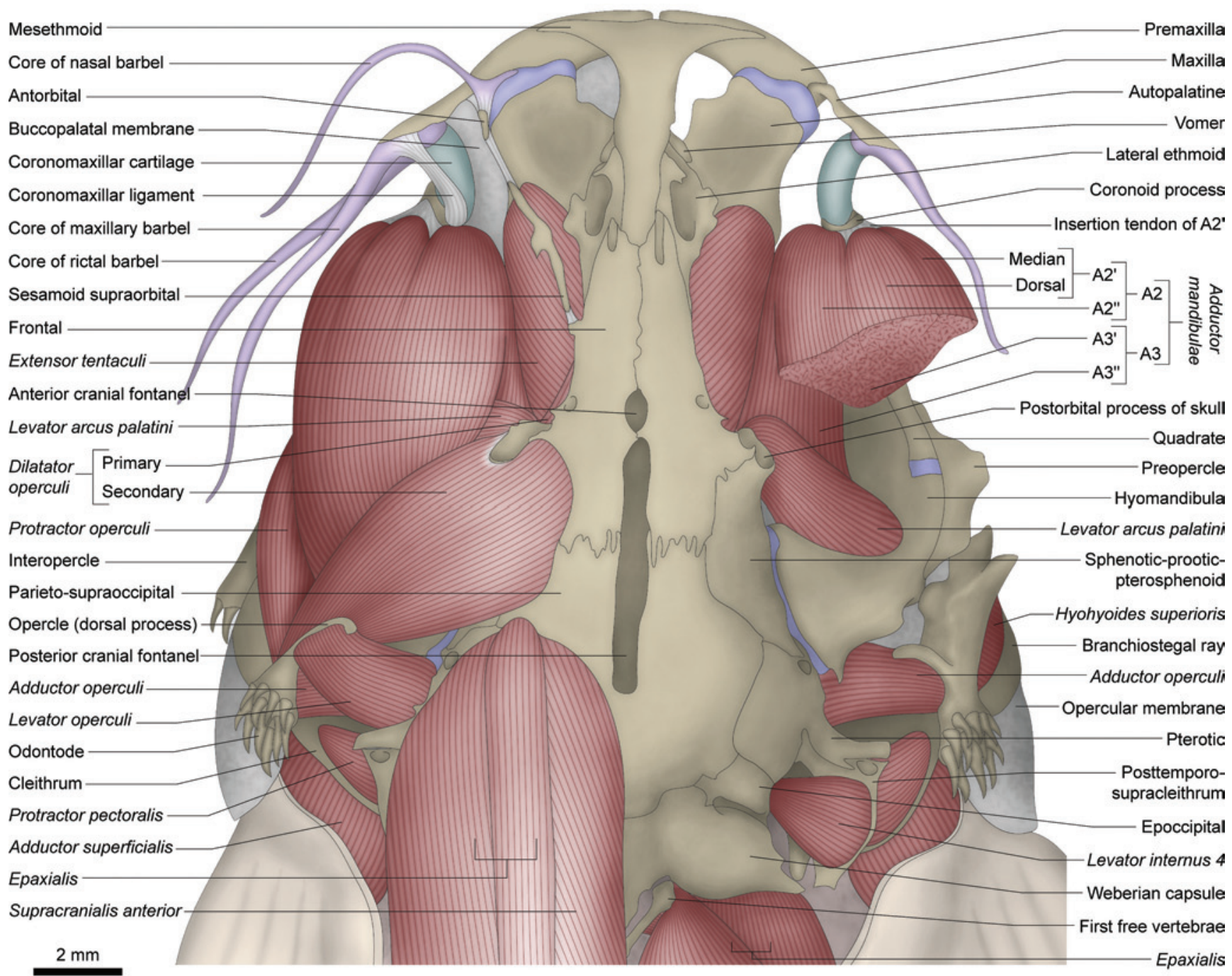

Fig. 10. Dorsal view of head of Trichomycterus cf. iheringi (Trichomycterinae), LIRP 3182 (72.2 mm SL). Right core of nasal barbel, interopercle, buccopalatal membane, dilatator operculi, levator operculi, protractor operculi, supracarinalis anterior, and superficial portions of epaxialis removed; right A2 and A3' sections of adductor mandibulae transversely sectioned. 
the midventral region of the lateral face of the opercle just anterior to its opercular patch of odontodes.

Dilatator operculi with its primary and secondary sections separated at their origin but partially continuous at their insertions (Figs. 9, 10, 14). The primary section passes medial to the levator arcus palatini and lateral to the adductor mandibulae. In some species it originates solely from the ventral surface of the postorbital process of skull whereas, in others, it extends anteriorly to involve also the midlateral region of the frontal (the portion just anterior to the postorbital process). Insertion is as in the Trichogeninae. The secondary section originates from the otic region of the cranial roof,

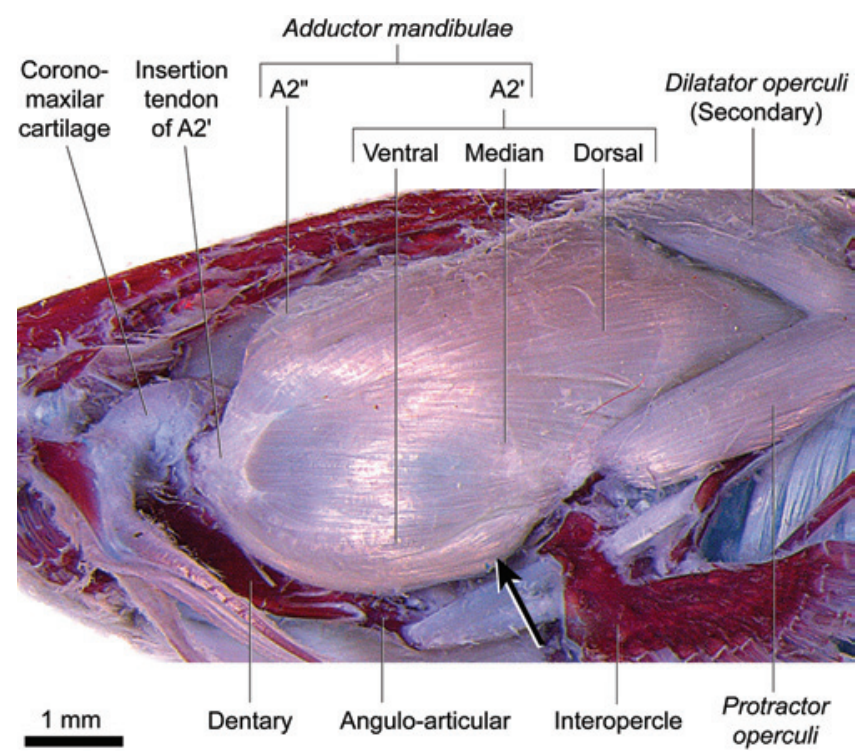

Fig. 11. Left lateral view of region of adductor mandibulae region of Trichomycterus cf. iheringi (Trichomycterinae), LIRP 3182 (72.2 mm SL). Arrow indicates posteroventral bundle of A2' which apparently corresponds to the "A1-OST" of Adriaens et al. (2010) (see "Discussion: Trichomycterinae").

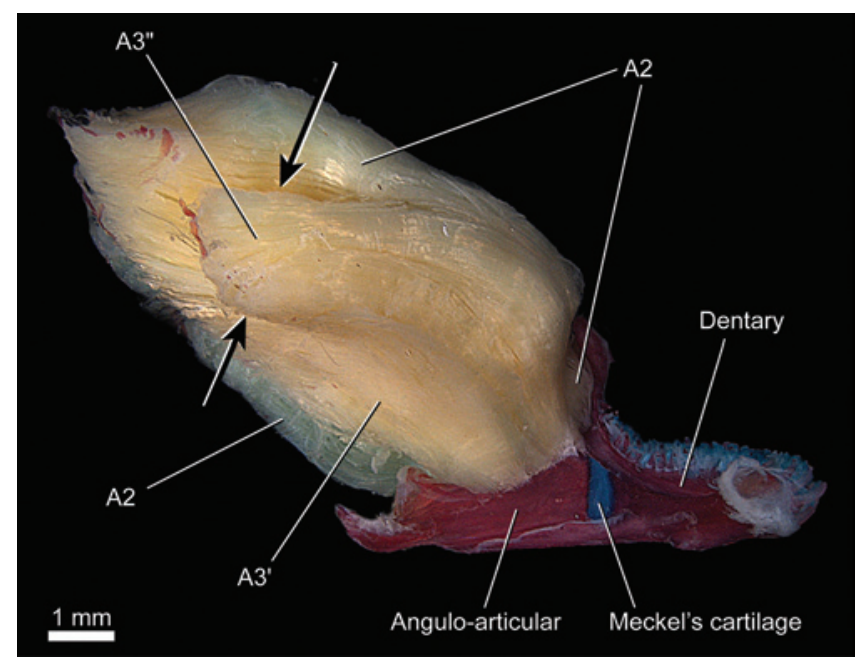

Fig. 12. Medial view of left adductor mandibulae and attached lower jaw of Trichomycterus brasiliensis (Trichomycterinae), LIRP 1968 (95.1 mm SL). Arrows indicates space occupied by levator arcus palatini. mainly on the sphenotic-prootic-pterosphenoid, along with the adjacent regions of the frontal, hyomandibula, and, sometimes, the parieto-supraoccipital. Insertion is onto the dorsal process of the opercle. Despite being undifferentiated in some species (Fig. 10), in most cases, a division of the secondary section into dorsal and ventral portions is evident, at least, in the region of its insertion (Figs. 9, 14). In such cases, the secondary-dorsal portion attaches more obviously to the tip of the dorsal process of the opercle, while the secondary-ventral part extends ventrally over the lateral face of the same process. In Bullockia maldonadoi, Hatcheria macraei, Trichomycterus areolatus, T. chiltoni, T. immaculatus, and T. zonatus the origin of the secondaryventral section of the dilatator operculi is much anteroventrally expanded, with its anterior limit approximately at the vertical through the middle of the protractor operculi. As a consequence the secondary-ventral section of the dilatator operculi assumes a triangular shape (Fig. 14).

The levator operculi (Figs. 9, 10,14) originates from the lateroventral region of the pterotic and inserts onto the

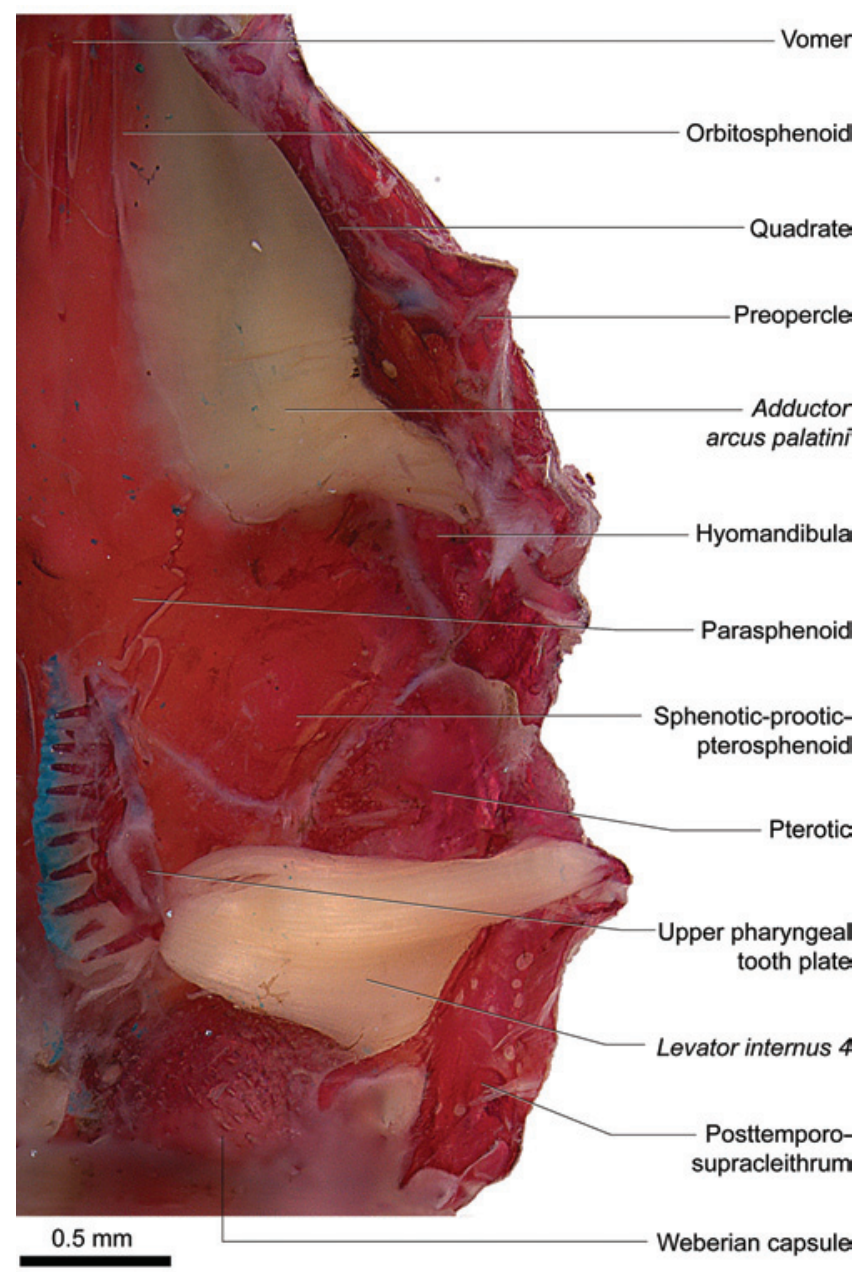

Fig. 13. Ventral view of left half of neurocranial floor of Ituglanis cf. gracilior (Trichomycterinae), MZUSP 86821 (53.2 $\mathrm{mm} \mathrm{SL}$ ). Internal suspensorial muscles and upper pharyngeal tooth plate with attached levator internus 4 retained; remaining elements of branchial arches removed. 
dorsomedial region of the opercle (see also some pertinent comments about this muscle under "Discussion: Nematogenyidae").

Adductor operculi situated medial to the levator operculi (Figs. 9, 10, 14). The adductor operculi originates from the ventral face of the pterotic (Fig. 13) passing medial to the hyomandibula (Fig. 10) to insert onto the dorsal face of the medial crest of opercle. Separation from the levator operculi seems to be incomplete in Ituglanis and some Trichomycterus.

\section{Sarcoglanidinae}

The adductor mandibulae of Sarcoglanis is similar to that of nematogenyids and most trichomycterines, notably for the levator arcus palatini which lies between the dorsoposterior parts of the A2 and A3. The A2 of Sarcoglanis originates from the ventral part of suspensorium on the hyomandibula, preopercle, and quadrate (Fig. 15). Insertion is onto the posterior portion of the coronoid process. That section exhibits a much tenuous anterior differentiation into A2' and A2", with the latter deflecting ventrad towards its insertion. At insertion, the A2' is more associated with the angulo-articular and the A2" with the dentary. The A3 of Sarcoglanis has two recognizable portions, both originating from the hyomandibula. The ventral A3' lies anteroventral to the levator arcus palatini and inserts onto the anteromedial region of the angulo-articular. The A3" originates medial to the levator arcus palatini and attaches to a small tendon that embeds into the buccopalatal membrane.

In Microcambeva and Stauroglanis the adductor mandibulae lacks clear subdivisions (Fig. 16). However, comparisons with other taxa, especially Sarcoglanis and

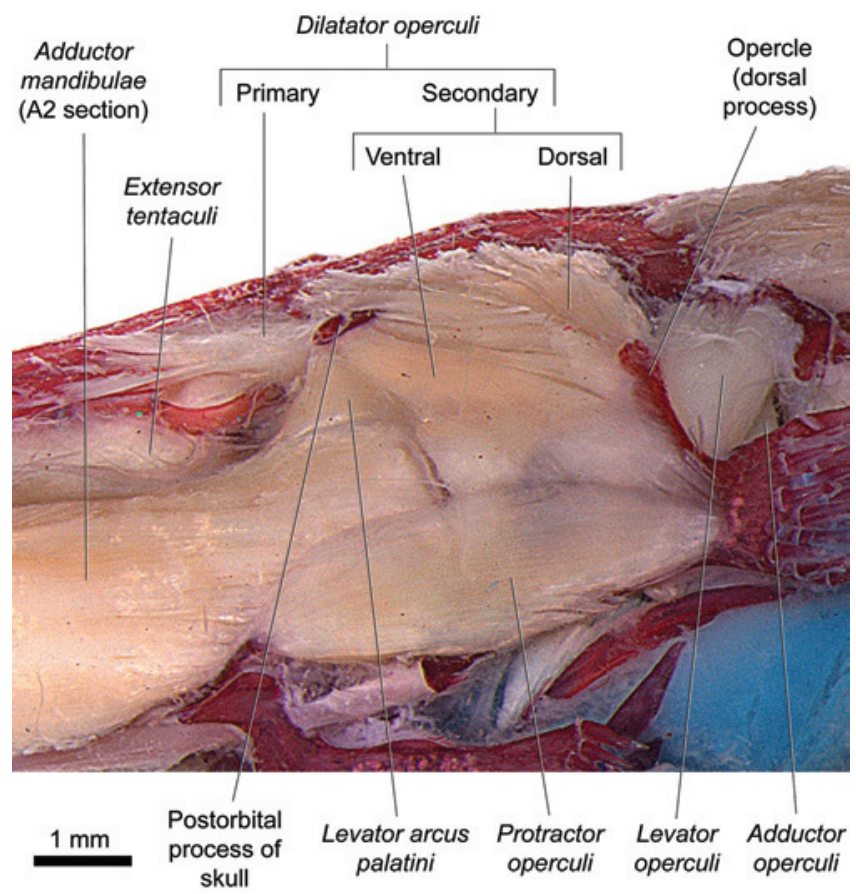

Fig. 14. Left lateral view of opercular region of Trichomycterus immaculatus (Trichomycterinae), LIRP 285 (83.7 mm SL).

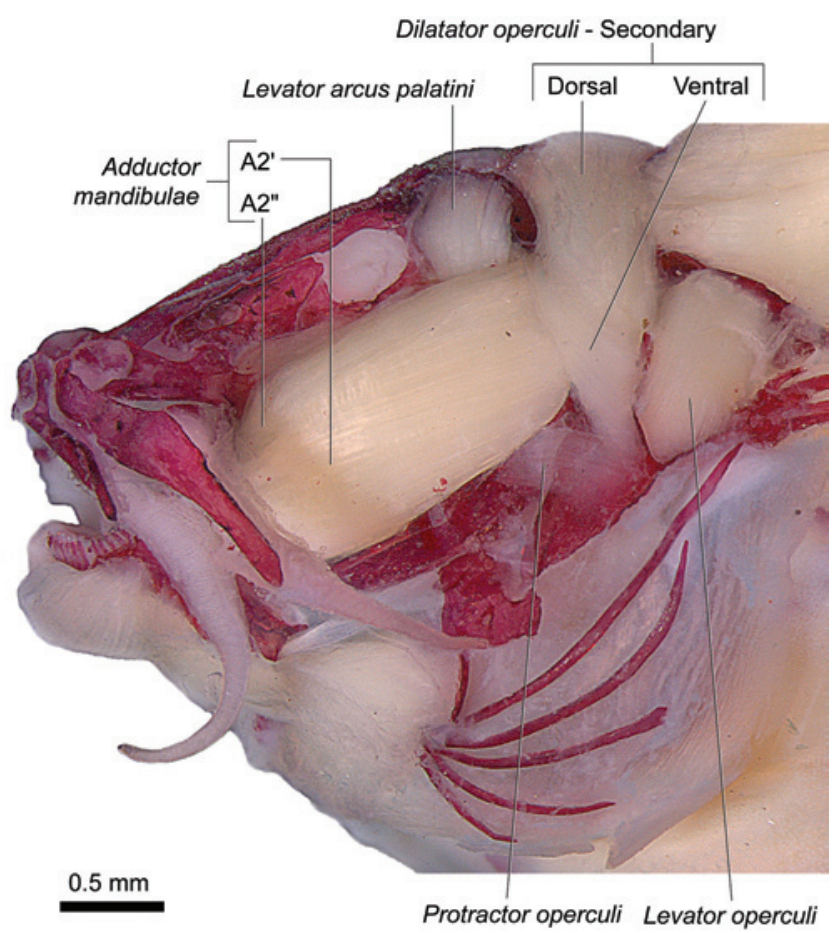

Fig. 15. Left lateral view of head of Sarcoglanis simplex (Sarcoglanidinae), LIRP 7437 (16.9 mm SL). Antorbital and sesamoid supraorbital bone removed.

glanapterygines, lead us to infer that both A2 and A3 sections are present in these genera. These sections in Microcambeva and Stauroglanis are fully continuous with each other along their entire length except near their insertion. The group of fibers apparently corresponding to the A2 of these genera lacks any evident subdivision into A2' and A2", but retains the same primary sites of origin and insertions of the A2 of Sarcoglanis. The A3 of Microcambeva and Stauroglanis also exhibits an anterior distinction into A3' and A3". As in Sarcoglanis, the A3" inserts onto the buccopalatal membrane whereas the A3' inserts onto the angulo-articular (Fig. 17). In contrast to the condition of Sarcoglanis, the A3 of Microcambeva and Stauroglanis is not divided posteriorly, having a common origin on the region of the hyomandibula just anterior to the levator arcus palatini (Fig. 15). The section $\mathrm{A} \omega$ is absent (Fig. 17).

The levator arcus palatini in Microcambeva and Stauroglanis is roughly conical, although anteriorly more elongated than in the Nematogenyidae, Copionodontinae, Trichogeninae, and Trichomycterinae (Fig. 16). That muscle in Microcambeva and Stauroglanis is located completely posterior to the adductor mandibulae with its origin and insertion comparable to that in the Nematogenyidae and the basal members of the Trichomycteridae. In Sarcoglanis this muscle is strap-like, having an origin and insertion of about the same width (Fig. 15). The origin of that muscle is from the dorsolateral region of the frontal, in the region just anterior to the postorbital process of skull, with the insertion comparable to that in the other nematogenyids and trichomycterids described. 


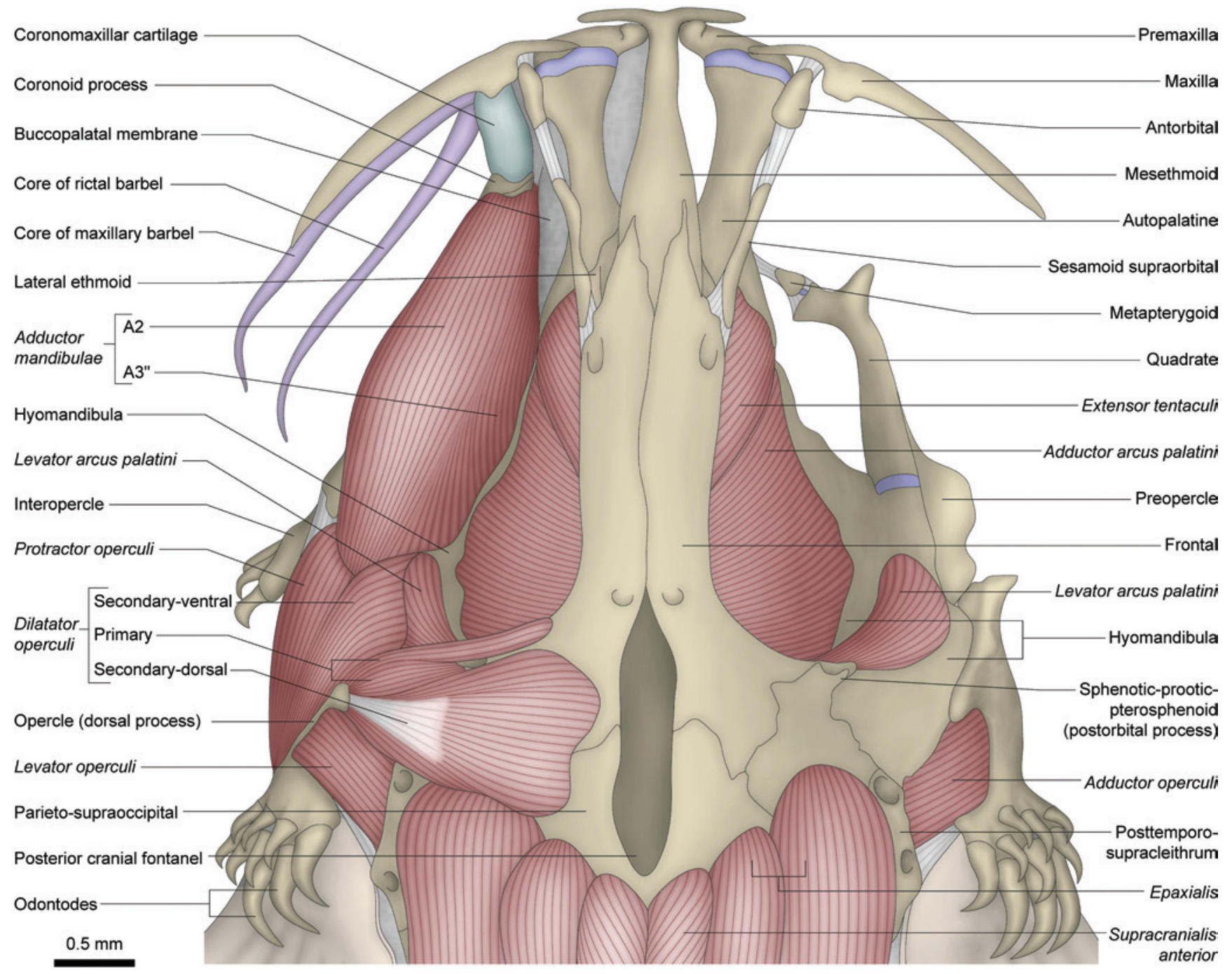

Fig. 16. Dorsal view of head of Microcambeva ribeirae (Sarcoglanidinae), MZUSP 65764 (41.8 mm SL). Core of nasal barbels and core of right maxillary barbel, rictal barbel, lower jaw, interopercle, adductor mandibulae, dilatator operculi, levator operculi, and protractor operculi removed.

Adductor arcus palatini (Fig. 16) originating from the lateral region of the parasphenoid and adjacent portions of the orbitosphenoid and sphenotic-prootic-pterosphenoid. The insertion is solely onto the dorsal portion of the medial face of the hyomandibula (mainly on its conspicuous anterior process) in Microcambeva. In Stauroglanis and Sarcoglanis, in addition to an insertion onto the dorsal portion of hyomandibula, this muscle also inserts onto the suspensorial membrane with some fibers reaching the dorsal portion of the quadrate.

Extensor tentaculi with an origin from the ventrolateral regions of the lateral ethmoid and orbitosphenoid and insertion onto the posterior region of the autopalatine (Fig. 16).

The adductor hyomandibulae is absent.

In Microcambeva the protractor operculi is posterodorsally fused to the highly modified anteroventral part of the dilatator operculi, forming a partially continuous complex muscle mass (Fig. 16). Despite that, comparisons with other trichomycterids permit us to infer the homologies of the different parts that form this compound muscle. As is other trichomycterids, the protractor operculi originates from posteroventral region of the suspensorium, on the preopercle and hyomandibula, and from a tendon shared with the A2 section of the adductor mandibulae. Posteriorly the protractor operculi fuses to a ventral bundle of the dilatator operculi and inserts onto the midventral region of the opercle. That ventral bundle of the dilatator operculi originates from the fascia of the levator arcus palatini and inserts onto the middorsal portion of the opercle. This site of insertion resembles that of the ventral portion of the secondary section of the dilatator operculi of copionodontines and trichomycterines (see Figs. 3, 9, 14). That fact in addition to the close association with the protractor operculi led us to infer that this ventral bundle corresponds to the secondaryventral section of the dilatator operculi. Attached to the anterodorsal rim of the dorsal process of opercle, there is a double bundle of fibers that seems to correspond to an atrophied primary section of the dilatator operculi (Fig. 16). The cord-like anterior most group of fibers originates from 


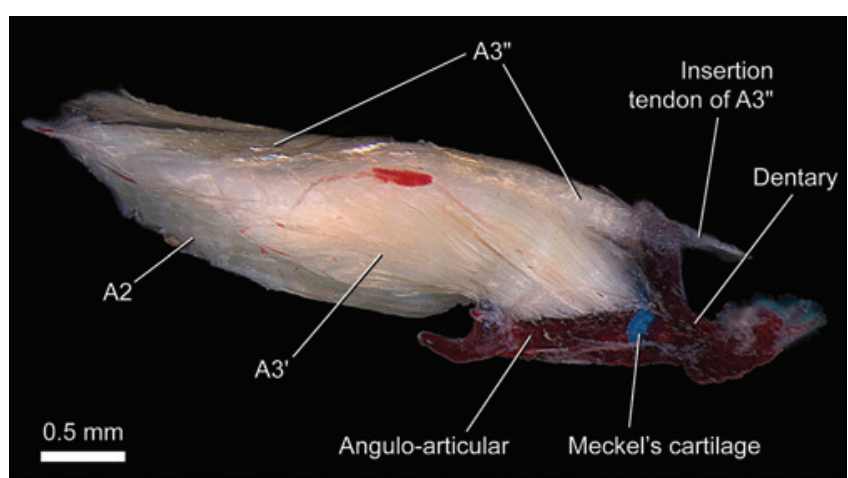

Fig. 17. Medial view of left adductor mandibulae and attached lower jaw of Microcambeva ribeirae (Sarcoglanidinae), MZUSP 65764 (41.8 mm SL).

the region of the frontal just anterior to the postorbital process of skull, then passes anterolaterally to the levator arcus palatini. The posterior most group of fibers originates from the ventral surface of the same process, lateral to the levator arcus palatini. The homology of these bundles with the primary section of the dilatator operculi is inferred based on their sites of origin and insertion which are basically the same as in the Nematogenyidae, Copionodontinae, Trichogeninae, and Trichomycterinae, in spite of passing dorsolateral to the levator arcus palatini (see below). A dorsoposterior bundle of the dilatator operculi is much better differentiated from the remaining muscle mass. That bundle certainly corresponds to the dorsal portion of the secondary division of the dilatator operculi inasmuch it retains the same basic form, position, and sites of attachment than in most other trichomycterids. The origin is from the otic region of the neurocranial roof, involving the sphenotic-prootic-pterosphenoid, frontal, and parieto-supraoccipital. Insertion is both tendinous and musculous onto the posterodorsal part of the dorsal process of the opercle. Note that, if our hypotheses of homology among the portions of the dilatator operculi are correct, differently of the basal trichomycterids, the primary section in Microcambeva passes lateral to the levator arcus palatini (as in other members of the TSVSG clade; see below). Apparently coupled with that feature, the secondary section of the dilatator operculi becomes split into dorsal and ventral parts by the interposing primary section (see Character 26).

In Stauroglanis and Sarcoglanis (Fig. 15), the protractor operculi and dilatator operculi are completely separated from each other. The protractor operculi in Stauroglanis is quite similar to that of trichomycterines, having the same overall shape (fusiform) and attachment sites on the skeleton as in the members of that subfamily. In Sarcoglanis it is a much flattened muscle with fibers arranged in parallel. Origin is from the posterior region of the preopercle and insertion onto the ventrolateral region of the opercle (Fig. 15).

In both Stauroglanis and Sarcoglanis, the dilatator operculi apparently lacks a primary section (Fig. 15). The secondary section is present and exhibits dorsal and ventral portions readily recognizable by the distinct orientation of their superficial fibers. The secondary-ventral portion originates from the anterolateral region of the sphenoticprootic-pterosphenoid and inserts onto the ventral region of the dorsal process of the opercle, contacting ventrally the protractor operculi. The secondary-dorsal section is basically comparable to that in Microcambeva.

Levator operculi (Fig. 16) is basically like that in the Trichomycterinae. In Sarcoglanis this muscle seems to be attached more laterally onto the opercle (Fig. 15). This condition, however, is more related to modifications of the opercle in that genus than it is to changes in the insertion of the muscle (see "Discussion: Nematogenyidae").

The adductor operculi (Fig. 16) is similar to that of the Trichomycterinae. The separation from the levator operculi is incomplete in Sarcoglanis.

\section{Glanapteryginae}

The adductor mandibulae has two principal sections, A2 and A3, both located lateral to the levator arcus palatini (Fig. 18). These sections are partially continuous with each other posteriorly, but more obviously separated anteriorly (Fig. 19). The A2 has its origin on the posteroventral region of the suspensorium, involving the hyomandibula, preopercle, and quadrate (Fig. 18). As in the Nematogenyidae, most Trichomycterinae, and the sarcoglanidine Sarcoglanis, this section of the muscle is partially differentiated into an A2' and A2" anteriorly near to its area of insertion. The A2' inserts mainly onto the posterolateral region of the coronoid process of the angulo-articular, while the A2" deflects ventrally and inserts primarily onto the medial face of the coronoid process of the dentary (Fig. 19). The A3 originates from the anterodorsal region of the hyomandibula. Despite being somewhat continuous near its origin, the A3 is well differentiated anteriorly into A3' and A3" (especially in Listrura tetraradiata). As in sarcoglanidines, the A3' inserts onto the medial aspect of the angulo-articular, while the fibers of A3" converge onto a tendon that embeds into the buccopalatal membrane (Figs. 18, 19). Section A $\omega$ is absent (Fig. 19).

The Levator arcus palatini originates from the ventrolateral regions of the sphenotic-prootic-pterosphenoid and frontal, extending anteriorly beyond the postorbital process of skull (more obviously in Listrura picinguabae) (Fig. 18). Its insertion, always wider than its origin, is onto the anterodorsal region of the hyomandibula, primarily onto the conspicuous anterior process of that bone.

Adductor arcus palatini (Fig. 18) with an origin like that in the Sarcoglanidinae. The insertion is onto the suspensorial membrane and the dorsomedial region of the hyomandibula, especially onto its conspicuous anterior process.

Extensor tentaculi originating from the ventrolateral parts of the lateral ethmoid and orbitosphenoid (Fig. 18). The insertion is onto the posterolateral region of the autopalatine.

The adductor hyomandibulae is absent.

Protractor operculi comparatively slender with an origin from the lateral region of the preopercle and an insertion onto the midventral region of the opercle just anterior to its patch of odontodes (Fig. 18). 


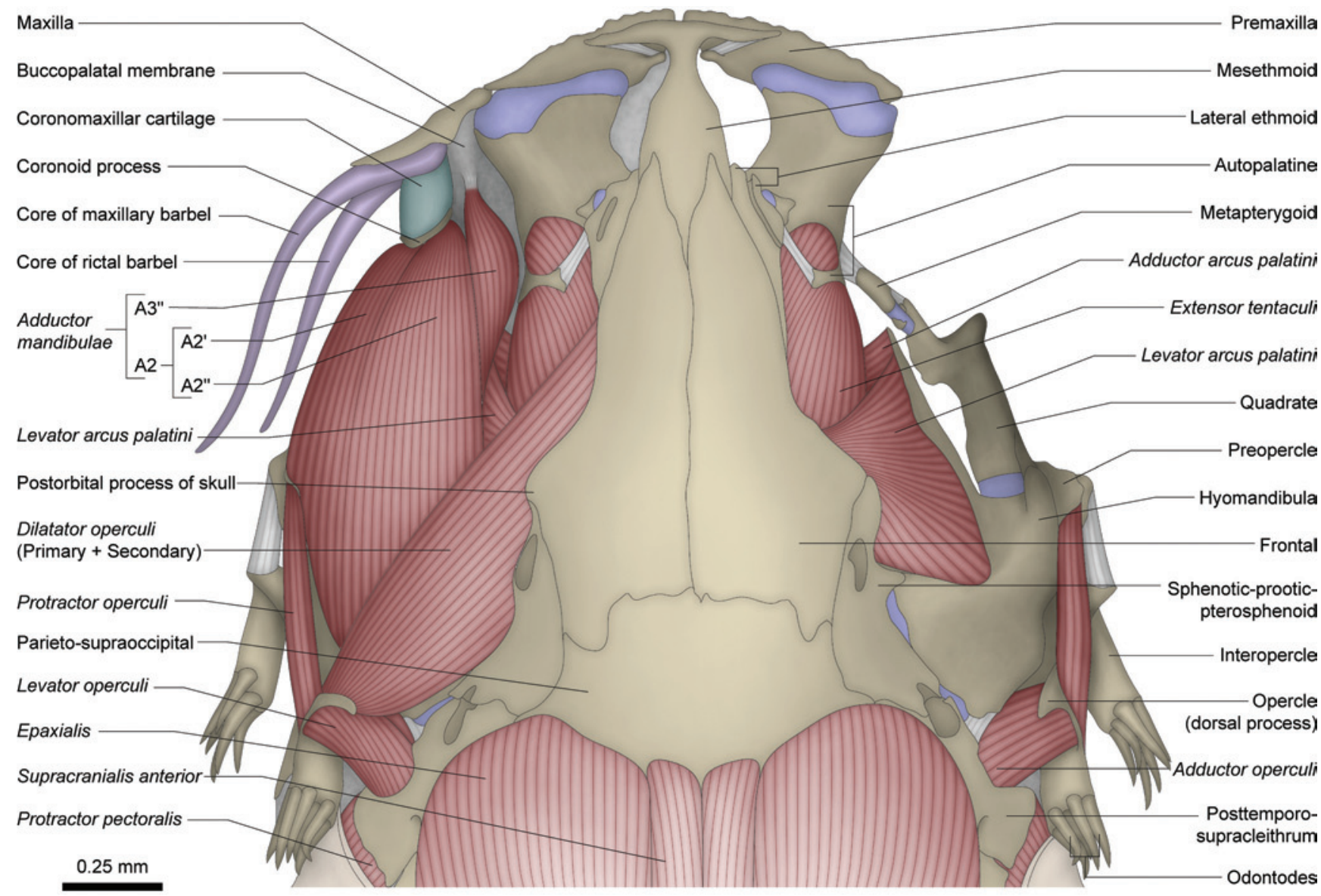

Fig. 18. Dorsal view of head of Listrura tetraradiata (Glanapteryginae), MNRJ 31534 (paratype; $39.0 \mathrm{~mm}$ SL). Antorbital, sesamoid supraorbital, and core of nasal barbels removed; right cores of maxillary and rictal barbels, buccopalatal membrane, coronomaxillar cartilage, maxilla, lower jaw, interopercle, adductor mandibulae, dilatator operculi, and levator operculi removed.

The dilatator operculi lacks any evident subdivision (Fig. 18). Comparisons with other taxa, however, lead us to infer that the groups of fibers that correspond to both the primary and secondary sections of the dilatator operculi of other trichomycterids are present in the Glanapteryginae. Existence of a secondary-dorsal portion is evidenced by the presence of a posterodorsal group of fibers that originates from dorsolateral region of sphenotic-prootic-pterosphenoid and inserts onto the tip of the dorsal process of opercle. An anterior most group of fibers originating from the lateral region of the frontal just anterior to the postorbital process of skull and inserting onto the anterodorsal region of the dorsal process of opercle indicates the existence of a primary section. Ventral to the primary portion, there is a group of fibers that inserts more ventrolaterally over the dorsal process of the opercle, a feature typical of the secondaryventral portion of other trichomycterids. Note that, as in the sarcoglanidine Microcambeva, tridentines, and many stegophilines and vandelliines, the primary section of the dilatator operculi of Listrura would pass dorsolateral to the levator arcus palatini and is located between the dorsal and ventral portions of the secondary section (see Character 26).
Levator operculi and adductor operculi (Fig. 18) as in the Trichomycterinae and Sarcoglanidinae, being always fully separated from each other.

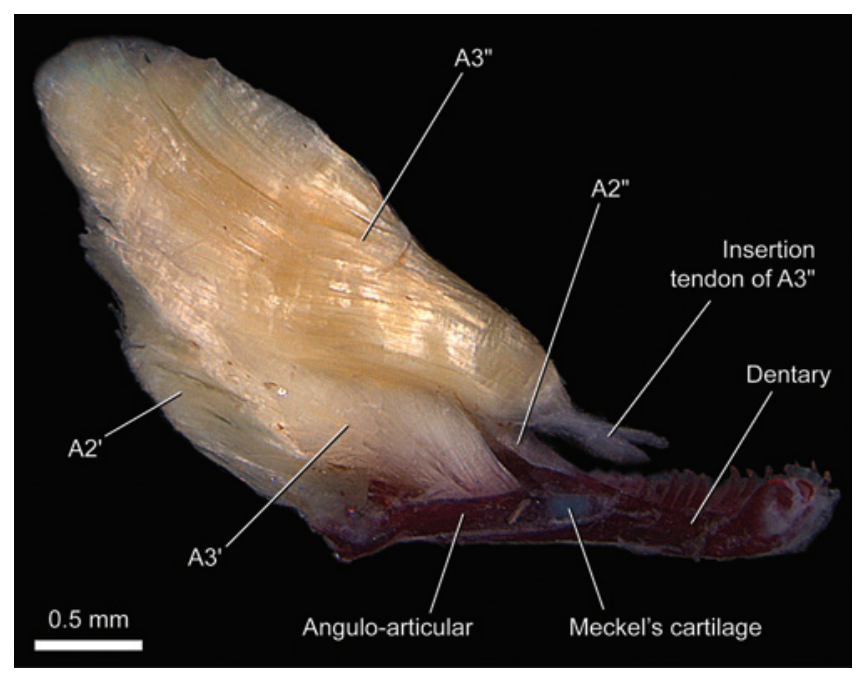

Fig. 19. Medial view of right adductor mandibulae and attached lower jaw of Listrura tetraradiata (Glanapteryginae), MNRJ 31534 (paratype; 39.0 mm SL). Image flipped horizontally to facilitate comparisons. 


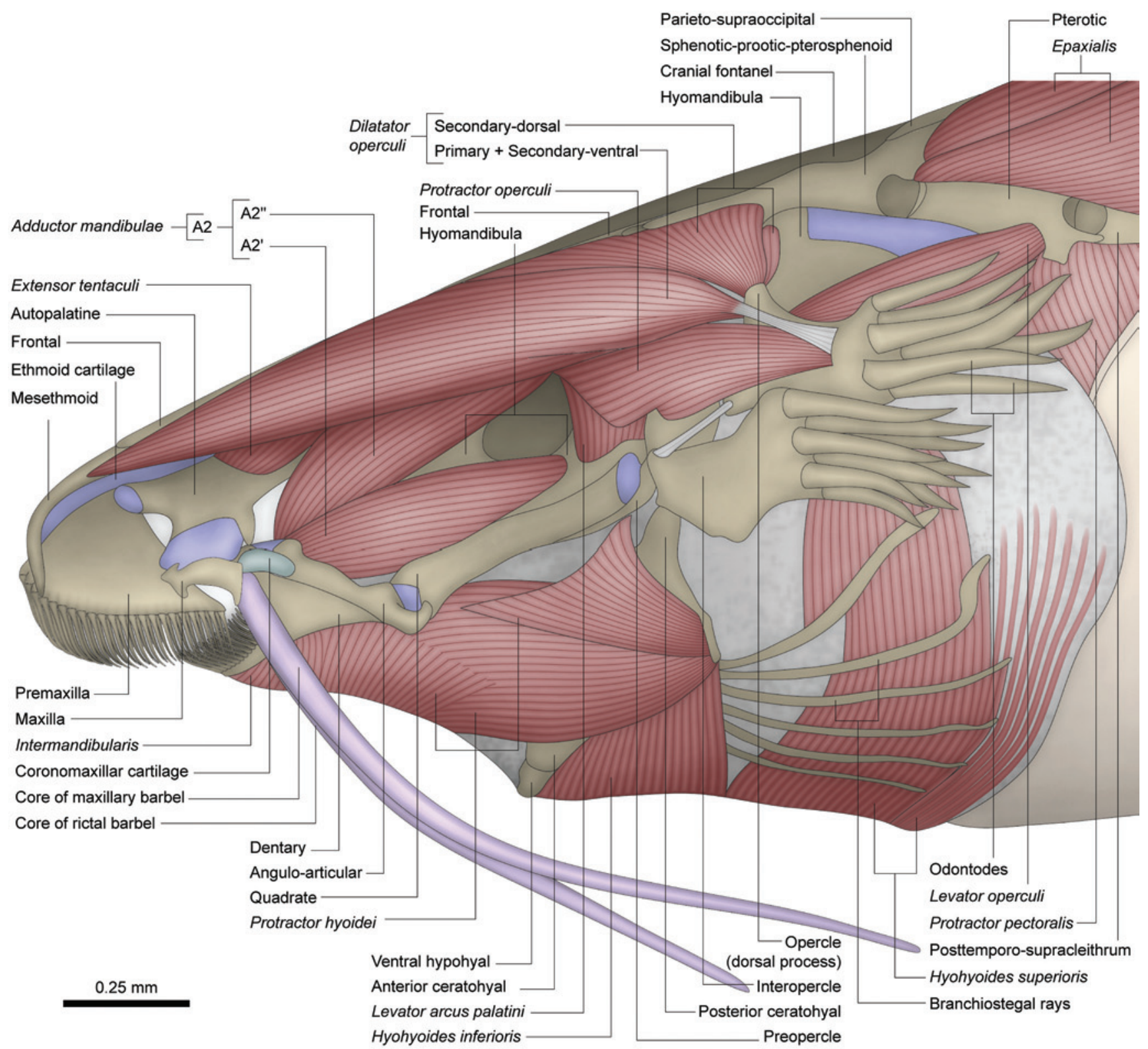

Fig. 20. Left lateral view of head of Tridentopsis pearsoni (Tridentinae), MZUSP 38671 (18.3 mm SL).

\section{Tridentinae}

Members of this subfamily possess comparatively enormous eyes placed ventrolaterally on their heads. This arrangement is coupled with profound modifications of several cephalic muscles in tridentines. The adductor mandibulae, for example, is "squeezed" by the large eyeballs, being comparatively the smallest of these muscles among all taxa examined herein (Fig. 20). Section A2 is fully separated from A3 (Fig. 21). The A2 also has almost fully separated A2' and A2" portions. The former originates from the anteroventral region of suspensorium on the quadrate and hyomandibula and inserts onto the posteromedial region of the anguloarticular. The A2" lies almost completely dorsal to the remaining sections of the adductor mandibulae, originating from both lateral and medial faces of the conspicuous posteriorly oriented anterodorsal process of the hyomandibula
(Fig. 20). Near to its insertion, the fibers of the A2" undergo the typical ventral deflection to allow its insertion primarily along the posteromedial rim of the dentary. The A3 is much smaller than the A2, having a nearly triangular shape (Fig. 21). It has a small partially tendinous origin on the hyomandibula and a broad insertion onto the ventromedial face of the angulo-articular. One might cast doubts on the identity of that section in tridentines because of its reduced size and narrow origin. However, in spite of these modifications, that section exhibits the same medial position and the same insertion site of the A3 of most other trichomycterids. Moreover, the two other lateral sections of the adductor mandibulae of tridentines clearly correspond to the A2' and A2" sections. Therefore, there are no reasons to do not consider the modified medial section of tridentines homologous to the A3. The A $\omega$ section is absent (Fig. 21). 


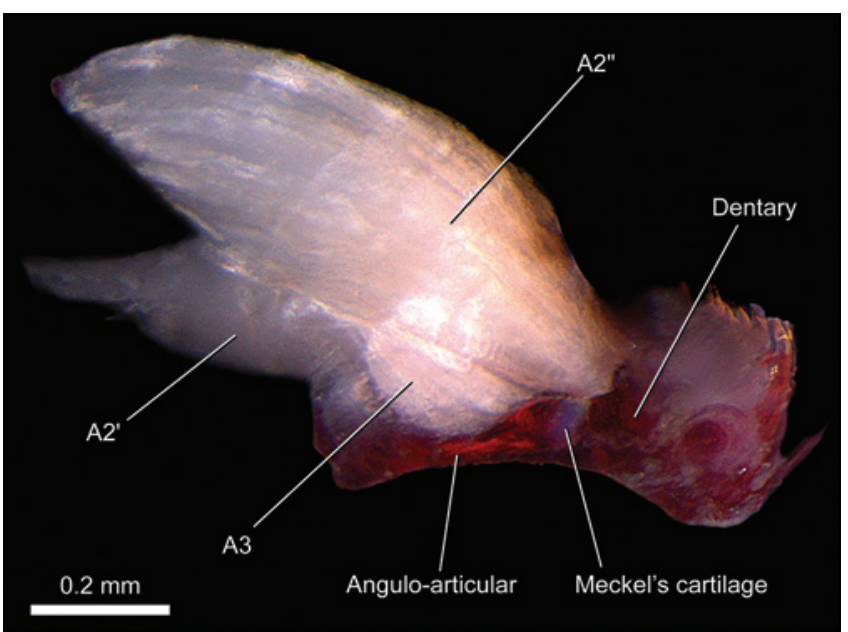

Fig. 21. Medial view of right adductor mandibulae and attached lower jaw of Tridentopsis pearsoni (Tridentinae), MZUSP 38671 (18.3 mm SL). Image flipped horizontally to facilitate comparisons.

The levator arcus palatini is broader at its origin than at the insertion, acquiring an inverted trapezoid shape from a lateral view. The origin is from the ventrolateral region of the frontal and the sphenotic-prootic-pterosphenoid. Insertion is onto the middorsal region of the hyomandibula (Fig. 20).

Adductor arcus palatini with an origin as in the Sarcoglanidinae and Glanapteryginae. The insertion is onto the dorsomedial part of the hyomandibula, mainly onto the conspicuous dorsoposterior process of the anterior part of this bone.

The extensor tentaculi (Fig. 20) originates from the lateral regions of the lateral ethmoid and orbitosphenoid. Insertion occurs onto the posterodorsal region of the autopalatine.

The adductor hyomandibulae is absent.

The protractor operculi originates primarily from the fascia of the levator arcus palatini, posteromedial to the eyeball (Fig. 20). Some of the deepest fibers attach to the hyomandibula and preopercle. The insertion is onto the lateral face of the opercle.

Dilatator operculi with subdivisions poorly differentiated from each other (Fig. 20), especially near its origin. A larger anterior most group of fibers originates far anteriorly on neurocranium from lateral portions of the mesethmoid and frontal. Some fibers of this part of the muscle insert onto the anterodorsal region of the dorsal process of the opercle, while other fibers attach to an elongate tendon that inserts onto the posterolateral region of the opercle. Although this section of the muscle cannot be readily subdivided into two distinct parts, its sites of origin and especially of insertion are typical of the primary and secondary-ventral sections of the dilatator operculi. These facts, together with an overall topological correspondence of this muscle with those observed in other trichomycterids, especially the closely related stegophilines and vandelliines, lead us to infer that this part of the muscle probably is a compound section formed by the fusion of the primary and secondary-ventral sections of the dilatator operculi. The fact of the origin of that compound section extends much more anteriorly compared to the basal trichomycterids is presumably attributed to an anterior expansion of the primary section of the dilatator operculi since that is the condition encountered in all stegophilines and vandelliines (see descriptions of those taxa below and Character 27). A closest association of the primary section with the secondary-ventral section is also usual in most members of the Sarcoglanidinae, Glanapteryginae, Stegophilinae, and Vandelliinae. The secondary-dorsal section is more distinctly separated from the remaining muscle mass, originating mainly from the lateral regions of the sphenotic-prootic-pterosphenoid and frontal, with a small posterior bundle originating from the hyomandibula. The insertion is onto the tip of the dorsal process of opercle.

The levator operculi is relatively slender (Fig. 20) compared with that of other trichomycterids. Sites of origin and insertion of this muscle are, however, basically the same as those in the Trichomycterinae, Sarcoglanidinae, and Glanapteryginae.

The adductor operculi is also comparatively slender and apparently partially continuous with the levator operculi along its anterior border. Sites of origin and insertion are basically the same as in the Trichomycterinae, Sarcoglanidinae, and Glanapteryginae.

\section{Stegophilinae}

Adductor mandibulae with the A2 and A3 sections fully separated from each other across their entire lengths (Figs. 22-24). The A2 is almost fully separated into ventral (A2') and dorsal (A2") parts. The A2' originates from the preopercle and quadrate and inserts mainly onto the posterior region of the laterally oriented coronoid process of the angulo-articular (Figs. 22, 25). In Ochmacanthus, Parastegophilus, Pseudostegophilus, and Pareiodon the anterodorsal most fibers of this section tenuously attach to a short tendon (Fig. 25) that embeds into the buccopalatal membrane (Fig. 26). The A2" is, at least, partially bipennate in most examined taxa (Fig. 25). It originates primarily from the posterodorsal region of the hyomandibula, with adjacent areas of the preopercle and sphenotic also involved in some cases. Fibers of this section converge anteriorly onto a long tendon that inserts onto the posterolateral rim of the dentary. As in tridentines, the A3 is much smaller than the other sections of the adductor mandibulae, being approximately triangular and notably anteriorly displaced on the suspensorium (Figs. 22-25). Its narrow origin is both musculous and tendinous in Haemomaster but only tendinous in all other stegophilines examined. The A3 originates from a small area on the anterodorsal region of the hyomandibula and sometimes also the quadrate. The insertion is broad onto the medial region of the lower jaw, reaching the borders of the dentary symphysis in most cases. The A $\omega$ section is absent (Fig. 24).

The levator arcus palatini (Fig. 22) is comparable to that in the Tridentinae. In Parastegophilus, Pseudostegophilus, and especially Pareiodon, however, this muscle is further expanded anteriorly. 


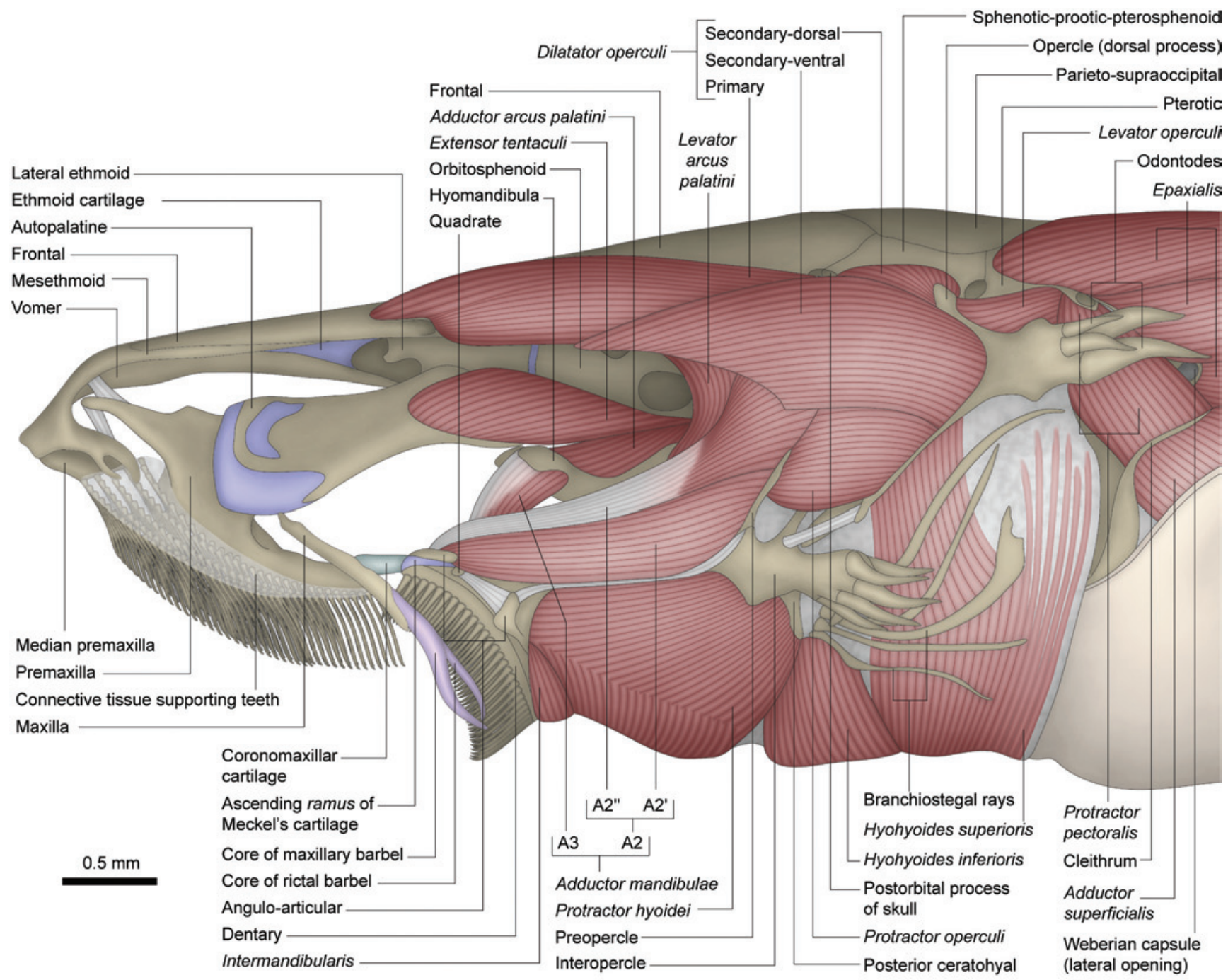

Fig. 22. Left lateral view of head of Haemomaster venezuelae (Stegophilinae), LIRP 7438 (36.9 mm SL).

The adductor arcus palatini originates from the parasphenoid, sphenotic-prootic-pterosphenoid, and sometimes also the orbitosphenoid and lateral ethmoid (Fig. 22). Insertion is primarily onto the medial face of the hyomandibula and quadrate with the metapterygoid sometimes also involved.

The extensor tentaculi originates from the ventrolateral regions of the orbitosphenoid and lateral ethmoid (Fig. 22) with the parasphenoid sometimes also involved. In Haemomaster this muscle inserts onto the posterior margin and dorsal face of the autopalatine. In other stegophilines it attaches solely onto the posterior border of this bone.

The adductor hyomandibulae is absent.

The protractor operculi is shorter and deeper compared to in other trichomycterids, often acquiring a parallelogram shape from a lateral view (Fig. 22). It originates from the posterolateral region of the preopercle and usually also from a shared tendon with the A2 part of the adductor mandibulae (as in Trichomycterinae). In Haemomaster the dorsal portion of the protractor operculi is covered by the superficial fibers of the secondary-ventral section of the dilatator operculi.
Some fibers of the protractor operculi in this genus also intermingle with both the secondary-ventral section of the dilatator operculi and the adductor mandibulae (A2" section). In Pareiodon most of the fibers of the muscle originate from the lateral fascia of the adductor mandibulae (Fig. 27). The insertion is onto the central region of the lateral face of the opercle, ventrally to its dorsal process and anteriorly to its patch of odontodes.

The dilatator operculi exhibits many modifications in several groups of the subfamily. In Haemomaster all three sections (primary, secondary-dorsal, and secondaryventral) are well differentiated although continuity along their insertions persists to some extent (Figs. 22, 23). The primary section is distinctly anteriorly elongate, being situated dorsolateral to the levator arcus palatini and between the secondary-dorsal and secondary-ventral sections. The primary section originates from the dorsolateral region of the frontal and inserts via a tendon onto the anterodorsal part of the dorsal process of the opercle. The secondary-dorsal section originates from the dorsolateral regions of the hyomandibula and sphenotic- 


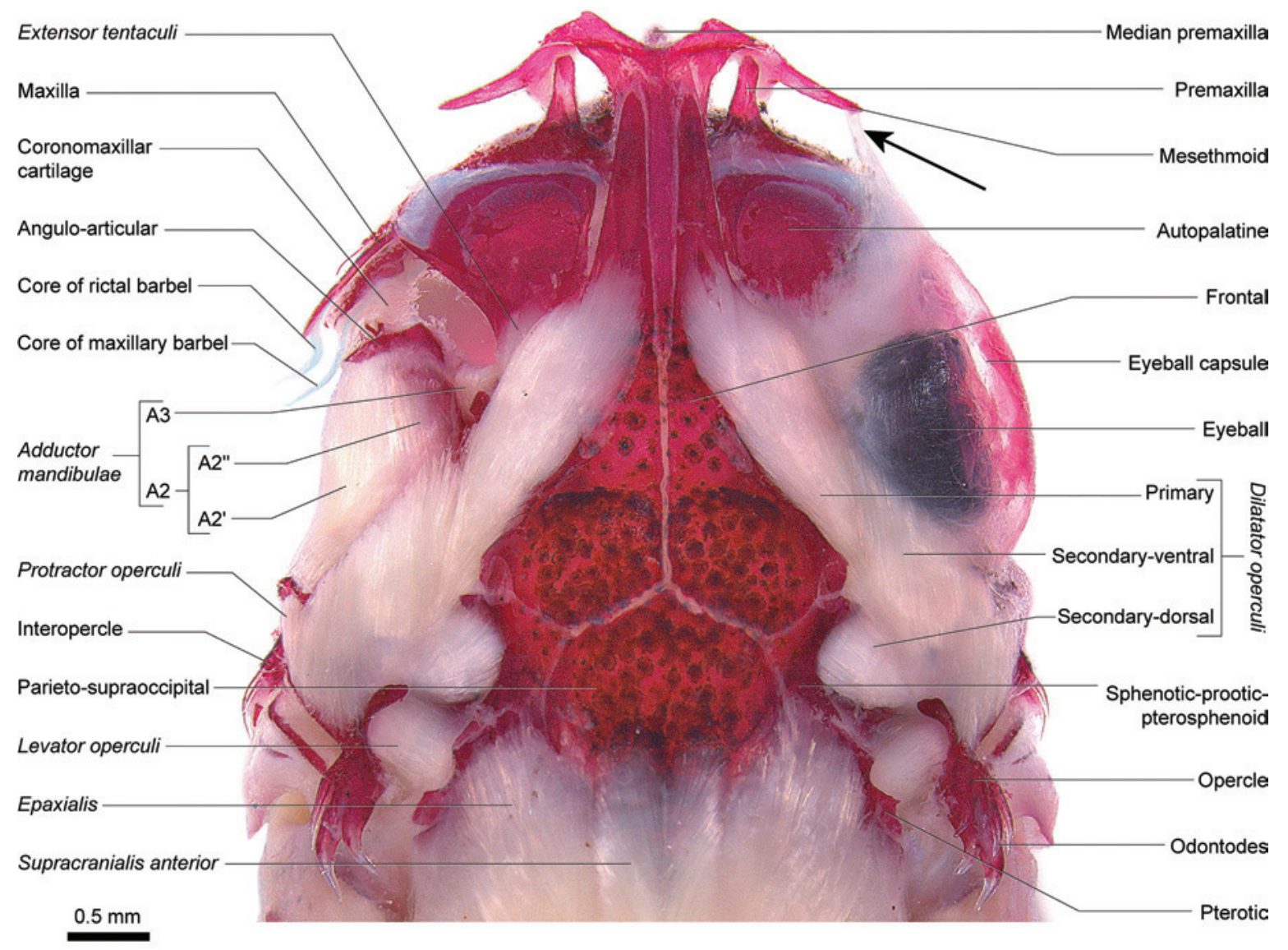

Fig. 23. Dorsal view of head of Haemomaster venezuelae (Stegophilinae), LIRP 7438 (36.9 mm SL). Left eye removed. Arrow indicates anterior projection of eyeball capsule anchoring to tip of mesethmoid cornu.

prootic-pterosphenoid. Insertion is onto the dorsomedial region of the dorsal process of the opercle. The secondaryventral section is deep and flat, attaching anteriorly to the eyeball capsule (a translucent membranous tissue that enwraps the eyeball; Fig. 23). Posteriorly, that section covers the dorsal part of the protractor operculi, being somewhat continuous with that muscle in this area. The insertion is onto the central region of the opercle just ventral to its dorsal process.

In Homodiaetus, Ochmacanthus, Parastegophilus, and Pseudostegophilus, the secondary-ventral section is much smaller than in Haemomaster, fusing anterodorsally with the primary section (Fig. 26) and, sometimes, also tenuously attaching to the eyeball capsule. In Pareiodon the secondaryventral section is continuous with the secondary-dorsal one, forming a single secondary section as in the basal most trichomycterids (Fig. 27). The insertion of the secondary-ventral section in all these cases is onto the ventral region of the dorsal process of the opercle. The primary section in these taxa is distinctly anteromedially expanded, contacting its counterpart along the mid-sagittal plane and attaching to the frontal and mesethmoid or lateral ethmoid (Fig. 27). As in Haemomaster, fibers of the primary section pass dorsolateral to the levator arcus palatini and merge into a tendon that inserts on the tip of the dorsal process of opercle. In Homodiaetus and
Ochmacanthus the secondary-dorsal section has basically the same configuration than that of Haemomaster (Fig. 26). In Parastegophilus and, more significantly in Pseudostegophilus and Pareiodon, this section is distinctly anteromedially expanded towards the mid-sagittal plane, attaching to the sphenotic-prootic-pterosphenoid, frontal, and sometimes the hyomandibula (Fig. 27).

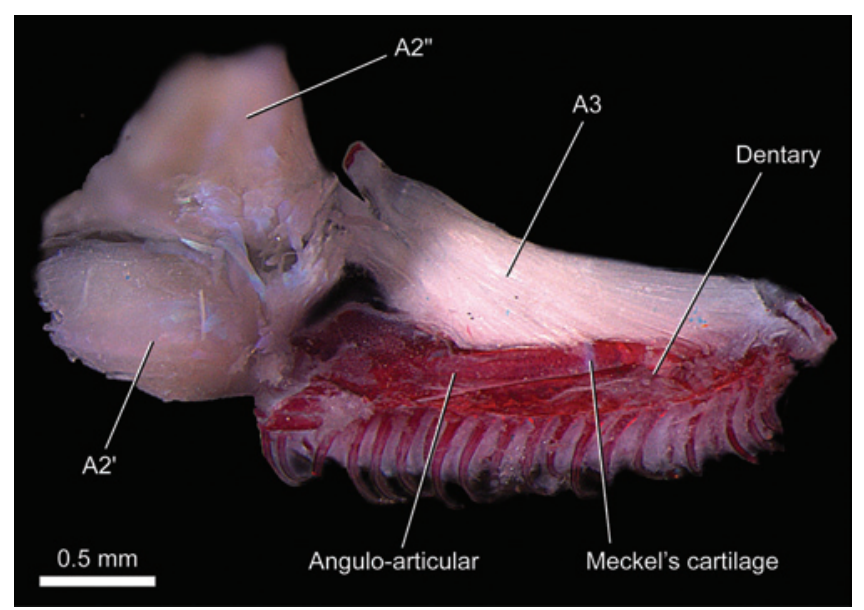

Fig. 24. Posterior view of left adductor mandibulae and attached lower jaw of Haemomaster venezuelae (Stegophilinae), LIRP 7438 (36.9 mm SL). 
The levator operculi (Figs. 22, 23, 27) and adductor operculi are basically as in the Trichomycterinae, Sarcoglanidinae, and Glanapteryginae.

\section{Vandelliinae}

Adductor mandibulae posterodorsally elongated with two main sections fully separated from each other: a lateral A2 and a medial A3 (Figs. 28, 29). Paracanthopoma seems to exhibit the less modified adductor mandibulae among all the examined vandelliines. In this genus the A2 lacks any obvious subdivision, but the fibers of its dorsal portion are posteriorly expanded and attach to an anterior marginal tendon of the muscle which runs parallel to the eyeball (see the descriptions for Vandellia below). These dorsal fibers originate from the hyomandibula and sphenotic. The portion of the A2 located ventral to the referred tendon originates from the anterior region of the suspensorium on the hyomandibula, preopercle, and quadrate. The A2 inserts onto the posterodorsal region of the lower jaw on both dentary and angulo-articular. As in tridentines and stegophilines, the A3 of Paracanthopoma is much anteriorly displaced and completely separated from the A2. It also retains the same insertion than the A3 of stegophilines, i.e., a broad attachment on the medial region of the lower jaw that involves both dentary and anguloarticular. However, uniquely among trichomycterids, the A3 of Paracanthopoma (and all the other examined vandelliines; see below) originates on the lateral part of the ventral face of the autopalatine and has its fibers more vertically oriented.

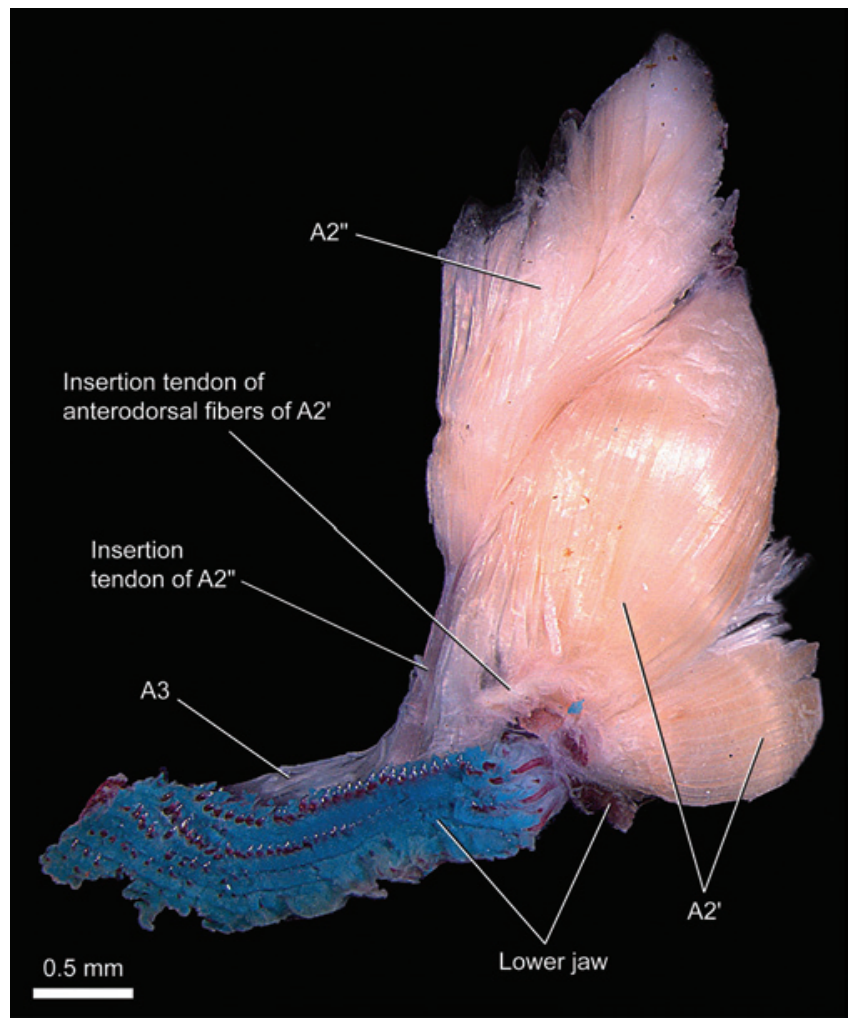

Fig. 25. Dorsolateral view of left adductor mandibulae and attached lower jaw of Parastegophilus paulensis (Stegophilinae), LISDEBE 1312 (46.5 mm SL).
In Vandellia and, in a lesser degree, in Paravandellia, the dorsal portion of the A2 (A2") which inserts onto the marginal tendon of the muscle is effectively separated from the ventral portion (A2') (Figs. 28, 29). The origin of the A2" is comparable to that in Paracanthopoma. The A2' in Paravandellia and Vandellia is further divided into distinct dorsal and ventral portions. Fibers of the A2'-dorsal have a common origin from the anterior region of the suspensorium on the preopercle, quadrate, and hyomandibula, but diverge anteriorly towards the insertion. All the medial fibers of the A2'-dorsal in Paravandellia, but only the dorsomedial fibers of this section in Vandellia, attach to a strong tendon that inserts onto the posterolateral region of the premaxilla (Fig. 29). The remaining fibers of the A2'-dorsal in Paravandellia and Vandellia insert onto the posterodorsal regions of the lower jaw. The A2'-ventral is undivided in Paravandellia, originating from the anterior regions of the preopercle and interopercle and inserting onto the lateral surface of the coronoid process. In Vandellia, the A2'-ventral occupies the same position as in Paravandellia, but it is clearly subdivided into superior and inferior parts (Fig. 28). The A2'-ventral-superior originates solely from the preopercle,

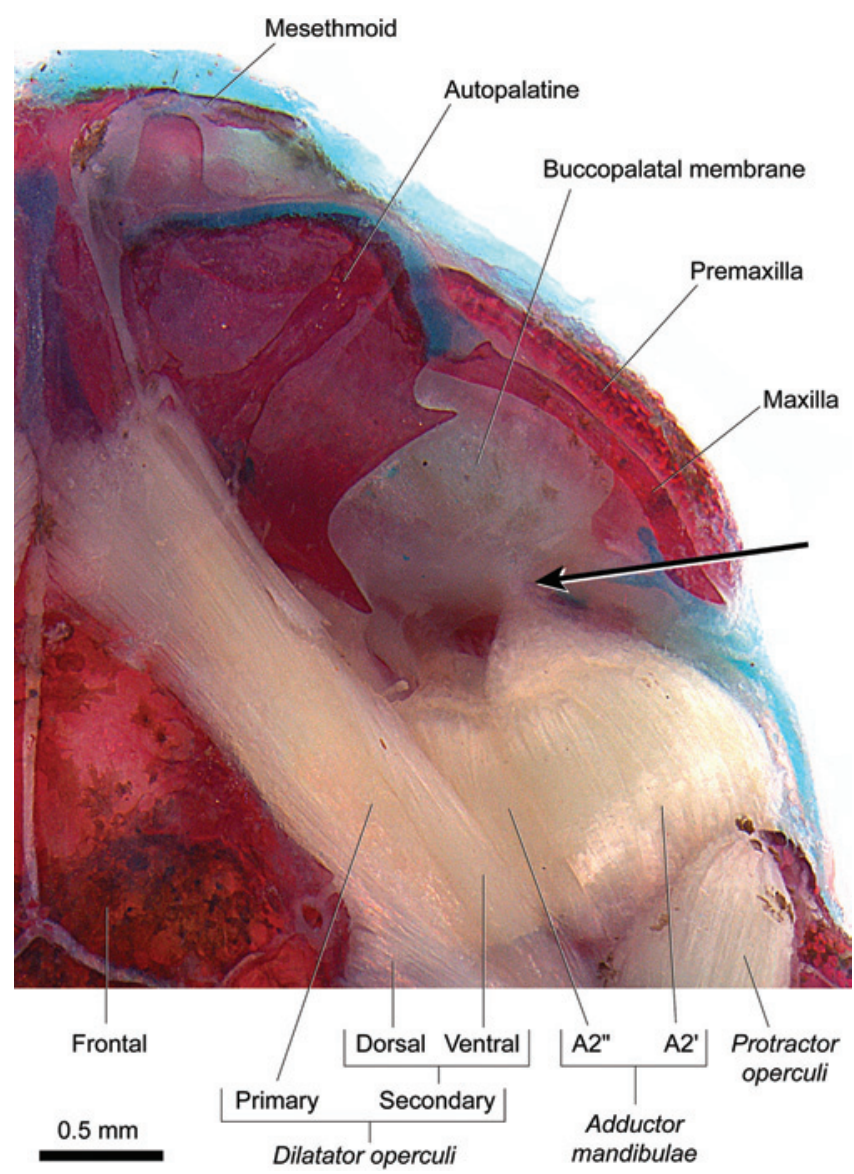

Fig. 26. Dorsal view of right anterior region of head of Ochmacanthus flabelliferus (Stegophilinae), LIRP 7439 (33.0 $\mathrm{mm} \mathrm{SL}$ ). Arrow indicates attachment of A2' section of adductor mandibulae to buccopalatal membrane. 


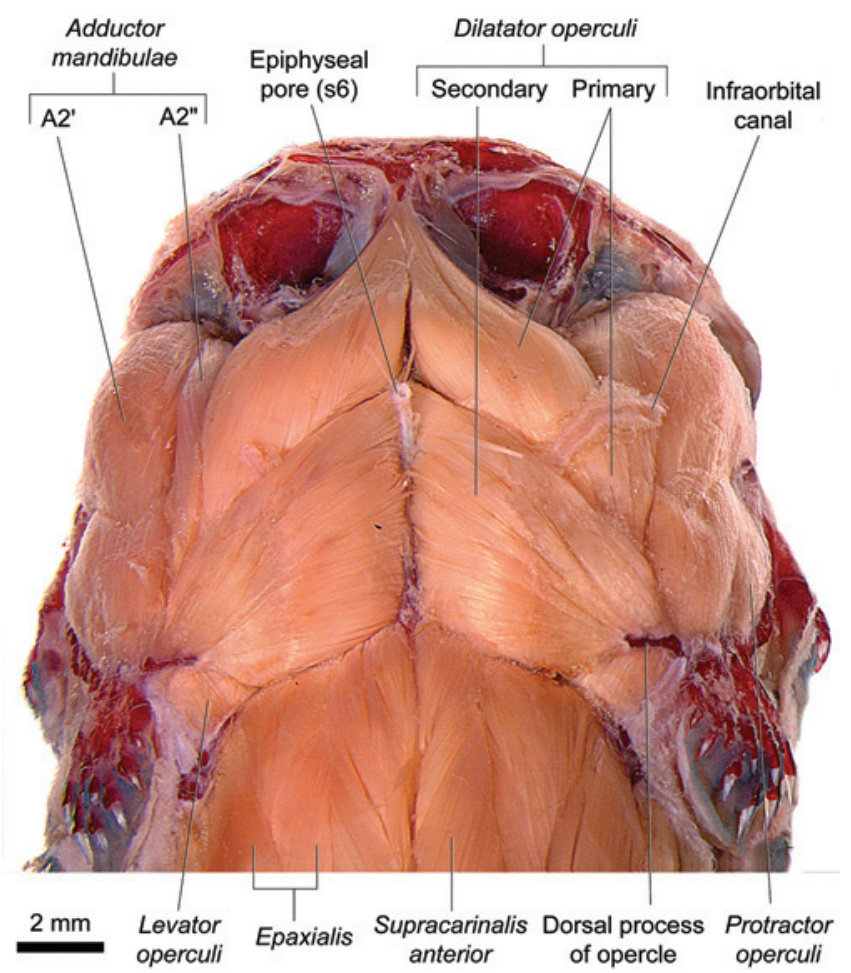

Fig. 27. Dorsal view of head of Pareiodon microps (Stegophilinae), LIRP 7422 (112.9 mm SL).

whereas the A2'-ventral-inferior (= "A1-OST" of $V$. cf. plazai of Adriaens et al., 2010: fig. 6C, p. 356) solely from the interopercle. Insertion of both sections is comparable to that in Paravandellia. The A3 of Paravandellia and Vandellia is mostly as described for Paracanthopoma, except for the fact that, in Vandellia, that section is completely subdivided into anterolateral and posteromedial subsections (Figs. 28, 30). These subdivisions in Vandellia seem not to be homologous to the subdivisions of the A3 into A3' and A3" of other trichomycterids (see Character 6). The A $\omega$ is absent in all vandelliines (Fig. 30).

The levator arcus palatini (Figs. 28, 29) is mostly comparable to that in the Tridentinae. Nevertheless, two groups of fibers with slightly distinct superficial orientations are evident on the lateral surface of this muscle in Vandellia sanguinea (Fig. 29).

Adductor arcus palatini (Fig. 29) fully separated from the extensor tentaculi and constrictor palatini (see below and Character 14). The origin of the adductor arcus palatini is from the lateral regions of the orbitosphenoid, parasphenoid, and sphenotic-prootic-pterosphenoid. Insertion is onto the dorsomedial region of hyomandibula, quadrate, and in Vandellia also onto the metapterygoid.

The constrictor palatini (a newly defined muscle) is a short sheet-like muscle situated anterior to the adductor arcus palatini (Figs. 28, 29). It originates from a median raphe ventral to the shaft of mesethmoid and inserts primarily along the medial rim of the autopalatine. Some fibers also continue slightly anteriorly to an attachment on the dorsal face of the autopalatine (Fig. 29).
Anterior to the constrictor palatini is another muscle, herein named the hyporostralis (a newly defined muscle; Figs. 28, 29). Its fibers originate from the median raphe and the fascia of the anterior face of constrictor palatini (all ventral to the mesethmoid shaft). The insertion occurs primarily onto the posterodorsal surface of the median premaxilla, but some of the lateral most fibers may also attach to the mesethmoid cornua and a small dorsal process on the proximal tip of the premaxilla.

The epirostralis (a newly defined muscle) is a superficial muscle positioned dorsal to the hyporostralis (Figs. 28, 29). Both muscles lie anteriorly to the olfactory cavity. The epirostralis originates from the anterolateral region of the shaft of the mesethmoid and inserts onto the anterior region of the dorsal face of the autopalatine.

The extensor tentaculi originates from the ventrolateral portions of the lateral ethmoid and orbitosphenoid (Figs. 28, 29). Its insertion is onto the posterolateral region of the autopalatine. In some Vandellia, this muscle forms two continuous but superficially readily distinguishable sections (dorsal and ventral) (Fig. 29).

The adductor hyomandibulae is absent.

The protractor operculi (Figs. 28, 29) originates from the lateral region of the preopercle. Its insertion is onto the ventrolateral region of the opercle, with fibers also attaching to the base of some of the anteroventral most odontodes (Fig. 28). In Vandellia this muscle is greatly expanded, occupying a large area on the cheek. In addition to the sites of attachment found in other vandelliines, the muscle origin in Vandellia also involves the dorsolateral portion of the interopercle, while the insertion extends dorsally over the opercle to also reaching the anterior part of the dorsal process of that bone.

The dilatator operculi apparently lacks a secondarydorsal section in Paracanthopoma and Paravandellia. In Vandellia that section is present, originating primarily from the dorsal face of sphenotic-prootic-pterosphenoid with small adjacent regions of the frontal and parieto-supraoccipital sometimes also involved (Figs. 28, 29). Insertion is onto the tip of the dorsal process of the opercle. The primary section is elongate, sometimes bipennate, and passes dorsolateral to the levator arcus palatini. Origin is primarily from the anterior region of the frontal with adjacent parts of the mesethmoid and sphenotic-prootic-pterosphenoid sometimes involved. The insertion is tendinous onto the anterodorsal rim of the dorsal process of the opercle. The ventrolateral section is continuous with the primary section. Its origin may be fused to the primary section (Paravandellia and Vandellia) or tenuously attached to the eyeball capsule (Paracanthopoma). Insertion is musculous onto the anterodorsal region of the dorsal process of the opercle.

Levator operculi with an origin from the posterolateral region of pterotic (Figs. 28, 29) and insertion onto the posterodorsal region of the opercle. In Vandellia and Paravandellia this insertion is partially tendinous onto the posterior region of the dorsal process of the opercle.

Adductor operculi basically as in the Trichomycterinae, Sarcoglanidinae, Glanapteryginae, and Stegophilinae. 


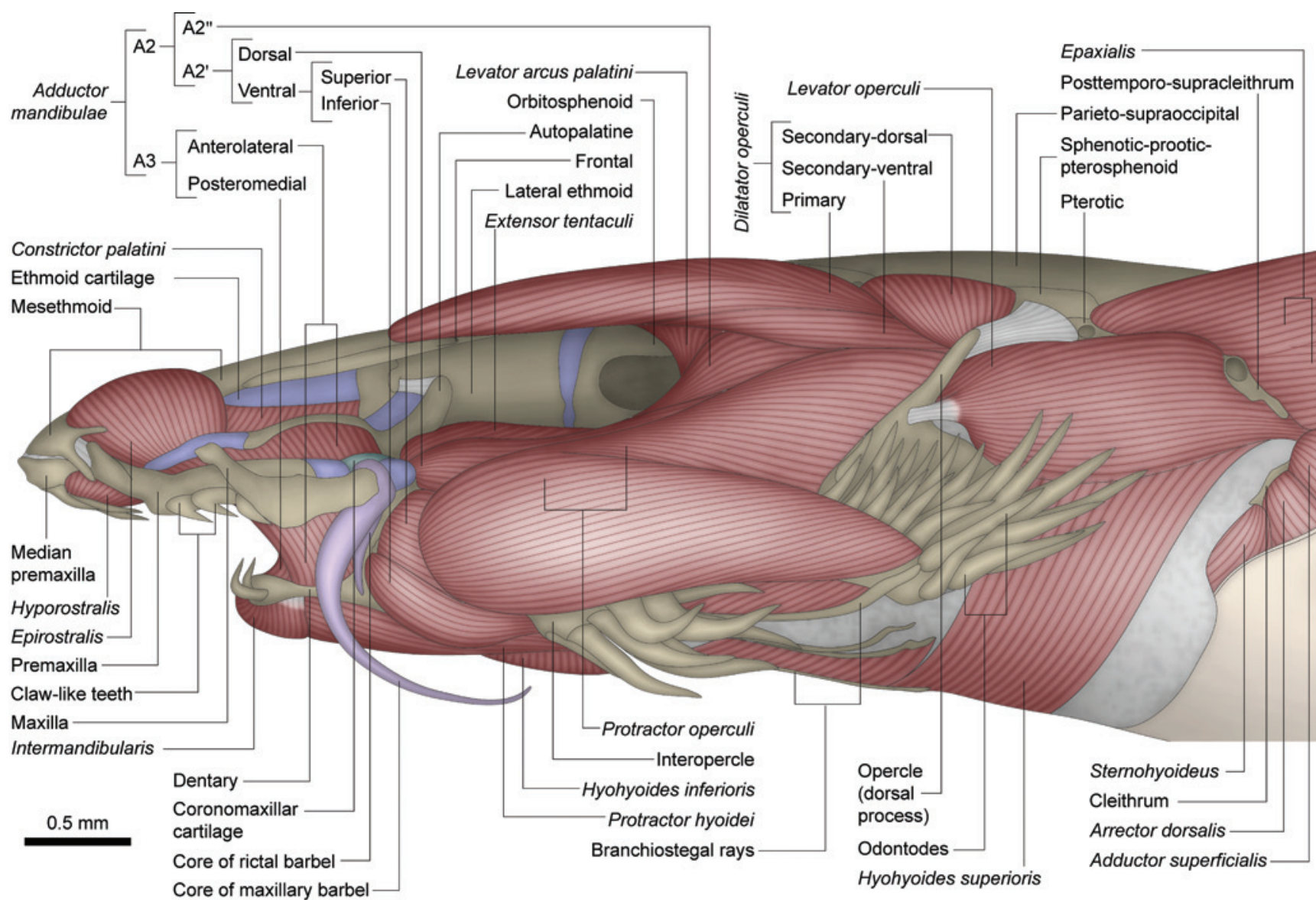

Fig. 28. Left lateral view of head of Vandellia sanguinea (Vandelliinae), LIRP 7414 (77.1 mm SL). Ventral most premaxillary claw-like teeth removed.

\section{Phylogenetic analysis}

A matrix with 35 terminal-taxa and 36 equally weighted characters (Table 2) yielded one single most parsimonious cladogram (Fig. 31) of 46 steps of length, consistency index (CI) 0.913, and retention index (RI) 0.974. A phylogram with diagnostic characters plotted according to the most parsimonious reconstruction is presented on Fig. 32. Numbers of characters below correspond to those from the matrix (Table 2). Letters assigned to the clades correspond to those of Fig. 31.

\section{Character descriptions and analyses}

1. Insertion of the anterodorsal fibers of the $\mathrm{A} 2$ ' section of the adductor mandibulae: (0) onto the lower jaw; (1) onto the buccopalatal membrane [CI: 1.00; RI: 1.00; steps: 1 ].

Plesiomorphically for Siluriformes, all fibers of section A2' of the adductor mandibulae insert onto the lower jaw (Alexander, 1965; Gosline, 1989; Diogo \& Chardon, 2000), as seen in Nematogenys (Fig. 1) and most trichomycterids (Figs. 7, 9, 10, 18, 20, 22). In the derived condition found in the stegophilines Ochmacanthus, Parastegophilus, Pseudostegophilus, and Pareiodon, the anterodorsal most fibers of this section tenuously attach to the buccopalatal membrane (Fig. 26). State 1 is interpreted as a synapomorphy for the clade formed by the above referred stegophilines (Clade O).
2. Insertion of the medial part of the A2' section of the adductor mandibulae: (0) onto the lower jaw; (1) onto the premaxilla [CI: 1.00; RI: 1.00 ; steps: 1 ].

In the primitive condition for Siluriformes, as observed in Nematogenyidae (Fig. 1) and most members of the Trichomycteridae (Figs. 7, 9, 10, 18, 20, 22), the entire A2' section of the adductor mandibulae inserts solely on the lower jaw (see Character 1). In the vandelliines Paravandellia and Vandellia, the medial most fibers of the A2' converge onto a tendon that attaches to the premaxilla (Fig. 29), a condition hypothesized as synapomorphic for the clade consisting of these taxa (Clade S). The direct attachment of part of the adductor mandibulae to the premaxilla probably results in a greater mobility for this bone and its associated claw-like teeth.

A similar condition to that of the vandelliines Paravandellia and Vandellia also occurs in the loricarioid clade Scoloplacidae + Astroblepidae + Loricariidae, which also possesses a division of adductor mandibulae, the retractor premaxillae muscle, inserting onto the premaxilla (Howes, 1983b; Schaefer \& Lauder, 1986; Schaefer, 1990; Schaefer \& Provenzano, 2008; Geerinckx et al., 2009). This muscle, however, is probably derived from A3" or A2"+A3" (as demonstrated by Geerinckx et al., 2009) whereas in the Vandelliinae it is derived from part of the A2'. 


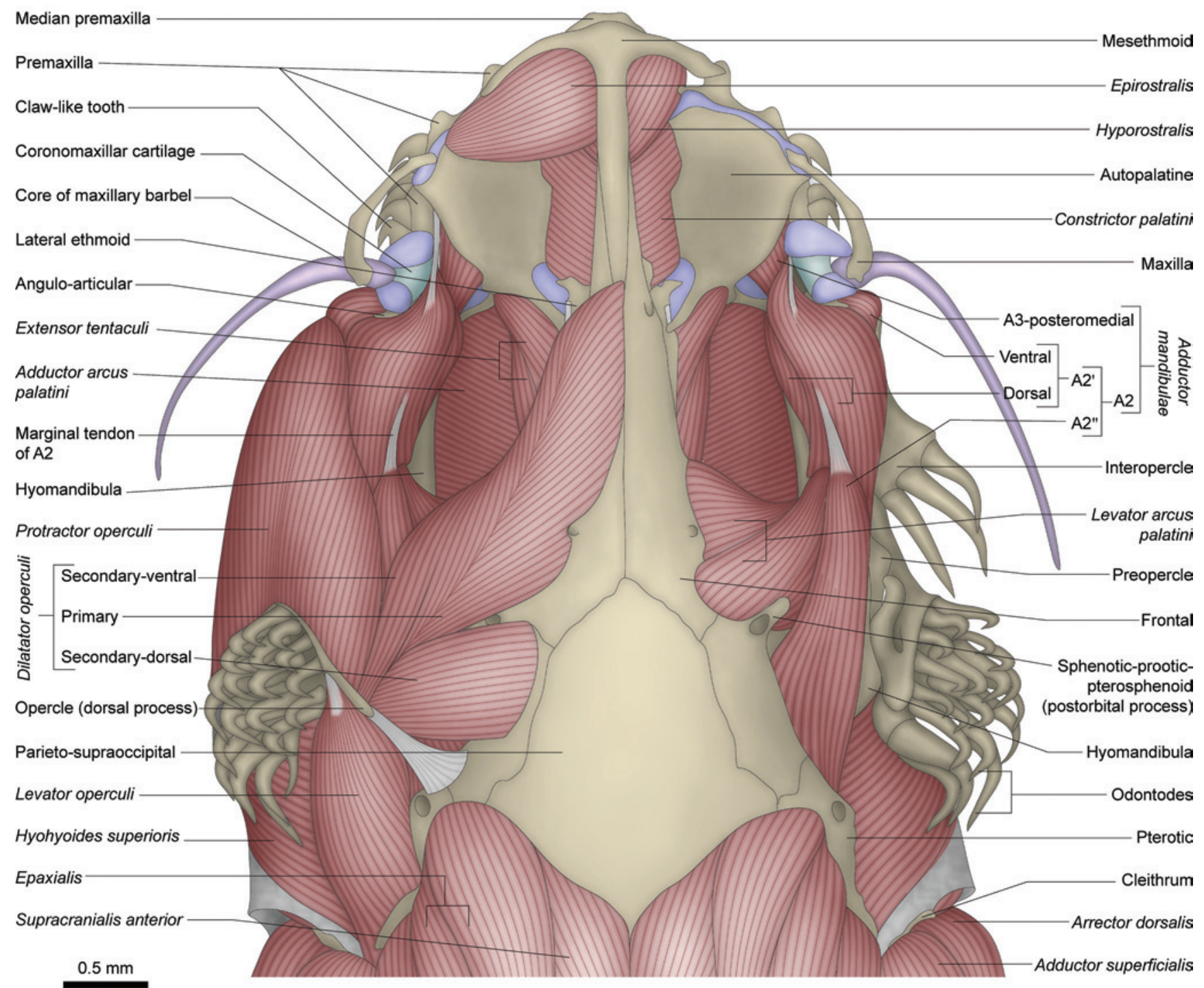

Fig. 29. Dorsal view of head of Vandellia sanguinea (Vandelliinae), LIRP 7414 (77.1 mm SL). Right adductor operculi, dilatator operculi, levator operculi, and protractor operculi removed.

3. Origin of the ventral portion of the A2' section of the adductor mandibulae: (0) from the suspensorium only; (1) from the suspensorium and interopercle [CI: 1.00; RI: 1.00; steps: 1$]$.

In nematogenyids (Fig. 1) and most trichomycterids (Figs. $7,9,10,18,20,22)$, the A2' section of the adductor mandibulae originates solely from the suspensorium, usually on the preopercle, hyomandibula, and quadrate. In the vandelliines Paravandellia and Vandellia, the ventral portion of this section is posteriorly expanded, also reaching the interopercle (Fig. 28). This state is proposed as a synapomorphy for the clade consisting of Paravandellia and Vandellia (Clade S).

4. Ventral portion of the A2' section of the adductor mandibulae: (0) undivided; (1) subdivided into superior and inferior portions [CI: 1.00; RI: 1.00; steps: 1 ].

The A2' section of the adductor mandibulae forms a single undivided muscle mass in nematogenyids (Fig. 1) and most trichomycterids (Figs. 7, 9, 18, 20, 22). In Vandellia this section has several subdivisions, with its ventral portion distinctly subdivided into superior and inferior parts (Fig. 28). This condition is hypothesized to be a synapomorphy for the genus Vandellia (Clade T). Some trichomycterines also exhibits a variable degree of differentiation of their A2' in subunits (e.g. Trichomycterus cf. iheringi, pers. obs., Figs. 10, 11; T. guianensis, Adriaens et al., 2010). Such a differentiation, however, is restricted to some portion of the A2' and is never as complete and obvious as in Vandellia. Coding the degree of differentiation of these subsections of the A2' in trichomycterines, is problematic, since the different species exhibit a continuous graduation between a more obvious partial separation (as seen in Trichomycterus cf. iheringi; Figs. 10,11) and the lack of such separation. In the absence of any precise and non-subjective method to quantify the degree of partial differentiation of these subsections of the A2' in trichomycterines, we prefer to not code it into distinct 
Table 2. Character matrix for the phylogenetic analysis of the Trichomycteridae based on the dorsolateral head muscles. Multistate ordered characters in bolt type; hyphen (-) indicates inapplicable state; outgroup taxon marked with an asterisk (*).

\begin{tabular}{|c|c|c|c|c|c|c|c|c|c|c|c|c|c|c|c|c|c|c|c|c|c|c|c|c|c|c|c|c|c|c|c|c|c|c|c|c|}
\hline Tаха & \multicolumn{36}{|c|}{ Characters } \\
\hline & 1 & 2 & & & & 6 & 7 & 8 & & 10 & 11 & 12 & 13 & 14 & & 16 & 17 & 18 & & & & 22 & & 24 & & & 27 & 28 & 29 & & 31 & 323 & & & & 36 \\
\hline Bullockia maldonadoi & 0 & 0 & 0 & 0 & 0 & 0 & 0 & $\mathbf{0}$ & 0 & $\mathbf{0}$ & 0 & 0 & 0 & 0 & 0 & 0 & 0 & 0 & 1 & 0 & 0 & 0 & 0 & 0 & $\mathbf{0}$ & 0 & 0 & 0 & 1 & 0 & $\mathbf{0}$ & 1 & 1 & 1 & 1 & 0 \\
\hline Copionodon pecten & 0 & 0 & 0 & 0 & 0 & 0 & 1 & $\mathbf{0}$ & 0 & $\mathbf{0}$ & 0 & 0 & 0 & 0 & 0 & 0 & 1 & 0 & U & - & - & - & - & - & $\mathbf{0}$ & 0 & 0 & 0 & 1 & 0 & $\mathbf{0}$ & 1 & 0 & 0 & 0 & 0 \\
\hline Haemomaster venezuelae & 0 & 0 & 0 & 0 & 1 & 0 & 0 & 1 & 1 & 1 & 1 & 0 & 0 & 0 & 0 & 0 & 0 & 1 & 1 & 0 & 0 & 1 & 0 & 0 & $\mathbf{0}$ & 1 & 1 & 0 & 1 & 0 & $\mathbf{0}$ & 1 & 0 & 1 & 0 & 0 \\
\hline Hatcheria macraei & 0 & 0 & 0 & 0 & 0 & 0 & 0 & $\mathbf{0}$ & 0 & $\mathbf{0}$ & 0 & 0 & 0 & 0 & 0 & 0 & 0 & 0 & 1 & 0 & 0 & 0 & 0 & 0 & $\mathbf{0}$ & 0 & 0 & 0 & 1 & 0 & $\mathbf{0}$ & 1 & 1 & 1 & 1 & 0 \\
\hline Homodiaetus anisitsi & 0 & 0 & 0 & 0 & 1 & 0 & 0 & 1 & 1 & 1 & 1 & 0 & 0 & 0 & 0 & 0 & 0 & 1 & 1 & 0 & 0 & 1 & 0 & 0 & $\mathbf{0}$ & 1 & 1 & 1 & 1 & 0 & $\mathbf{0}$ & 1 & 0 & 1 & 0 & 0 \\
\hline Ituglanis cf. gracilior & 0 & 0 & 0 & 0 & 0 & 0 & 0 & $\mathbf{0}$ & 0 & $\mathbf{0}$ & 0 & 0 & 0 & 0 & 0 & 0 & 0 & 0 & 1 & 0 & 0 & 0 & 0 & 0 & $\mathbf{0}$ & 0 & 0 & 0 & 1 & 0 & $\mathbf{0}$ & 1 & 0 & 1 & 1 & 0 \\
\hline Ituglanis proops & 0 & 0 & 0 & 0 & 0 & 0 & 0 & $\mathbf{0}$ & 0 & $\mathbf{0}$ & 0 & 0 & 0 & 0 & 0 & 0 & 0 & 0 & 1 & 0 & 0 & 0 & 0 & 0 & $\mathbf{0}$ & 0 & 0 & 0 & 1 & 0 & $\mathbf{0}$ & 1 & 0 & 1 & 1 & 0 \\
\hline Listrura camposi & 0 & 0 & 0 & 0 & 0 & 0 & 2 & $\mathbf{0}$ & 0 & $\mathbf{0}$ & 0 & 0 & 0 & 0 & 0 & 0 & 0 & 0 & 1 & 0 & 0 & 0 & 0 & 0 & $\mathbf{0}$ & 1 & 0 & 0 & 1 & 0 & $\mathbf{0}$ & 1 & 0 & 1 & 0 & 0 \\
\hline Listrura tetraradiata & 0 & 0 & 0 & 0 & 0 & 0 & 2 & $\mathbf{0}$ & 0 & $\mathbf{0}$ & 0 & 0 & 0 & 0 & 0 & 0 & 0 & 0 & 1 & 0 & 0 & 0 & 0 & 0 & $\mathbf{0}$ & 1 & 0 & 0 & 1 & 0 & $\mathbf{0}$ & 1 & 0 & 1 & 0 & 0 \\
\hline Microcambeva ribeirae & 0 & 0 & 0 & 0 & 0 & 0 & 2 & $\mathbf{0}$ & 0 & $\mathbf{0}$ & 0 & 0 & 0 & 0 & 0 & 0 & 0 & 0 & 1 & 1 & 0 & 0 & 1 & 0 & 1 & 1 & 0 & 0 & 1 & 1 & $\mathbf{0}$ & 1 & 0 & 1 & 0 & 0 \\
\hline *Nematogenys inermis & 0 & 0 & 0 & 0 & 0 & 0 & 0 & $\mathbf{0}$ & 0 & $\mathbf{0}$ & 0 & 0 & 0 & 0 & 0 & 0 & 0 & 0 & U & - & - & - & - & - & $\mathbf{0}$ & 0 & 0 & 0 & 0 & - & - & 0 & - & 0 & 0 & 0 \\
\hline Ochmacanthus flabelliferus & 1 & 0 & 0 & 0 & 1 & 0 & 0 & 1 & 1 & 2 & 1 & 0 & 0 & 0 & 0 & 0 & 0 & 1 & 1 & 0 & 0 & 1 & 0 & 0 & $\mathbf{0}$ & 1 & 1 & 1 & 1 & 0 & $\mathbf{0}$ & 1 & 0 & 1 & 0 & 0 \\
\hline Paracanthopoma parva & 0 & 0 & 0 & 0 & 1 & 0 & 0 & 2 & 0 & $\mathbf{0}$ & 1 & 0 & 0 & 1 & 1 & 1 & 0 & 1 & 1 & 0 & 1 & 0 & 0 & 0 & $\mathbf{0}$ & 1 & 1 & 0 & 0 & - & - & 1 & 0 & 1 & 0 & 0 \\
\hline Parastegophilus paulensis & 1 & 0 & 0 & 0 & 1 & 0 & 0 & 1 & 1 & 2 & 1 & 0 & 0 & 0 & 0 & 0 & 0 & 1 & 1 & 0 & 0 & 1 & 0 & 0 & $\mathbf{0}$ & 1 & 1 & 1 & 1 & 0 & 1 & 1 & 0 & 1 & 0 & 0 \\
\hline Paravandellia oxyptera & 0 & 1 & 1 & 0 & 1 & 0 & 0 & 2 & 0 & $\mathbf{0}$ & 1 & 0 & 0 & 1 & 1 & 1 & 0 & 1 & 1 & 0 & 1 & 0 & 0 & 0 & $\mathbf{0}$ & 1 & 1 & 0 & 0 & - & - & 1 & 0 & 1 & 0 & 0 \\
\hline Pareiodon microps & 1 & 0 & 0 & 0 & 1 & 0 & 0 & 1 & 1 & 2 & 1 & 0 & 0 & 0 & 0 & 0 & 0 & 1 & 1 & 0 & 0 & 1 & 0 & 0 & $\mathbf{0}$ & 1 & 1 & 1 & 1 & 0 & 2 & 1 & 0 & 1 & 0 & 1 \\
\hline Pseudostegophilus nemurus & 1 & 0 & 0 & 0 & 1 & 0 & 0 & 1 & 1 & 2 & 1 & 0 & 0 & 0 & 0 & 0 & 0 & 1 & 1 & 0 & 0 & 1 & 0 & 0 & $\mathbf{0}$ & 1 & 1 & 1 & 1 & 0 & 2 & 1 & 0 & 1 & 0 & 1 \\
\hline Sarcoglanis simplex & 0 & 0 & 0 & 0 & 0 & 0 & 2 & $\mathbf{0}$ & 0 & $\mathbf{0}$ & 0 & 0 & 0 & 0 & 0 & 0 & 0 & 0 & & 0 & 0 & 0 & 1 & 0 & 2 & - & - & 0 & 1 & 1 & $\mathbf{0}$ & 1 & 0 & 1 & 0 & 0 \\
\hline Scleronema angustirostris & 0 & 0 & 0 & 0 & 0 & 0 & 0 & $\mathbf{0}$ & 0 & $\mathbf{0}$ & 0 & 0 & 0 & 0 & 0 & 0 & 0 & 0 & 1 & 0 & 0 & 0 & 0 & 0 & $\mathbf{0}$ & 0 & 0 & 0 & 1 & 0 & $\mathbf{0}$ & 1 & 0 & 1 & 1 & 0 \\
\hline Stauroglanis gouldingi & 0 & 0 & 0 & 0 & 0 & 0 & 2 & $\mathbf{0}$ & 0 & $\mathbf{0}$ & 0 & 0 & 0 & 0 & 0 & 0 & 0 & 0 & 1 & 0 & 0 & 0 & 1 & 0 & 2 & - & - & 0 & 1 & 1 & $\mathbf{0}$ & 1 & 0 & 1 & 0 & 0 \\
\hline Trichogenes longipinnis & 0 & 0 & 0 & 0 & 0 & 0 & 0 & $\mathbf{0}$ & 0 & $\mathbf{0}$ & 0 & 0 & 1 & 0 & 0 & 0 & 1 & 0 & 0 & - & - & - & - & - & $\mathbf{0}$ & 0 & 0 & 0 & 1 & 0 & $\mathbf{0}$ & 1 & 0 & 0 & 0 & 0 \\
\hline Trichomycterus areolatus & 0 & 0 & 0 & 0 & 0 & 0 & 0 & $\mathbf{0}$ & 0 & $\mathbf{0}$ & 0 & 0 & 0 & 0 & 0 & 0 & 0 & 0 & 1 & 0 & 0 & 0 & 0 & 0 & $\mathbf{0}$ & 0 & 0 & 0 & 1 & 0 & $\mathbf{0}$ & 1 & 1 & 1 & 1 & 0 \\
\hline Trichomycterus brasiliensis & 0 & 0 & 0 & 0 & 0 & 0 & 0 & $\mathbf{0}$ & 0 & $\mathbf{0}$ & 0 & 0 & 0 & 0 & 0 & 0 & 0 & 0 & 1 & 0 & 0 & 0 & 0 & 0 & $\mathbf{0}$ & 0 & 0 & 0 & 1 & 0 & $\mathbf{0}$ & 1 & 0 & 1 & 1 & 0 \\
\hline Trichomycterus candidus & 0 & 0 & 0 & 0 & 0 & 0 & 0 & $\mathbf{0}$ & 0 & $\mathbf{0}$ & 0 & 0 & 0 & 0 & 0 & 0 & 0 & 0 & & 0 & 0 & 0 & 0 & 0 & $\mathbf{0}$ & 0 & 0 & 0 & 1 & 0 & $\mathbf{0}$ & 1 & 0 & 1 & 1 & 0 \\
\hline Trichomycterus cf. iheringi & 0 & 0 & 0 & 0 & 0 & 0 & 0 & $\mathbf{0}$ & 0 & $\mathbf{0}$ & 0 & 0 & 0 & 0 & 0 & 0 & 0 & 0 & 1 & 0 & 0 & 0 & 0 & 0 & $\mathbf{0}$ & 0 & 0 & 0 & 1 & 0 & $\mathbf{0}$ & 1 & 0 & 1 & 1 & 0 \\
\hline Trichomycterus chiltoni & 0 & 0 & 0 & 0 & 0 & 0 & 0 & $\mathbf{0}$ & 0 & $\mathbf{0}$ & 0 & 0 & 0 & 0 & 0 & 0 & 0 & 0 & 1 & 0 & 0 & 0 & 0 & 0 & $\mathbf{0}$ & 0 & 0 & 0 & 1 & 0 & $\mathbf{0}$ & 1 & 1 & 1 & 1 & 0 \\
\hline Trichomycterus corduvensis & 0 & 0 & 0 & 0 & 0 & 0 & 0 & $\mathbf{0}$ & 0 & $\mathbf{0}$ & 0 & 0 & 0 & 0 & 0 & 0 & 0 & 0 & 工 & 0 & 0 & 0 & 0 & 0 & $\mathbf{0}$ & 0 & 0 & 0 & 1 & 0 & $\mathbf{0}$ & 1 & 0 & 1 & 1 & 0 \\
\hline Trichomycterus davisi & 0 & 0 & 0 & 0 & 0 & 0 & 0 & $\mathbf{0}$ & 0 & $\mathbf{0}$ & 0 & 1 & 0 & 0 & 0 & 0 & 0 & 0 & 1 & 0 & 0 & 0 & 0 & 0 & $\mathbf{0}$ & 0 & 0 & 0 & 1 & 0 & $\mathbf{0}$ & 1 & 0 & 1 & 1 & 0 \\
\hline Trichomycterus immaculatus & 0 & 0 & 0 & 0 & 0 & 0 & 0 & $\mathbf{0}$ & 0 & $\mathbf{0}$ & 0 & 0 & 0 & 0 & 0 & 0 & 0 & 0 & 1 & 0 & 0 & 0 & 0 & 0 & $\mathbf{0}$ & 0 & 0 & 0 & 1 & 0 & $\mathbf{0}$ & 1 & 1 & 1 & 1 & 0 \\
\hline Trichomycterus maracaya & 0 & 0 & 0 & 0 & 0 & 0 & 0 & $\mathbf{0}$ & 0 & $\mathbf{0}$ & 0 & 0 & 0 & 0 & 0 & 0 & 0 & 0 & 1 & 0 & 0 & 0 & 0 & 0 & $\mathbf{0}$ & 0 & 0 & 0 & 1 & 0 & $\mathbf{0}$ & 1 & 0 & 1 & 1 & 0 \\
\hline Trichomycterus stawiarski & 0 & 0 & 0 & 0 & 0 & 0 & 0 & $\mathbf{0}$ & 0 & $\mathbf{0}$ & 0 & 1 & 0 & 0 & 0 & 0 & 0 & 0 & 1 & 0 & 0 & 0 & 0 & 0 & $\mathbf{0}$ & 0 & 0 & 0 & 1 & 0 & $\mathbf{0}$ & 1 & 0 & 1 & 1 & 0 \\
\hline Trichomycterus zonatus & 0 & 0 & 0 & 0 & 0 & 0 & 0 & $\mathbf{0}$ & 0 & $\mathbf{0}$ & 0 & 0 & 0 & 0 & 0 & 0 & 0 & 0 & 1 & 0 & 0 & 0 & 0 & 0 & $\mathbf{0}$ & 0 & 0 & 0 & 1 & 0 & $\mathbf{0}$ & 1 & 1 & 1 & 1 & 0 \\
\hline Tridentopsis pearsoni & 0 & 0 & 0 & 0 & 1 & 0 & 0 & 1 & 1 & 1 & 0 & 0 & 0 & 0 & 0 & 0 & 0 & 1 & 1 & 0 & 0 & 0 & 0 & 2 & $\mathbf{0}$ & 1 & 1 & 0 & 1 & 0 & $\mathbf{0}$ & 1 & 0 & 1 & 0 & 0 \\
\hline Vandellia cirrhosa & 0 & 1 & 1 & 1 & 1 & 1 & 0 & 2 & 0 & $\mathbf{0}$ & 1 & 0 & 0 & 1 & 1 & 1 & 0 & 1 & 1 & 0 & 1 & 0 & 0 & 1 & $\mathbf{0}$ & 1 & 1 & 1 & 1 & 0 & $\mathbf{0}$ & 1 & 0 & 1 & 0 & 0 \\
\hline Vandellia sanguinea & 0 & 1 & 1 & 1 & 1 & 1 & 0 & 2 & 0 & $\mathbf{0}$ & 1 & 0 & 0 & 1 & 1 & 1 & 0 & 1 & & 0 & 1 & 0 & 0 & 1 & $\mathbf{0}$ & 1 & 1 & 1 & 1 & 0 & $\mathbf{0}$ & 1 & 0 & 1 & 0 & 0 \\
\hline
\end{tabular}

character states. Nonetheless, this does not invalidate the condition herein coded for Vandellia that exhibits a quite distinct total division of its A2'.

5. Degree of separation between A2 and A3 sections of the adductor mandibulae: (0) partial; (1) total [CI: 1.00; RI: 1.00; steps: 1].

In the Nematogenyidae (Fig. 2), Copionodontinae (Fig. 5), Trichogeninae (Fig. 8), Trichomycterinae (Figs. 10, 12), Sarcoglanidinae (Figs. 16, 17), and Glanapteryginae (Fig. 19) the A2 and A3 sections of the adductor mandibulae are always, at least, partially continuous with each other, despite being separable, to some extent, along their origins and/or insertions. In the Tridentinae (Fig. 21), Stegophilinae (Figs. 22, 24), and Vandelliinae (Figs. 28, 29), these two sections are completely separated from origin to insertion without any interchange of fibers between them. The complete separation between the A2 and A3 sections is interpreted as a synapomorphy for the clade formed by these three subfamilies (the Vandelliinae-group, Clade K).

6. The A3 section of the adductor mandibulae: (0) undivided along the vertical plane; (1) fully subdivided along the vertical plane [CI: 1.00; RI: 1.00; steps: 1].
The A3 section of the adductor mandibulae in Nematogenys and most trichomycterids is either undivided or, at most, partially subdivided along a horizontal plane, thereby forming a ventral (A3') and a dorsal (A3") subsection

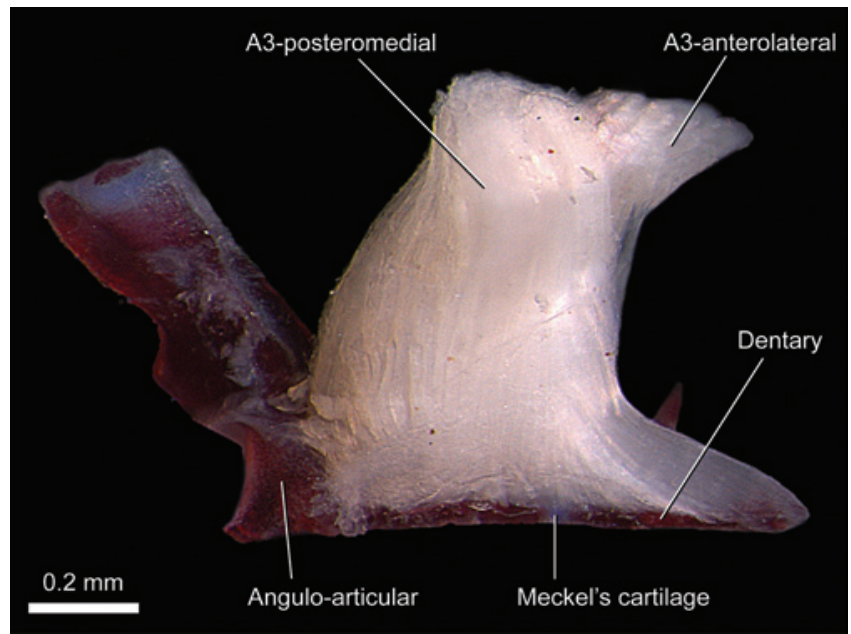

Fig. 30. Posterior view of right A3 section of adductor mandibulae and attached lower jaw of Vandellia cirrhosa (Vandelliinae), LIRP 7401 (36.9 mm SL). Image flipped horizontally to facilitate comparisons. 
(Figs. 2, 4, 5, 8, 12, 17, 19, 21, 24). In Vandellia the A3 is divided along the vertical plane thereby forming an anterolateral and a posteromedial subsection (Fig. 30). These two types of subdivision of the A3 (along the horizontal and the vertical plane) seem to produce non-homologous subsections, even considering the highly modified A3 and lower jaw of the vandelliines. An additional evidence for this non-homology is that in Vandellia both anterolateral and posteromedial sections of A3 insert in parallel across the posteromedial face of the lower jaw on both angulo-articular and dentary (Fig. 30). That configuration was not found elsewhere among trichomycterids and, as such, state 1 is proposed as an autapomorphy for Vandellia (Clade T).

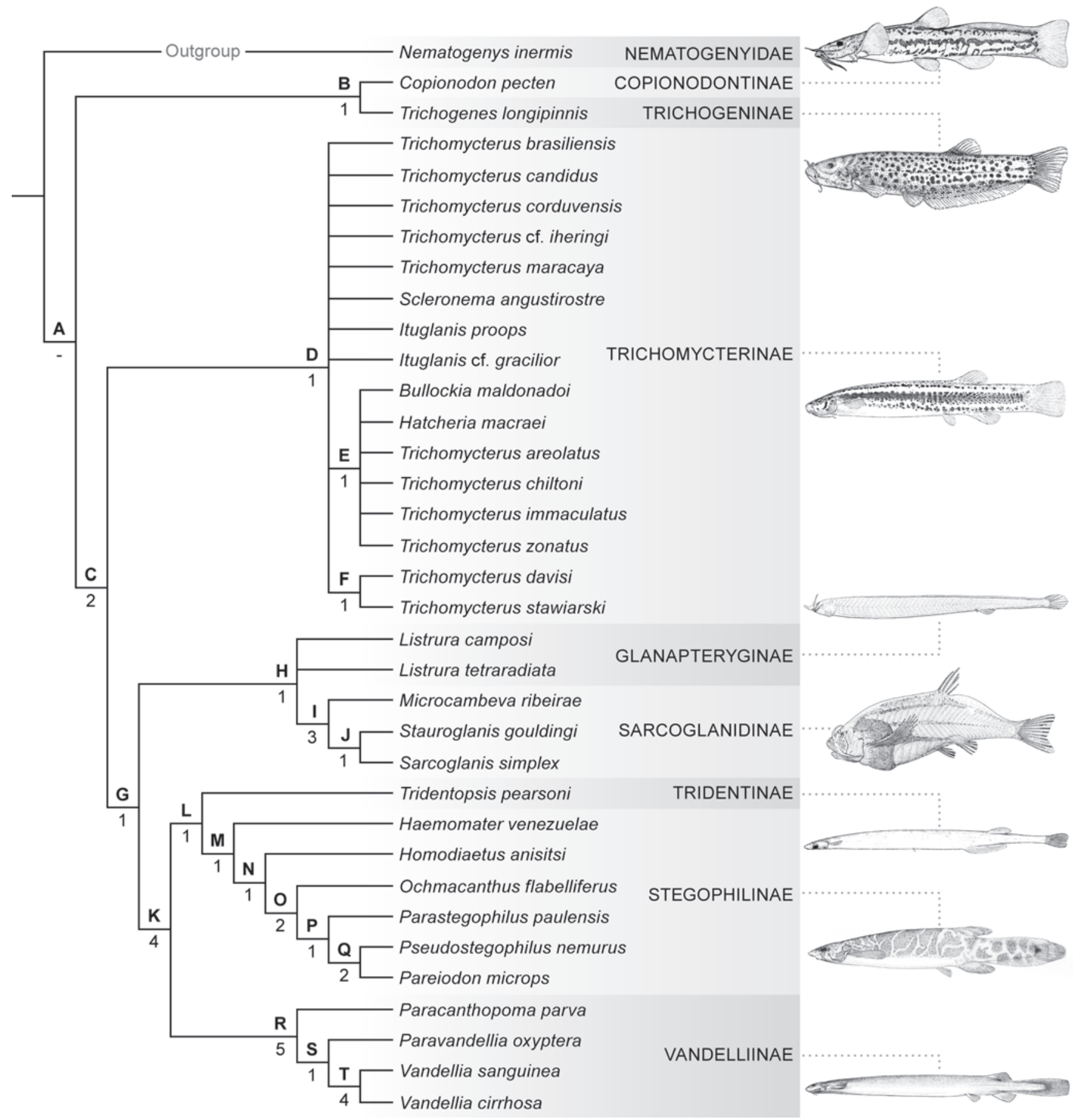

Fig. 31. Most parsimonious cladogram of relationships of Trichomycteridae derived from character matrix in Table 2. Letters above nodes are conform to those used in text; numbers below nodes are their respective Bremer supports. Representative images for each subfamily modified from following (from top to bottom): Copionodon pecten (de Pinna, 1992), Trichogenes longipinnis (Sazima, 2004), Trichomycterus reinhardti (Eigenmann, 1918), Sarcoglanis simplex (Myers \& Weitzman, 1966), Typhlobelus ternetzi (Myers, 1944), Tridens melanops (Eigenmann, 1918), Ochmacanthus alterus (Myers, 1944), and Vandellia sanguinea (Eigenmann, 1918). 
The division of the $\mathrm{A} 3$ section into $\mathrm{A} 3$ ' and $\mathrm{A} 3$ " was not coded because this type of separation, that differs from that described in state 1 for Vandellia, occurs to varying degrees within the Trichomycteridae, making it impossible to establish unequivocal, non-arbitrary, limits between character states.

7. Insertion of the dorsal part of the A3 section of the adductor mandibulae (A3"): (0) solely onto the lower jaw; (1) onto the lower jaw and, mainly, maxilla (retractor tentaculi); (2) onto the buccopalatal membrane [multistate unordered; CI: 1.00; RI: 1.00; steps: 2].

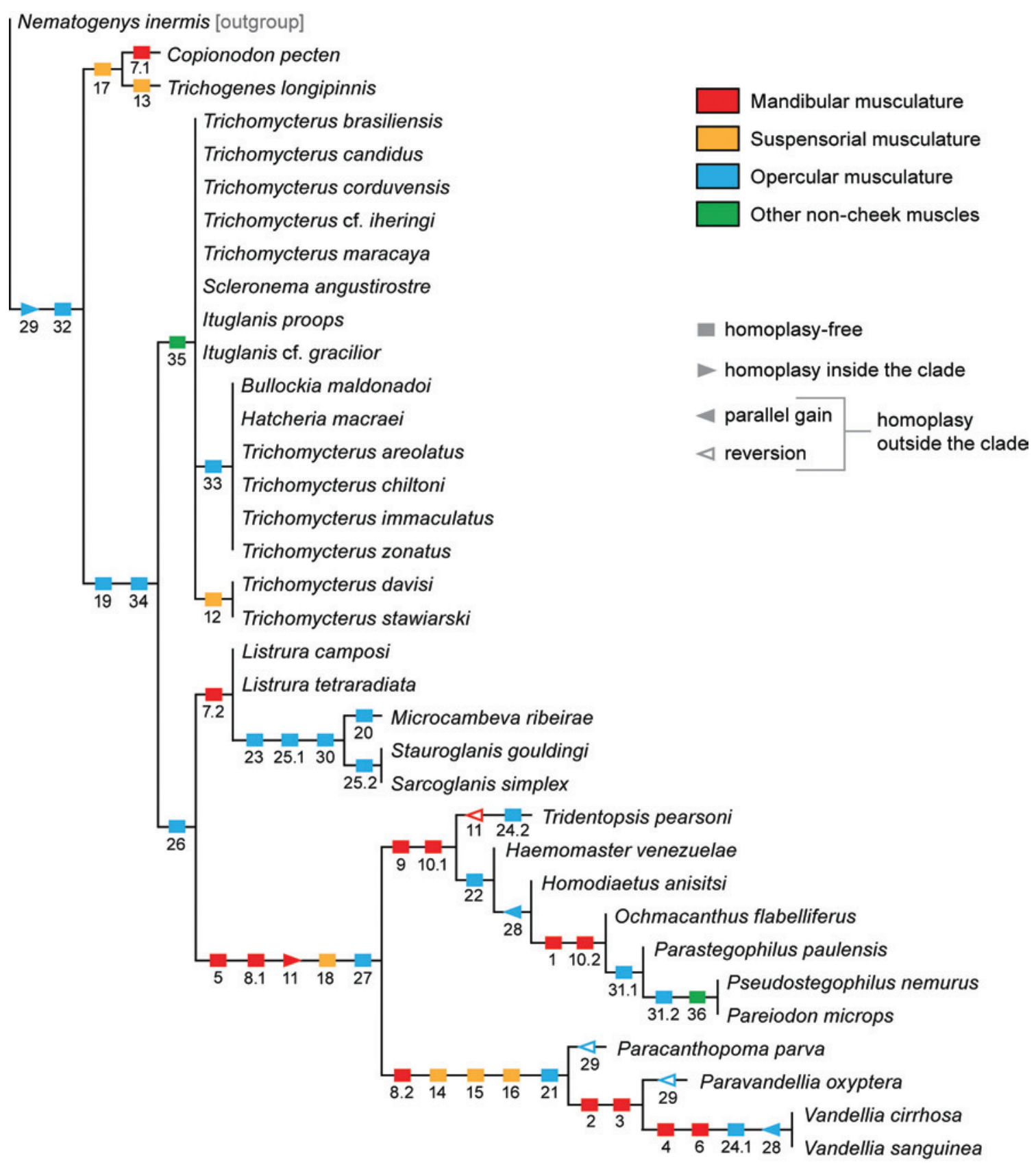

Fig. 32. Most parsimonious phylogram of relationships of Trichomycteridae derived from character matrix in Table 2 with diagnostic characters plotted according to the most parsimonious reconstruction. Characters numbered as in text and Table 2; synapomorphic state indicated after a period (.) for multistate characters.
Regardless of being separated or not from the remaining muscle mass, the dorsal portion of the A3 section of the adductor mandibulae (A3") inserts onto the lower jaw in the Nematogenyidae (Fig. 2) and most members of the Trichomycteridae (Figs. 8, 12, 21, 24, 25, 30). Exclusively in the Copionodontinae, the A3" attaches mainly onto the maxilla, forming a so-called retractor tentaculi muscle (Figs. 3-5), although its deepest fibers still attach to the coronoid process of the lower jaw (state 1). This deeper attachment onto the lower jaw may be considered as a residue of the ancestral condition of the A3" in which this section inserts solely onto the lower jaw. State 1 is hypothesized to be an autapomorphy for the Copionodontinae. 
The insertion of parts of the A3 onto the maxilla, thereby forming the so-called retractor tentaculi, apparently evolved independently in several other catfish lineages (Alexander, 1965; Howes, 1983a; Adriaens \& Verraes, 1996; Diogo \& Chardon, 2000; Geerinckx et al., 2009). As clearly demonstrated by Geerinckx et al. (2009), the "retractor tentaculi" of loricariids (Howes, 1983a; Schaefer \& Lauder, 1986, 1996; Schaefer, 1997; Diogo \& Vandewalle, 2003; Geerinckx et al., 2007) is actually derived from the extensor tentaculi, what lead them to rename it as the levator tentaculi. Within the Loricarioidea a retractor tentaculi derived from the adductor mandibulae complex is also reported in the Callichthyidae (Howes, 1983b; Schaefer \& Lauder, 1986; Huysentruyt et al., 2007; Geerinckx et al., 2009). The retractor tentaculi of this family, however, seems to be a compound muscle derived from both the A2" (the "A2" of Geerinckx et al., 2009) and A3" (Geerinckx et al., 2009) whereas in the Copionodontinae it is derived solely from the A3".

In all sarcoglanidines (Fig. 16) and glanapterygines (Fig. 18) herein examined the A3" inserts onto the buccopalatal membrane (state 2). This condition is interpreted as a synapomorphy for the clade formed by these two subfamilies (Clade H). Attachment of fibers of the adductor mandibulae to the buccopalatal membrane also occurs in some stegophilines (Fig. 26), but, in these fishes, the fibers involved pertain to the A2' (see Character 1) rather than the A3".

8. The origin of the A3 section of the adductor mandibulae: (0) extending to the posterior region of the suspensorium (contacting the levator arcus palatini); (1) limited to the anterior region of the suspensorium, but not reaching the autopalatine; (2) exclusively from the autopalatine [multistate ordered; CI: 1.00; RI: 1.00; steps: 2].

In the plesiomorphic condition for the Nematogenyidae and Trichomycteridae, the A3 section of the adductor mandibulae has its origin extending far posteriorly over the suspensorium near to the origin of the A2 section (Figs. 2, 4, $5,8,12,17,19)$ and with its posterior most fibers lying adjacent to the levator arcus palatini (Fig. 10). In tridentines (Fig. 21), stegophilines (Figs. 22, 23), and vandelliines (Fig. 28) the origin of the A3 is much anteriorly positioned relative to the origin of the A2, being limited to the anterior region of the suspensorium (but never reaching the autopalatine) and lying distant from the levator arcus palatini (Fig. 22). This condition (state 1) is interpreted as a synapomorphy for the clade Tridentinae + Stegophilinae + Vandelliinae (Clade K). In the Vandelliinae the origin of the A3 section of the adductor mandibulae is positioned further anteriorly, occurring exclusively on the ventral face of autopalatine (state 2) (Figs. $28,29)$. This state is interpreted as an autapomorphy for this subfamily (Clade R).

9. Width of the origin of the A3 section of the adductor mandibulae: (0) larger or about as broad as its insertion; (1) distinctly narrower, less than one quarter of its insertion [CI: 1.00; RI: 1.00; steps: 1 ].
The origin of the A3 section of the adductor mandibulae of the Nematogenyidae (Fig. 2) and most trichomycterids (Figs. $5,8,12,17,19,30)$ is as wide as or wider than its insertion. In tridentines (Fig. 21) and stegophilines (Fig. 24) the origin of this section is distinctly narrower than its insertion (less than a $20 \%$ of the width of the insertion) given to this section an overall triangular shape. Such a condition is hypothesized to be a synapomorphy for the clade formed by the Tridentinae and Stegophilinae (Clade L).

Although the origin of the A3 appears a little narrower than its insertion in Vandellia sanguinea from the view of the Fig. 30, they are actually approximately the same width. This apparent contradiction is due to the fact of the A3 section in Vandellia undergoes a rotation across its length, with its greatest width being oriented anteroposteriorly at its origin (see also Fig. 28) and lateromedially at its insertion.

10. Type of origin of the A3 section of the adductor mandibulae: (0) musculous only; (1) musculous and tendinous; (2) fully tendinous [multistate ordered; CI: 1.00; RI: 1.00; steps: 2].

The A3 section of the adductor mandibulae of most trichomycterids (Figs. 5, 8, 12, 17, 19, 30) has an exclusively musculous origin. In the tridentine Tridentopsis and the stegophilines Haemomaster (Fig. 22) and Homodiaetus this origin is primarily tendinous, although some muscular fibers still attach directly onto the bones of the suspensorium (state 1). A more extreme condition is found in all remaining examined stegophilines, in which the A3 possesses a fully tendinous origin (state 2). In an ordered multistate transformation, state 1 is interpreted as a synapomorphy for all stegophilines plus Tridentinae (Clade $\mathrm{M}$ ), whereas state 2 is a synapomorphy for a less inclusive group of Stegophilinae composed of Ochmacanthus, Parastegophilus, Pseudostegophilus, and Pareiodon (Clade O).

11. Sites of insertion of the A3 section of the adductor mandibulae on the lower jaw: (0) not extending anteriorly beyond the Meckel's cartilage; (1) extending anteriorly beyond the Meckel's cartilage [CI: 0.50; RI: 0.89; steps: 2].

In the primitive condition for nematogenyids (Fig. 2) and trichomycterids (Figs. 8, 12, 21), the insertion of the A3 section of the adductor mandibulae is restricted to the posterior region of the lower jaw, never reaching the part anterior to the Meckel's cartilage. In stegophilines (Fig. 22) and vandelliines (Fig. 30) the insertion of the A3 is much expanded anteriorly, extending beyond the Meckel's cartilage and reaching the ventral part of the dentary. In many cases, the insertion of the A3 is further extended anteromedially along the ventral border of that bone until reach the dentary symphysis (Figs. 22, 30). Optimization of this character on the current phylogenetic tree is ambiguous since it is equally parsimonious to suppose that state 1 could be either (A) evolved at the basis of the clade Tridentinae + Stegophilinae + Vandelliinae (the Vandelliinae-group; Clade K) and subsequently reversed in the Tridentinae (ACCTRAN) or (B) independently acquired at the base of the Stegophilinae 
(Clade M) and of the Vandelliinae (Clade R) (DELTRAN). It is generally accepted by morphologists that secondary losses are more likely to happen than parallel gains of complex structures (de Pinna, 1991; Agnarsson \& Miller, 2008). According to such argument, the most parsimonious reconstruction for this character is hypothesis (A) (ACCTRAN). The state 1 is, thus, hypothesized to be a synapomorphy for the Vandelliinae-group (Clade K), having been secondarily reversed in the Tridentinae.

12. Origin of the extensor tentaculi: (0) from neurocranium only; (1) from neurocranium and suspensorium [CI: 1.00; RI: 1.00; steps: 1].

In Nematogenys (Fig. 1) and most trichomycterids (Figs. 3, 7, $9,10,16,18,22,28,29)$, the extensor tentaculi originates exclusively from the ethmoidal region of the neurocranium. In Trichomycterus davisi and $T$. stawiarski this muscle is enlarged with its origin ventrally expanded and involving the suspensorium in addition to the neurocranium. This state is herein proposed as a synapomorphy for the clade consisting of these taxa (Clade F).

13. Insertion of the extensor tentaculi: (0) solely onto the autopalatine; (1) onto both the autopalatine and metapterygoid [CI: 1.00; RI: -; steps: 1].

In all catfishes herein examined except for Trichogenes, the extensor tentaculi inserts solely onto the autopalatine (Figs. 3, 10, 16, 18, 20, 22, 28, 29). In the Trichogeninae this muscle inserts onto both the autopalatine and metapterygoid, a condition considered autapomorphic for this taxon.

14. Constrictor palatini muscle: (0) absent; (1) present [CI: 1.00; RI: 1.00; steps: 1 ].

The muscle herein named the constrictor palatini is located on the anterior portion of the ethmoidal region of the skull (Figs. $28,29)$. As the case with the extensor tentaculi, the constrictor palatini also seems to be derived from the adductor arcus palatini (Fig. 29). The constrictor palatini is a sheet-like muscle connecting the neurocranium solely with the autopalatine. The extensor tentaculi lies posterior to the constrictor palatini and dorsal to the adductor arcus palatini (Fig. 29). Despite being placed closely to each other and probably derived from the same primordial muscle mass, these three muscles are completely separated in all specimens examined. The possession of a constrictor palatini muscle is unique to vandelliines, thereby constituting a synapomorphy for this subfamily (Clade R).

15. Hyporostralis muscle: (0) absent; (1) present [CI: 1.00; RI: 1.00; steps: 1].

Anterior to the constrictor palatini of the vandelliines (Character 14), is another muscle found exclusively in this subfamily, which is herein termed the hyporostralis (Figs. 28, 29). This muscle inserts primarily onto the toothed median premaxilla (Fig. 28). Its position and origin from the fascia of the constrictor palatini suggest a derivation from the adductor arcus palatini (Fig. 29). The presence of the hyporostralis is hypothesized to be a synapomorphy for the Vandelliinae (Clade R).
16. Epirostralis muscle: (0) absent; (1) present [CI: 1.00; RI: 1.00; steps: 1$]$.

This muscle is positioned dorsal to the hyporostralis of vandelliines, almost fully covering it from a dorsal view (Figs. 28,29 ). Contraction of the epirostralis may act as a stabilizer for the autopalatine when contraction of the A3 section of the adductor mandibulae (Figs. 28, 29) lifts the lower jaw. Without the synergic contraction of the epirostralis, the contraction of the A3 could lower the autopalatine instead of raising the lower jaw. The close placement of the epirostralis and the hyporostralis also suggest a common origin of these muscles from the adductor arcus palatini (Figs. 28, 29). State 1 occurs uniquely in the Vandelliinae, being interpreted as an additional synapomorphy for the subfamily (Clade R).

17. Adductor hyomandibulae muscle: (0) absent; (1) present [CI: 1.00; RI: 1.00; steps: 1].

The adductor hyomandibulae is a suspensorial muscle that apparently arose independently in several lineages within the Teleostei (Winterbottom, 1974a) and is probably derived from a posterior differentiation of the same primordial muscle that forms the adductor arcus palatini (Takahasi, 1925; Winterbottom, 1974a). Among nematogenyids and trichomycterids the adductor hyomandibulae is found solely in copionodontines (Fig. 6) and trichogenines, being interpreted as a synapomorphy for the clade formed by these two subfamilies (Clade B).

18. Width of origin of the levator arcus palatini: (0) narrower than its insertion; (1) broader than its insertion [CI: 1.00; RI: 1.00; steps: 1$]$.

In the Nematogenyidae, Copionodontinae, Trichogeninae, Trichomycterinae (Fig. 10), Sarcoglanidinae (Fig. 16), and Glanapteryginae (Fig. 18), the levator arcus palatini has an origin that is narrower than its insertion. In most cases the origin of this muscle is restricted solely to the ventral surface of the postorbital process of the skull (Figs. 1, 3, 7, 9, 10, 14, 16), such that this muscle has a nearly triangular or conical shape in lateral view. In other taxa such as Ituglanis gracilior (Trichomycterinae), Sarcoglanis simplex (Sarcoglanidinae) (Fig. 15), and Listrura camposi (Glanapteryginae) (Fig. 18) the origin of the muscle is somewhat broader, but still clearly narrower than its insertion. In all tridentines, stegophilines, and vandelliines the origin of the levator arcus palatini is much anteriorly expanded across the frontal, being markedly broader than the insertion of the muscle (state 1) (Fig. 29). The muscle consequently has the approximate shape of an inverted trapezoid in lateral view. This state is hypothesized to be a synapomorphy for the Vandelliinae-group (Clade K).

19. Protractor operculi muscle: (0) absent; (1) present (de Pinna, 1992: 212, Character 22; de Pinna, 1998: 309, Clade 2) [CI: 1.00; RI: 1.00; steps: 1 ].

This muscle was firstly reported by Howes (1983b: 329, Fig. 12: "preopercular muscle") and subsequently explicitly named by de Pinna (1992). In the phylogenetic scheme of de 
Pinna (1992), the presence of this muscle (Figs. 9, 10, 11, 14$16,18,20,22,23,26-29)$ is considered a synapomorphy for all trichomycterids except for the Copionodontinae and Trichogeninae ( $c f$. Figs. 3, 7); a hypothesis confirmed herein (Clade C).

20. Relationship among protractor operculi and secondaryventral section of dilatator operculi: (0) fully separated from each other; (1) continuous with each other and forming a compound muscle [CI: 1.00; RI:-; steps: 1].

In almost all trichomycterids in which it is present, the protractor operculi is fully separated from the secondaryventral section of dilatator operculi (Figs. 9, 10, 14, 15, 18, $20,22,26,27,28)$. Uniquely in Microcambeva, these structures are broadly continuous with each other thereby forming a compound muscle mass (Fig. 16); a condition considered autapomorphic for this taxon.

Since the ontogenetic origin of protractor operculi is unknown, it is currently impossible to determine whether the protractor operculi of Microcambeva is fused to or undifferentiated from the dilatator operculi. Howes (1983b: 329) suggested that the protractor operculi could be derived either from the adductor mandibulae or from the dilatator operculi. The condition of the protractor operculi of Microcambeva might favor the hypothesis of the derivation of that muscle from the dilatator operculi, with the fusion of these two muscles in that genus being a possible retention of a juvenile stage in which these muscles are still undifferentiated. Although to a lesser degree than in Microcambeva, a partial continuity between the protractor operculi and dilatator operculi also occurs in the stegophiline Haemomaster (see "Anatomical descriptions of the cheek muscles"). On the other hand, in Haemomaster, some fibers of the adductor mandibulae extend posteriorly and fuse with the protractor operculi. A delicate tendinous tissue found at the origin of the protractor operculi in many other trichomycterids, especially the trichomycterines (see Fig. 9), may also be continuous with some fibers of the adductor mandibulae. These conditions would argue in favor of the common ontogenetic origin of the protractor operculi and adductor mandibulae. The continuity between these two muscles is not in any cases as pronounced as that observed between the protractor operculi and the dilatator operculi in Microcambeva and Haemomaster. These facts point out that the conundrum of the ontogenetic origin of the protractor operculi can be only solved by direct study of the development of these muscles in trichomycterids.

The nematogenyids, copionodontines, and trichogenines lack a protractor operculi (Character 19) and their conditions were coded as inapplicable.

21. The insertion of the protractor operculi onto the opercle: (0) with fibers not reaching the opercular odontodes; (1) with fibers reaching the base of some of the anteroventral most opercular odontodes [CI: 1.00; RI: 1.00; steps: 1].

The protractor operculi in trichomycterids primitively inserts onto a region of the opercle anterior to its patch of odontodes (Figs. 9, 10, 14-16, 18, 20, 22, 23). In vandelliines, the fibers of this muscle stretch posteriorly attaching to the bases of some of the anteroventral most opercular odontodes (Fig. 28). Such a condition is interpreted as a synapomorphy for the Vandelliinae (Clade R).

Due to their lacking of a protractor operculi (Character 19), the conditions for Nematogenyidae, Copionodontinae, and Trichogeninae were coded as inapplicable.

22. Shape of the protractor operculi: (0) longer than deep; (1) much shorter than deep [CI: 1.00; RI: 1.00; steps: 1].

In the basal condition for trichomycterids, the protractor operculi is a fusiform muscle distinctly longer than deep (Figs. $9,10,14-16,18,20,28,29)$. In all stegophilines this muscle is considerably shortened, often with its attachment site vertically expanded resulting in parallelogram shaped muscle from lateral view in most cases (Fig. 22). Although this parallelogram shape is not evident in Ochmacanthus (Fig. 26), the protractor operculi in this genus is still distinctly shorter than deep, fitting the definition of state 1 . This state is hypothesized to be a synapomorphy for the Stegophilinae (Clade M).

Inapplicable conditions were coded for the Nematogenyidae, Copionodontinae, and Trichogeninae, since they lack a protractor operculi (Character 19).

23. Orientation of the fibers of main axis of the protractor operculi: (0) directed posterodorsally towards its insertion; (1) directed posteroventrally towards its insertion [CI: 1.00; RI: 1.00; steps: 1].

Most trichomycterids have the fibers of the main axis of the protractor operculi posterodorsally oriented towards its insertion onto the opercle (Figs. 9, 11, 20, 22, 28). Exclusively in the Sarcoglanidinae, these fibers are posteroventrally oriented towards their insertion (Fig. 15), a condition herein interpreted as a synapomorphy for the members of this subfamily (Clade I).

The Nematogenyidae, Copionodontinae, and Trichogeninae, were coded as inapplicable for the character, since the protractor operculi is absent in these taxa (Character19).

24. Origin of the protractor operculi: (0) solely from the suspensorium; (1) from both the suspensorium and interopercle; (2) from the suspensorium and the fascia of the levator arcus palatini [multistate unordered; CI: 1.00; RI: 1.00; steps: 2].

The protractor operculi plesiomorphically originates solely from the preopercle among trichomycterids (Figs. 9, 14, 15, 18, 22). In the vandelliine Vandellia, this muscle is distinctly enlarged with its origin expanding ventrally to reach the interopercle (state 1) (Fig. 28). Although its deepest fibers also originate from the preopercle, the main site of origin of the protractor operculi in the tridentine genus Tridentopsis is the fascia of the levator arcus palatini (state 2) (Fig. 20). State 1 is hypothesized to be a synapomorphy for Vandellia (Clade T), whereas state 2 is an autapomorphy for Tridentopsis. 
Nematogenyids, copionodontines, and trichogenines lack the protractor operculi (Character 19) and were coded as inapplicable for this character.

25. The primary section of the dilatator operculi: (0) present and well developed; (1) present but extremely reduced; (2) absent [multistate ordered; CI: 1.00; RI: 1.00; steps: 1].

The dilatator operculi of most Siluriformes is composed of a single bundle of fibers that originates from the orbital region of the neurocranium (primarily from the frontal) and inserts tendinously onto the dorsal process of the opercle (Fig. 1). In trichomycterids this muscle is greatly expanded, acquiring a portion herein termed the "secondary section" which, in turn, may be subdivided into secondary-ventral and secondary-dorsal subsections in many taxa (see Characters 29 and 32) (Figs. 3, 7, 9, 10, 14-16, 18, 20, 22, 23, 2629). Howes (1983b: 329), Diogo (2005: Character 245, state 2), and Adriaens et al. (2010) also recognized these two main subdivisions of the dilatator operculi of trichomycterids without, however, explicitly indicate which of these subdivisions was derived for the group. For comparative purposes, the part of this muscle of trichomycterids that corresponds to the plesiomorphic dilatator operculi of other catfishes is herein referred as the "primary section" (= "medial part" of Howes, 1983b; "ventral division” of Diogo, 2005; and "medial bundle" of Adriaens et al., 2010). We do not retain Howes' (1983b) original nomenclature because the primary section is not always medial to the levator arcus palatini throughout all of the Trichomycteridae (see Character 26). This renders use of the term "medial" for referring to this section inappropriate in such cases.

A well developed primary section of the dilatator operculi (state 0 ) is present in all trichomycterids examined, except for the Sarcoglanidinae. In Microcambeva this section is extremely reduced, appearing as a slender cord-like bundle of fibers (Fig.16). This condition (state 1 ) seems to constitute an intermediary step towards a complete loss of the primary section that occurs in the sarcoglanidine genera Sarcoglanis (Fig. 15) and Stauroglanis (state 2). In these sarcoglanidines, the sole remnants of the dilatator operculi are their secondary-dorsal and secondaryventral sections (Fig. 15). State 1 is interpreted as a synapomorphy for the Sarcoglanidinae (Clade I), whereas state 2 is synapomorphic for Stauroglanis plus Sarcoglanis (Clade J).

26. Primary section of the dilatator operculi: (0) passing medial to the levator arcus palatini; (1) passing dorsolateral to the levator arcus palatini [CI: 1.00; RI: 1.00; steps: 1].

As in other catfishes, the primary section of the dilatator operculi passes medial to the levator arcus palatini in the Nematogenyidae (Fig. 1), Copionodontinae (Fig. 3), Trichogeninae (Fig. 7), and Trichomycterinae (Figs. 9, 10, 14). Alternatively, in the sarcoglanidine Microcambeva (Fig. 16), the Glanapteryginae (Fig. 18), Tridentinae (Fig. 20), Stegophilinae (Figs. 22, 23, 26, 27), and Vandelliinae (Figs. 28, 29), this section passes dorsolateral to the levator arcus palatini. Apparently coupled with that feature, the secondary section of the dilatator operculi of most of these fishes becomes split into dorsal and ventral parts by the interposing primary section. This state is, thus, interpreted as a synapomorphy for the clade TSVSG (Clade G).

Due to their lack of a primary section of the dilatator operculi (see Character 25), the conditions in Stauroglanis and Sarcoglanis were coded as inapplicable.

27. Origin of the primary section of the dilatator operculi: (0) restricted to the region posterior to the olfactory foramen; (1) anteriorly expanded beyond the olfactory foramen [CI: 1.00; RI: 1.00; steps: 1$]$.

In nematogenyids (Fig. 1) and basal trichomycterids (Figs. $3,7,9,10,14,16,18$ ), the primary section of dilatator operculi originates primarily from the orbital region of the neurocranium posterior to the olfactory foramen (mainly the middle part of the frontal). In the Tridentinae (Fig. 20), Stegophilinae (Figs. 22, 23, 26, 27), and Vandelliinae (Figs. 28, 29), this section is considerably expanded anteriorly, with some fibers reaching the ethmoidal region of neurocranium anterodorsally to the olfactory foramen (anterior part of frontal and, usually, also the mesethmoid). This condition is proposed as a synapomorphy for the clade formed by these three subfamilies, the Vandelliinae-group (Clade K).

Since the primary section of dilatator operculi is missing in the sarcoglanidines Stauroglanis and Sarcoglanis (see Character 25), this character was coded as inapplicable in those genera.

28. Origin of the primary section of the dilatator operculi: (0) not meeting its counterpart along the mid-sagittal plane; (1) meeting its counterpart along the mid-sagittal plane [CI: 0.50 ; RI: 0.83; steps: 2].

In the Nematogenyidae and most of the Trichomycteridae, the primary section of the dilatator operculi on each side of the head falls short of its counterpart along the mid-sagittal plane of the cranial roof (Figs. 10, 16, 18, 23). In the stegophilines Homodiaetus, Ochmacanthus (Fig. 26), Parastegophilus, Pseudostegophilus, and Pareiodon (Fig. 27) and the vandelliine Vandellia (Fig. 29) the primary section of the dilatator operculi is medially expanded over the roof of the skull contacting its antimere along the mid-sagittal line. Such contact is interpreted as having evolved independently at the base of the clade formed by all stegophilines except Haemomaster (Clade N) and at the base of the genus Vandellia (Clade T).

Conditions for Stauroglanis and Sarcoglanis were assigned as inapplicable due to the absence of the primary section of the dilatator operculi in these taxa (see Character 25).

29. Secondary-dorsal section of the dilatator operculi: (0) absent; (1) present [CI: 0.33; RI: -; steps: 3].

As mentioned under Character 25, the dilatator operculi of trichomycterids is highly specialized, developing an additional secondary section (= "lateral part" of Howes, 1983b; “dorsal division” of Diogo, 2005; "lateral bundle” of 
Adriaens et al., 2010) (Figs. 3, 7, 9, 10, 14-16, 18, 20, 22, 23, 2629) from the single primitive section present in other catfishes [the section herein named the primary section (= "medial part" of Howes, 1983b; "ventral division" of Diogo, 2005; and "medial bundle" of Adriaens et al., 2010)] (Fig. 1). Although the secondary section is further subdivided only to a limited degree in some trichomycterids (Figs. 3, 7), two distinct parts may nonetheless be easily identified in most cases, the secondary-ventral (= "ventral portion” of Howes, 1983b: 329) and the secondary-dorsal subsections (Figs. 3, 9, 10, 14-16, 20, 22, 23, 26-29). This separation appears somewhat artificial for some trichomycterids in which these three sections are less differentiated (Figs. 3, 7, 9, 10, 18). Nonetheless, such a nomenclatural division has proven be useful (see "Discussion: Trichomycteridae") in a more encompassing comparative study that includes taxa with fully separated secondary-dorsal and secondary-ventral sections (Figs. 16, $22,23,28,29)$. Furthermore, even when not well differentiated from each other, the presence of each section of the dilatator operculi can be undoubtedly confirmed by their well established positions and sites of origin and insertion (see "Anatomical descriptions of the cheek muscles" and paragraph below).

The secondary-dorsal section of the dilatator operculi originates from the dorsolateral portion of the otic region of the neurocranium and inserts onto the tip of the dorsal process of the opercle (Figs. 9, 10, 14-16, 20, 22, 23, 28, 29). An apparently reliable and useful landmark for distinguish the secondary-dorsal section from the primary section of the muscle in trichomycterids is the location of the pore for the infraorbital canal of the cephalic laterosensory system. In all trichomycterids herein examined this pore is always placed posterior to the origin of the primary section and anterior to the secondary-dorsal section. This character is so conservative that even in species with highly modified and hypertrophied dilatator operculi muscles (as some stegophilines), the tube of the infraorbital canal still lies between the fibers of these two sections (Fig. 27).

The possession of the secondary-dorsal section of the dilatator operculi is interpreted as a synapomorphy for the Trichomycteridae (Clade A; but see "Discussion: Trichomycteridae"); being, however, secondarily absent in the vandelliines Paracanthopoma and Paravandellia. Given the obtained phylogeny, the optimization of this character in the Vandelliinae is ambiguous since it is equally parsimonious to suppose that the secondary-dorsal section of the dilatator operculi was (A) lost at the base of the subfamily (Clade R) and reacquired in Vandellia (Clade T) or that (B) it was independently lost in Paracanthopoma and in Paravandellia. It is generally accepted that secondary losses are more likely to have happened than parallel evolution of complex structures; such as is the case of the primary section of the dilatator operculi herein (de Pinna, 1991; Agnarsson \& Miller, 2008). As demonstrated by Amorim (1997) and Agnarsson \& Miller (2008) this assumption does not necessarily imply the adoption of ACCTRAN optimization (despite of the claims to the contrary; e.g. de Pinna, 1991). Actually, in the case of the present character, the choice that maximizes parallel loss over convergent gains of complex structures is hypothesis (B). Therefore, in the most parsimonious reconstruction, the loss of the secondary-dorsal section of dilatator operculi is assumed to have occurred independently in Paracanthopoma and in Paravandellia (thus, DELTRAN optimization). These losses may be associated with the paedomorphic feature of poor ossification of their cranial roof in these genera, which ultimately leads to the formation of a single large cranial fontanel in these taxa. This wide cranial fontanel occupies the space of the bones that typically serves as sites of origin of this section in other trichomycterids. "Trichomycterus" hasemani and tridentines also possesses a wide cranial fontanel (cf. Baskin, 1973: fig. 28; de Pinna, 1989a: fig. 24), similar to those of Paracanthopoma and Paravandellia (cf. Baskin, 1973: fig. 17: de Pinna, 1989a: fig. 26). The secondarydorsal section of dilatator operculi in "Trichomycterus" hasemani and the Tridentinae, however, is undoubtedly present (despite being partially continuous with the primary section in the former). Notwithstanding, the secondary-dorsal section in " $T$." hasemani and tridentines is comparatively smaller than that in other trichomycterids.

30. Orientation of the central axis of the secondary-dorsal section of the dilatator operculi: (0) directed anteromedially towards its origin; (1) directed posteromedially towards its origin [CI: 1.00; RI: 1.00; steps: 1].

In all trichomycterids except for the Sarcoglanidinae, the central axis of the secondary-dorsal section of the dilatator operculi is anteromedially oriented towards its origin on the neurocranium (Figs. 3, 7, 9, 10, 14, 18, 20, 22, 23, 28, 29). In the derived state found only in all examined sarcoglanidines, this axis is oriented slight posteromedially towards the origin of the secondary-dorsal section (Figs. 15, 16). This condition is hypothesized to be a synapomorphy for the Sarcoglanidinae (Clade I).

Nematogenys and the vandelliines Paracanthopoma and Paravandellia lack a secondary-dorsal section of the dilatator operculi (Character 29) and were coded as inapplicable for this character.

31. The origin of the secondary-dorsal section of the dilatator operculi: (0) restricted to the dorsolateral region of the neurocranium, never meeting its counterpart along the midsagittal plane; (1) anteromedially expanded, contacting its counterpart along the mid-sagittal plane only anteriorly; (2) fully medially expanded, meeting its counterpart along the mid-sagittal plane along its entire medial border [multistate ordered; CI: 1.00; RI: 1.00; steps: 2].

The secondary-dorsal section of the dilatator operculi of trichomycterids plesiomorphically originates from the dorsolateral part of the otic region of the neurocranium. In this condition that section never contacts its counterpart along the cranial roof (Figs. 7, 9, 10, 14, 16, 18, 20, 23, 29). In the stegophilines Parastegophilus, Pseudostegophilus, and 
Pareiodon this section has an origin much expanded anteromedially, such that the anterior most fibers contact their counterparts along the mid-sagittal plane (state 1). In Pseudostegophilus and Pareiodon this medial expansion of the muscle is more extreme, with the entire medial border of the secondary-dorsal section of the dilatator operculi meeting its antimere along the mid-sagittal plane (state 2) (Fig. 27). State 1 is interpreted as a synapomorphy uniting Parastegophilus, Pseudostegophilus, and Pareiodon (Clade $P$ ), whereas the state 2 unites the two latter genera (Clade Q).

A secondary-dorsal section of the dilatator operculi is absent in the Nematogenyidae and the vandelliines Paracanthopoma and Paravandellia (Character 29) and their conditions were coded as inapplicable for this character.

32. The secondary-ventral section of the dilatator operculi: (0) absent; (1) present [CI: 1.00; RI: -; steps: 1].

As mentioned under Characters 25 and 29, the dilatator operculi of trichomycterids usually has three sections: the primary, secondary-dorsal, and secondary-ventral. The secondary-ventral section (the "ventral portion" of Howes, 1983b: 329) is always the smaller, being ventrally positioned relative to the secondary-dorsal section (Figs. 3, 9, 10, 14-16, $20,22,23,26,27,28)$. It is also the most "versatile" of the sections of the dilatator operculi, being sometimes intimately fused to the other sections of this muscle or the protractor operculi (see also Character 20), and sometimes attached to the eyeball capsule in some stegophilines and vandelliines (see "Anatomical descriptions of the cheek muscles"). Recognition of the secondary-ventral section of the dilatator operculi is nonetheless easy due to its insertion which extends ventrolateral to the attachment of the tendon for the insertion of the primary section. In most taxa, that area of insertion of the secondary-ventral section of the dilatator operculi involves primarily the region at the base of the dorsal process of the opercle just anterior to the patch of odontodes. The secondary-ventral section of the dilatator operculi was found in all trichomycterids examined; constituting thereby a synapomorphy for the entire family (Clade A; but see "Discussion: Trichomycteridae").

33. The insertion of the secondary-ventral section of the dilatator operculi: (0) narrow and restricted to the posterior region of the opercle; (1) significantly expanded anteriorly and reaching articular region of the opercle with the hyomandibula [CI: 1.00; RI: 1.00; steps: 1].

The secondary-ventral section of the dilatator operculi of trichomycterids is plesiomorphically a band-like bundle of fibers with a narrow insertion onto the lateral face of the opercle near to the posterior end of protractor operculi (when the latter muscle is present; pers. obs.; Howes, 1983b: 329) (Figs. 9, 10, 15, 16, 20, 22, 23, 26, 28, 29). In Hatcheria macraei, Bullockia maldonadoi, Trichomycterus areolatus, T. chiltoni, T. immaculatus, and T. zonatus the secondary-ventral section of the dilatator operculi is considerably broader ventrally, acquiring an overall triangular shape, with the insertion anteriorly expanded as far as the vertical through the middle of the protractor operculi (Fig. 14). Such a condition is considered to be a synapomorphy uniting all the cited taxa into a monophyletic assemblage (Clade E).

Nematogenys lacks a secondary-ventral section of the dilatator operculi (Character 32) and was coded as inapplicable for this character.

34. The orientation of the fibers of the levator operculi: (0) directed anterodorsally towards its origin; (1) directed posterodorsally towards its origin [CI: 1.00; RI: 1.00 ; steps: 1 ].

In the apparent primitive condition for the Siluriformes, the levator operculi has its fibers oriented slightly anterodorsally towards its origin on the neurocranium (pers. obs.; cf. Howes, 1983a, 1985b; Diogo, 2005). This condition is also found in copionodontines (Fig. 3) and trichogenines (Fig. 7). In all other trichomycterids the fibers of this muscle are distinctly posterodorsally oriented towards its origin (Figs. $9,10,14-16,18,20,22,23,27,28,29)$. Such a condition is interpreted as synapomorphic for the non-copionodontine, non-trichogenine trichomycterids (Clade C). The levator operculi of Nematogenys is highly hypertrophied with its fibers spreading over the lateral surface of the opercle and consequently oriented in anterodorsal and posterodorsal directions (Fig. 1). However, since most of its fibers, as well as the central axis of the muscle, are oriented slightly anterodorsally towards its origin, we code it as state 0 .

35. The origin of the levator internus 4: (0) solely from the neurocranial floor; (1) from both the neurocranial floor and the dorsal face of the posttemporo-supracleithrum [CI: 1.00; RI: 1.00; steps: 1].

The levatores interni are extrinsic dorsal branchial muscles that connect the dorsal elements of branchial basket to the skull (or vertebral column). Although we had not planned to include the branchial muscles in our study, this character was discovered due to its unusual exposure on the dorsal surface of skull in trichomycterines. In all examined nematogenyids and non-trichomycterines trichomycterids, the levator internus 4 (see Springer \& Johnson, 2004, for a discussion of the identity and homology of this muscle) originates solely from the ventral surface of pterotic and/or posttemporo-supracleithrum and inserts onto the upper pharyngeal tooth plate (Fig. 6). In all examined members of the Trichomycterinae (lato sensu, i.e., including Ituglanis and Scleronema), the posterior part of this muscle is more developed and diverges from the remaining muscle at its origin (Fig. 13). Most of the fibers of this posterior portion of the levator internus 4 pass through a fenestra between the medial border of posttemporo-supracleithrum and the neurocranium (pterotic and epioccipital) and spreads out to an attachment over the dorsal surface of the posttemporosupracleithrum (Figs. 10, 33). In non-trichomycterines trichomycterids, only the epaxialis musculature attaches to the dorsal face of the posttemporo-supracleithrum. State 1 is herein interpreted as a homoplasy-free synapomorphy 
for all of the Trichomycterinae (lato sensu) herein examined (Clade D).

Although the fenestra for the posterior part of levator internus 4 is apparently a necessary condition for the attachment of this muscle onto the dorsal face of the posttemporo-supracleithrum, the inverse does not always apply. For example, "Trichomycterus" hasemani [a species clearly not related to the remaining trichomycterines and improperly placed under the genus Trichomycterus (de Pinna, 1989a); see "Discussion: Trichomycterinae")], possesses such a small fenestra but not the state 1 of the levator internus 4 . Some trichomycterines have extremely small fenestrae, as in the case with most members of the Clade $\mathrm{E}$ of the present study, but the attachment of the posterior ramus of the levator internus 4 onto the dorsal face of the posttemporo-supracleithrum is still present. In these cases, the dorsally exposed part of this muscle may be extremely thin and somewhat translucent (Fig. 33). On the other hand, some trichomycterines (e.g. Trichomycterus brasiliensis and T. maracaya) posses a much developed and expanded dorsally exposed portion of the levator internus 4, such that its lateral border may be visualized even without the removal of the epaxialis (see Fig. 9).

36. Anterior border of the anterodorsal trunk muscles on the posterodorsal region of the skull: (0) from concave to almost straight at mid-sagittal plane; (1) distinctly convex at midsagittal plane [CI: 1.00; RI: 1.00; steps: 1].

The anterodorsal trunk muscles, the epaxialis and supracarinalis anterior, attach anteriorly on the posterodorsal region of the skull. In the Nematogenyidae and most members of the Trichomycteridae the anterior border of these muscles ranges from almost straight to concave at midsagittal line from a dorsal view (Figs. 10, 16, 18, 23, 29). In the stegophilines Pseudostegophilus and Pareiodon that border is distinctly convex at mid-sagittal plane, extending more anteriorly and covering the area of the cranial roof between the dilatator operculi and levator operculi (Fig. 27). As a consequence of this elaboration in conjunction with the Characters 28 and 31, almost the entire cranial roof of Pseudostegophilus and Pareiodon is covered by muscles (Fig. 27). State 1 is interpreted as a synapomorphy for the clade formed by these two genera (Clade Q).

\section{Discussion}

\section{Relationships of the Nematogenyidae and Trichomycteridae}

According to de Pinna (1992), the sister-group relationship of the Nematogenyidae and Trichomycteridae is supported by three osteological synapomorphies: absence of dorsal-fin spine and locking mechanism; first dorsal-fin pterygiophore inserted posterior to the neural spine of the ninth free vertebrae; and medial juncture between scapulo-coracoids without interdigitations. Although our character matrix does not include catfish families other than the Nematogenyidae and Trichomycteridae, we carried out comparisons with several members of others families of Siluriformes. This permits us to advance hypotheses about the relationships among these two families and their monophyletic status based on myological evidence.

Howes (1983a, 1983b) reported a connective tissue sheet connecting the lower jaw to the maxilla and maxillary barbel in Nematogenys. We found this connective sheet not only in Nematogenys but also across all trichomycterids examined in our study. This sheet of dense irregular connective tissue enwraps a stout cylindrical block of fibro/cell-rich cartilage (sensu Benjamin, 1990) which attaches posteriorly to the anterior rim of the coronoid process and anteriorly to the base of the maxillary barbel and, often, the maxilla (pers. obs.; Adriaens et al., 2010: 342). This cartilaginous block, herein termed the coronomaxillar cartilage, is never or only poorly stained by the Alcian Blue (Figs. 1, 3, 4, 7, 9, 10, 16, 18, 20, 22, $23,28,29)$. That occurs because it is formed by a type of matrix-poor cartilage (Benjamin, 1990) that seems to be more resistant and flexible than the typical hyaline cartilage. Macroscopically, the coronomaxillar cartilage resembles a kind of connective tissue, so that it was referred as so by Howes (1983b: 326) in his brief description of the adductor mandibulae of trichomycterids. The coronomaxillar cartilage also was erroneously identified as a ligament by Diogo et al.

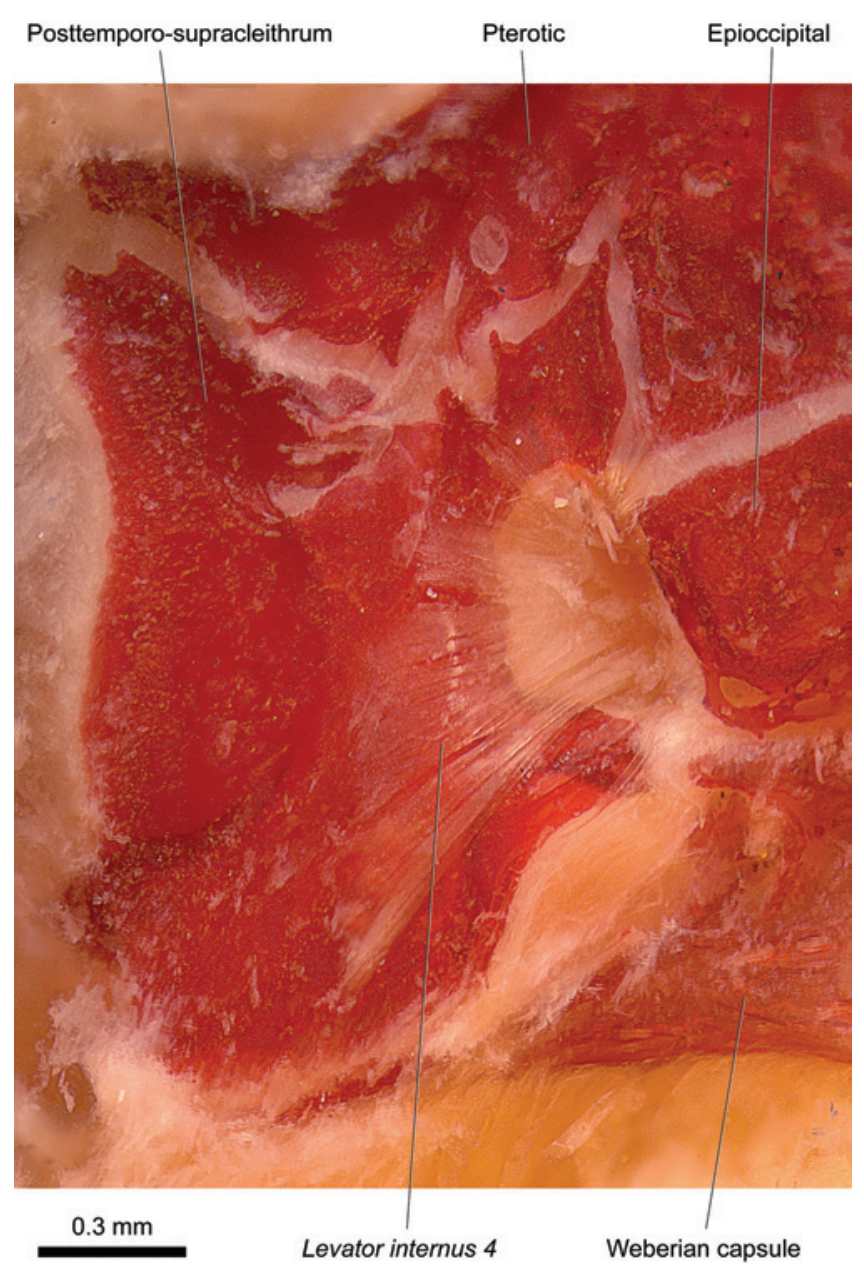

Fig. 33. Dorsal view of the left posterolateral region of the head of Trichomycterus chiltoni, LBP 1001 (104.2 mm SL). 
(2006: fig. 1: ligamentum primordium). Histological sections of that structure (Fig. 34) reveal that it is neither a ligament (Takashima \& Hibiya, 1995) nor a “connective tissue”, being rather a fibro/cell-rich cartilage (Benjamin, 1990). Although not identical to the condition found in the Nematogenyidae and Trichomycteridae, a similar coronomaxillar cartilage attached to the maxillary barbel is present in arioids (sensu Sullivan et al., 2006) (pers. obs.; de Pinna, 1993: 149-150) and claroteids (de Pinna, 1993: 149-150). Apparently, all remaining Siluriformes have the core of the maxillary barbel directly attached to the maxillary bone only (pers. obs.; Alexander, 1965; Adriaens \& Verraes, 1996, 1997). Since the phylogenetic relationships among some of the major lineages of catfishes are currently subject to controversy (cf. Mo, 1991; de Pinna, 1998; Sullivan et al., 2006;
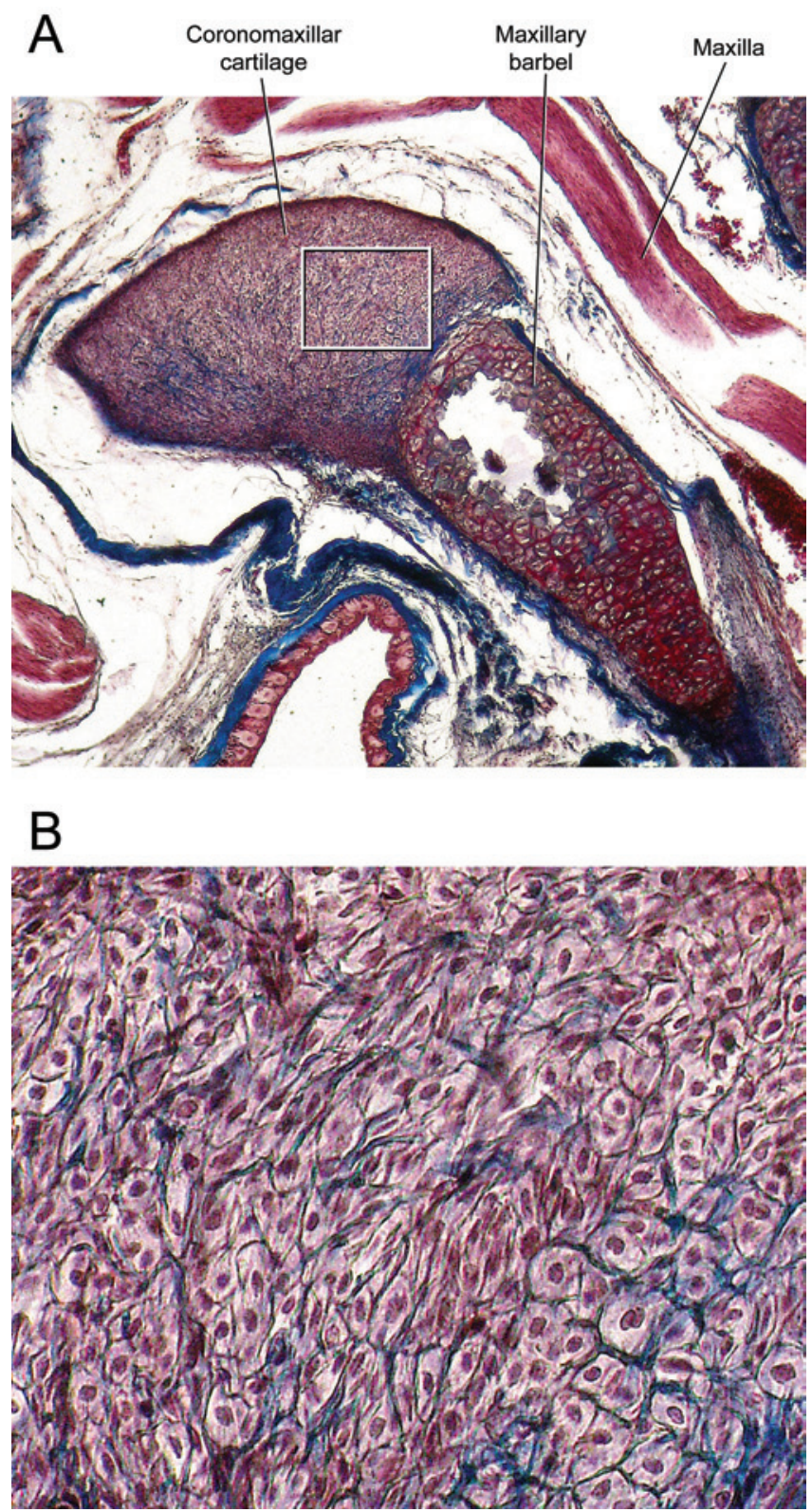

Fig. 34. Longitudinal section of right rictal region of Trichomycterus davisi, LIRP 2798 (37.5 mm SL). (A) 20× magnification; (B) magnification of rectangle of (A).
Lundberg et al., 2007), the optimization of the presence of a coronomaxillar cartilage associated with the base of the maxillary barbel is ambiguous. Nevertheless, the possibility of that character to constitute an additional synapomorphy for the clade Nematogenyidae + Trichomycteridae (de Pinna, 1992, 1998) must to be considered.

Diogo (2005: Character 211, state 1) recognized the possession of a dilatator operculi situated markedly lateral to the A2 section of the adductor mandibulae as a synapomorphy for the Nematogenyidae (Fig. 1) and Trichomycteridae (Figs. 3, 7, 9, 10, 14, 15, 18, 20, 22, 28, 29), with the same condition also homoplastically occurring in the callichthyid Callichthys. Although that is a possibility, these conclusions might be a consequence of problematic coding and polarization of this character in Diogo's (2005) analysis. In addition to its lateral position relative to the A2 section of the adductor mandibulae, the dilatator operculi of ostariophysans may be also either medial or fully posterodorsal to the A2 (pers. obs.; cf. Takahasi, 1925; Alexander, 1964; Vari, 1979; Howes, 1976, 1978, 1982, 1985a, 1985b; Aguilera, 1986). In his coding of the character, Diogo (2005) disregarded these two latter distinct conditions, placing them rather under the same character state (Character 211, state 0: "not markedly lateral to the adductor mandibulae A2”). All Gonorynchiformes, Characiformes, and Gymnotiformes examined by us and reported in literature ( $c f$. Alexander, 1964; Vari, 1979; Howes, 1976, 1985a; Aguilera, 1986), as well as many Cypriniformes (cf. Takahasi, 1925; Saxena, 1960; Howes, 1978, 1982), exhibit a dilatator operculi situated lateral or posterodorsal to the A2 section of the adductor mandibulae. Therefore, we can almost certainly consider one of these two conditions to represent the plesiomorphic state for Siluriformes. We are, however, unable to determine at present which of these two conditions is in fact more primitive for catfishes. The fact is that the dilatator operculi situated medial to the A2 section of the adductor mandibulae as present in the Diplomystidae and most nonloricarioid catfishes (pers. obs.; Alexander, 1965; Howes, 1983a, 1983b, 1985b; Adriaens \& Verraes, 1996) must be certainly considered a derived state for the Siluriformes. This condition is never found in the Loricarioidei. The Nematogenyidae, Trichomycteridae, and the callichthyid Callichthys have a dilatator operculi situated lateral to the A2 section of the adductor mandibulae, whereas all other loricarioids have the dilatator operculi located posterodorsal to the A2 (pers. obs.; Diogo, 2005; Howes, 1983a, b; Huysentruyt et al., 2007; Geerinckx et al., 2007; Geerinckx \& Adriaens, 2008). This character-state distribution across the Ostariophysi might be taken as a potential morphological evidence for the basal placement of the Loricarioidei within Siluriformes as proposed by Sullivan et al. (2006). In that scheme, the dilatator operculi situated lateral to the A2 section of the adductor mandibulae would be viewed as a plesiomorphic condition retained in the basal most lineages of the Loricarioidei (Nematogenyidae, Trichomycteridae and some Callichthyidae), whereas the dilatator operculi situated 
lateral to the A2 would constitute an additional synapomorphy joining the Diplomystidae with the remaining non-loricarioid catfishes. Accordingly, the dilatator operculi placed posterodorsal to the A2 might constitute a derived condition homoplastically found in both the apical most taxa of Loricarioidei as well as in a few other lineages of nonloricarioid catfishes. However, this character seems to require a more detailed anatomical investigation. Apparently different and independent modifications in the arrangement of the bones of skull and the degree of development of the A2 section of the adductor mandibulae produce the same result in terms of the relative position of the dilatator operculi, what ultimately can lead to inappropriate assessments of homology when only the muscles are superficially surveyed.

Despite not being related to the musculature, Diogo (2005: Character 78, state 1) cites the presence of a nasal barbel on the anterior nostril "supported by anterodorsal surface of premaxillae" as a supposed synapomorphy for Nematogenyidae plus Trichomycteridae. The presence of a nasal barbel associated with the anterior nostril is, indeed, an evident synapomorphy for this clade, as previously recognized by Mo (1991) and de Pinna (1998). The association of this barbel with the premaxilla, as mentioned by Diogo (2005), however, seems incorrect. In all trichomycterids examined in this study (including three of the four species examined by Diogo, 2005) the core of the nasal barbel never associates with the premaxilla. The proximal part of its core is usually expanded and associated with a loose connective tissue that surrounds the olfactory cavity. This connective tissue, in turn, is primarily loosely associated with the autopalatine. When present, the antorbital is the only bone that is associated with the core of the nasal barbel (Fig. 10) (pers. obs.; Adriaens et al., 2010: 342). The nasal barbel in Nematogenys (pers. obs.; Arratia, 1987; de Pinna, 1998) as well as juveniles of some trichomycterids (de Pinna, 1998) seem to lack an evident internal core, being rather an expansion of the skin fold that surrounds the anterior nostril and which is evidently not associated with the premaxilla.

\section{Nematogenyidae}

Until recently, the single widely accepted autapomorphy of the Nematogenyidae was the levator operculi covering most of the lateral surface of the opercle (Fig. 1) (Howes, 1983b; Arratia, 1992; de Pinna, 1992, 1998; Diogo, 2005). This condition also occurs homoplastically in a few heptapterids (pers. obs.; Arratia, 1992; Bockmann, 1998; Diogo, 2005, 2007) and apparently to a lesser degree in the austroglanidid Austroglanis (Diogo, 2005; Diogo \& Bills, 2006). Although the levator operculi of some trichomycterids at first sight also seems to be inserted onto the lateral face of the opercle, as de Pinna (1998) demonstrated - and we confirm - this arrangement is not the same condition found in the Nematogenyidae. Rather, this is a mistaken impression derived from the highly modified opercle of some of the more derived trichomycterids. In most siluriforms examined, as well as many other Ostariophysi, the levator operculi inserts primarily onto the medial face of the laminar part of the opercle situated dorsal to the medial crest of that bone (Fig. 35). This situation also occurs in the basal trichomycterid subfamilies Copionodontinae and Trichogeninae. Notwithstanding, since the levator operculi of these fishes is comparatively hypertrophied (pers. obs., Howes, 1983b), its deeper fibers also reaches the dorsal face of the well developed medial crest of opercle (Fig. 35). In the more derived trichomycterids, most of the dorsal laminar part of the opercle is lacking with only the dorsal process remaining (see Figs. 9, 14, 20, 22). This arrangement laterally exposes the posterior part of the levator operculi which, in turn, becomes more directly inserted onto the medial crest of opercle (Fig. 35). To further complicate the issue, the medial crest of the opercle of some taxa is slightly rotated dorsolaterally, thereby more laterally exposing the insertion of the levator operculi (Fig. 35) as is seen, for example, in Sarcoglanis (Fig. 15). Nevertheless, the site of insertion of the levator operculi remains the same across all of these trichomycterids, i.e., the dorsal face of the medial crest of the opercle. The most noticeable modifications associated with the lateral exposition of that muscle occur, thus, in the structure of their opercle, rather than in their levator operculi. A small change in the insertion of the levator operculi within the Trichomycteridae apparently occurs only in some vandelliines, in which this muscle attaches to the dorsal process of the opercle (Figs. 28, 29). In Nematogenys, most of the dorsal laminar portion of the opercle is also lacking, but, differently from trichomycterids, the levator operculi in this genus indeed inserts onto the lateral face of the laminar portion of the opercle ventral to the medial crest of this bone (Fig. 35). This condition is unquestionably distinct from that of trichomycterids and most other Siluriformes.
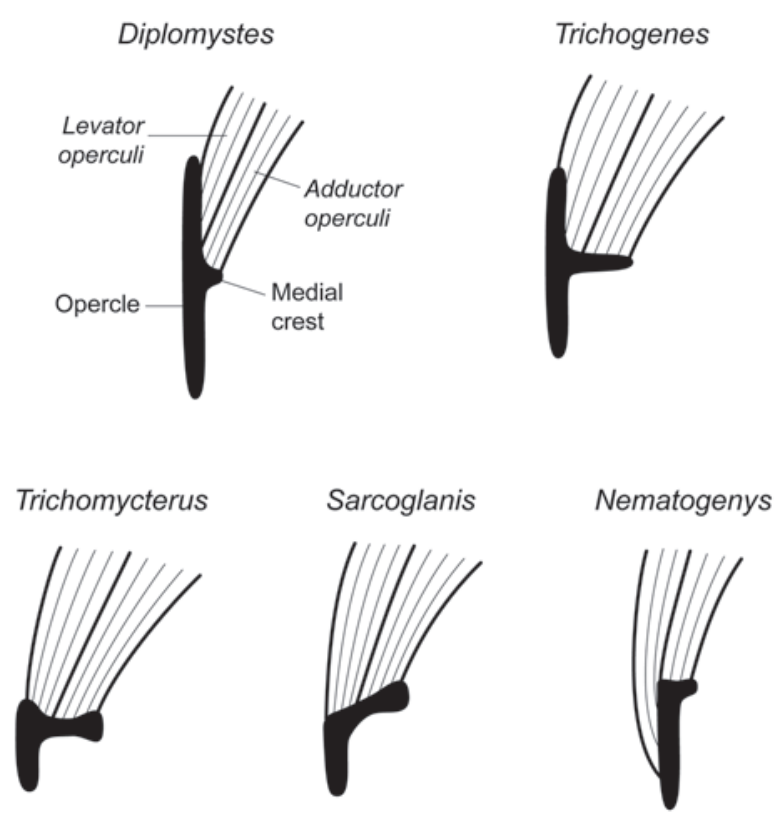

Fig. 35. Schematic representation of a transverse section through posterior region of opercle and attached opercular muscles of various catfishes. 
In addition to the just discussed character, Diogo (2005) listed several additional new purported autapomorphies for Nematogenys, with three being from the muscular system. We review all of them and evaluate whether they constitute unquestionable autapomorphies for the Nematogenyidae.

The first of these characters is the extensor tentaculi and adductor arcus palatini being "mixed" to each other (Diogo, 2005: Character 221, state 0). The extensor tentaculi (Figs. 1, $3,7,9,10,16,18,20,22,28,29)$, a muscle exclusively found in catfishes, is associated with the movement of the maxillary barbel (Takahasi, 1925; Alexander, 1965; Winterbottom, 1974a; Gosline, 1975; Diogo \& Chardon, 2000). This muscle develops from the anterior portion of the adductor arcus palatini (Takahasi, 1925; Winterbottom, 1974a; Gosline, 1975; Diogo, 2005) which, in the apparent plesiomorphic condition for the Ostariophysi, inserts onto the posterior bones of the suspensorium but not the autopalatine (pers. obs.; cf. Takahasi, 1925; Alexander, 1964; Howes, 1976, 1981, 1984, 1985a, 1985b; Aguilera, 1986). The undivided adductor arcus palatini of Nematogenys inserts onto the suspensorium including the autopalatine. In most other catfishes, the anterior muscular portion attached to the autopalatine is separate from the remaining muscle mass of the adductor arcus palatini and, as a consequence, is termed the extensor tentaculi. The condition found in the Nematogenyidae, thus, might be viewed as a first evolutionary step along a transformation series in direction of the total differentiation of the extensor tentaculi from the adductor arcus palatini in the Siluriformes. A similar condition to that of Nematogenys seems to occur in some diplomystids (Diogo, 2005) and the plotosid Plotosus anguillaris (Takahasi, 1925). According to the traditional schemes of relationships of the Siluriformes, wherein the Diplomystidae appears as the basal most lineage of Siluriformes (Grande, 1987; Mo, 1991; de Pinna, 1998), the non-separation of the extensor tentaculi from the adductor arcus palatini might, indeed, constitute an autapomorphy for the Nematogenyidae. Consequently, the occurrences of the same condition in the Diplomystidae and in Plotosus would have independently evolved, given that cetopsids, all non-nematogenyid loricarioids, and most other catfishes have these muscles fully separated from each other (pers. obs.; Takahasi, 1925; Alexander, 1964; Howes, 1983a, 1983b; Diogo, 2005). Under the phylogenetic scheme of Sullivan et al. (2006), however, the condition in Nematogenys, as well as that of the Diplomystidae, would merely be the retention of a plesiomorphic state that appears at the base of Siluriformes and, therefore, is not a valid autapomorphy for Nematogenyidae.

Another supposed autapomorphy for the Nematogenyidae proposed by Diogo (2005) is an adductor arcus palatini covering a significant part of the lateral surface of metapterygoid (his "ento-ectopterygoid”), a character homoplastically found, according to that author, in the ariid genera Arius and Genidens (Diogo, 2005: Character 237, state 1). We confirm this condition in Nematogenys and Genidens (Arius was not examined by us), and in addition we also found it to be present, albeit to a lesser degree, in the trichomycterid Trichogenes. That condition is, in fact, distinct from that found in most other catfishes, where the adductor arcus palatini inserts solely onto the medial face of the suspensorium. However, the lateral insertion of the anterior part of the adductor arcus palatini onto the lateral surface of the metapterygoid may be, again, a mere retention of a plesiomorphic state arisen much earlier in the evolution of the ostariophysans, especially under the phylogeny proposed by Sullivan et al. (2006). The same condition is found in the gonorynchiform Chanos (pers. obs.; Howes, 1985: fig. 3), some cypriniforms (Howes, 1978: 55, fig. 43; Howes, 1984: 287, fig. 4A), and apparently all Characiformes (pers. obs.; Howes, 1976) and Gymnotiformes (pers. obs.).

The final supposed myological autapomorphy for the Nematogenyidae proposed by Diogo (2005: Character 219, state 1 ) is the A3" section of the adductor mandibulae originating from both the suspensorium and neurocranium (vs. originating solely from the suspensorium). As recognized by Diogo (2005), this is a highly homoplastic character found in many other siluriforms, including the Auchenipteridae, Chacidae, Clariidae, Hypophthalmus (Pimelodidae), Plotosidae, and Pseudopimelodidae. Furthermore, an A3" originating from the suspensorium and neurocranium is found in almost all members of the Gymnotiformes (at least in the Apteronotidae, Hypopomidae, Rhamphichthydae, and the basal Gymnotidae; pers. obs.; Aguilera, 1986), the sister-group of Siluriformes. Again, in the scheme of Sullivan et al. (2006) this feature should be interpreted as synapomorphic for the clade formed by Siluriformes plus Gymnotiformes (Fink \& Fink, 1981), rather than constituting an autapomorphy for the Nematogenyidae.

A final clarification in relation to the adductor mandibulae of Nematogenyidae is required. A researcher referring to the literature to identify and name the sections of this muscle in the Siluriformes would probably be, at minimum, confused. In addition to the problems regarding the homology among the facial sections of this muscle and the incredible number of different names applied to its sections (cf. Takahasi, 1925; Winterbottom, 1974a; Gosline, 1989; Diogo \& Chardon, 2000; Wu \& Shen, 2004; Schaefer \& Provenzano, 2008; Geerinckx et al., 2009), another more frustrating issue arises. Different authors apparently "see" very different subdivisions in this muscle in a same taxon. The case of Nematogenys inermis well illustrates this situation. Its adductor mandibulae has been reported as having two (Howes, 1983a, 1983b) or even five different sections (Diogo et al., 2006).

In order to attempt to conduct an unbiased investigation of the discrepancies involving the adductor mandibulae of the Nematogenyidae, we present herein not only our drawing in lateral view of this muscle (Fig. 1B) but also the photograph from which it was based (Fig. 1A), its photograph in medial view (Fig. 2), and the reproduced illustrations of Howes (1983a) (Fig. 36A) and Diogo et al. (2006) (Fig. 36B). According to Diogo et al. (2006), the adductor mandibulae of Nematogenys is divided into the following five sections: "A1-ost”, “A2", 
“A3'-d”, “A3'-v”, and “A3"”. Howes (1983a, b), on the other hand, describes and illustrates it as having only "inner" and "outer" "divisions [... . not well differentiated" (Howes, 1983a: p. 12; fig. 7). Our observations are far more in agreement with those of Howes (1983a, b) than those of Diogo et al. (2006). We also found a more distinct division of the adductor mandibulae of Nematogenys between a portion lateral and another medial to the levator arcus palatini. Accordingly, the "outer division" of Howes (1983a, 1983b) corresponds to the section herein named A2 plus the A3', while his "inner division" corresponds to our A3". Howes (1983b) also reports that the ventral part of his "outer" division inserts onto the lateral face of angulo-articular, while its dorsal portion inserts onto the dorsal rim of dentary, which largely agrees with our descriptions of A2' and A2", respectively. Although not
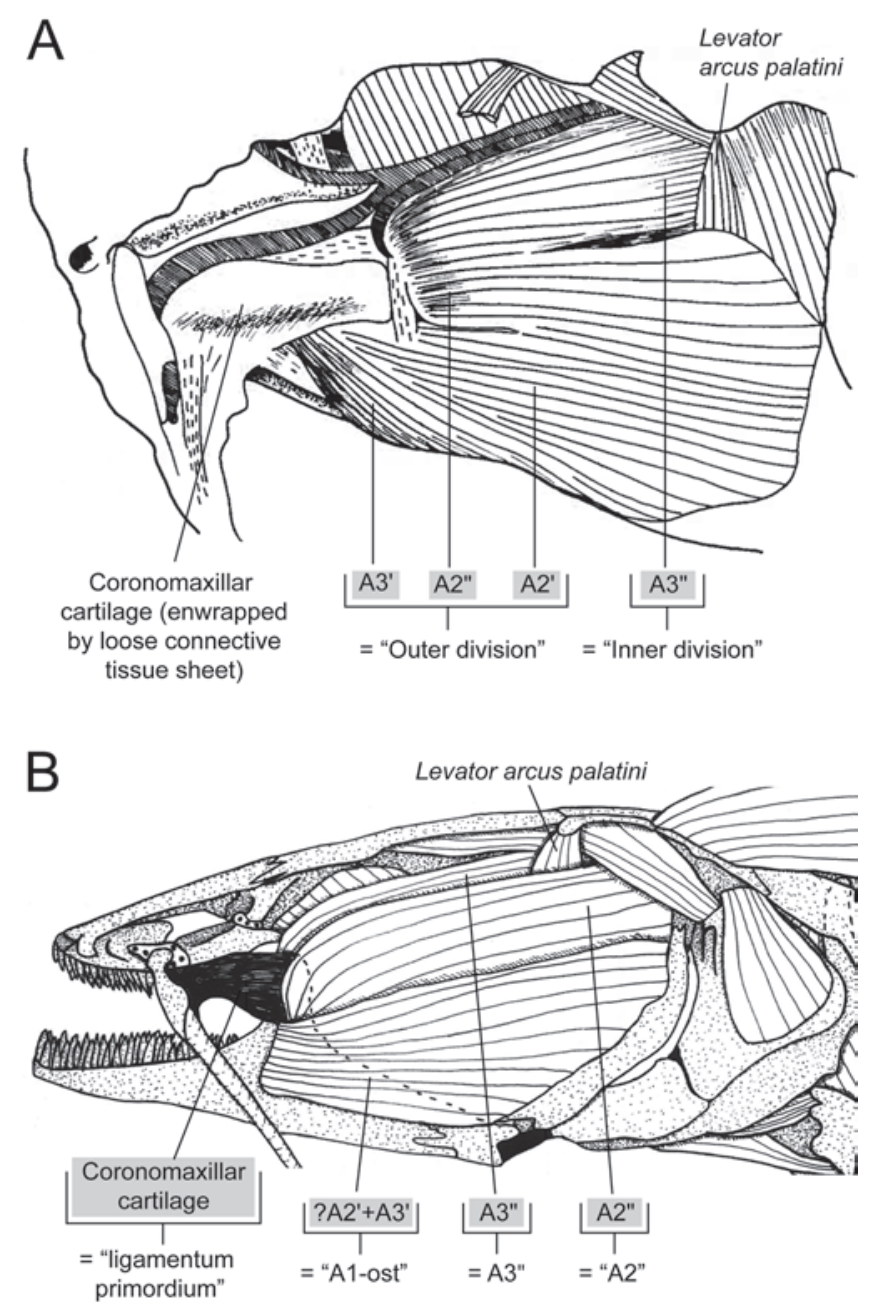

Fig. 36. Illustrations of cranial musculature of Nematogenys inermis by (A) Howes (1983a) (right dorsolateral view of anterior region of head) and (B) Diogo et al. (2006) (right lateral view of head). Both illustrations flipped horizontally to facilitate comparisons with other figures. Drawings not altered, but labels modified in order to clarify different names for portions of adductor mandibulae (see explanation on text). Terminology used in the present study marked with gray background. discussed in the text, Howes' (1983a) illustration also confirms such distinction of the insertion of his "outer" portion (see Fig. 36A; note also the deflection ventrad of the A2" towards its insertion). We may also clearly indentify in this illustration a ventral portion of fibers oriented anterodorsally towards the insertion, perfectly corresponding to the configuration of our A3' (compare Figs. 1 and 36A).

Comparisons with the data provided by Diogo et al. (2006) are much more complicated. These authors omit any statement about the degree of separation among the reported five sections of the adductor mandibulae of Nematogenys inermis. Such sections are described and illustrated by Diogo et al. (2006: 21, fig. 1) as being completely separated from each other, a statement strongly discordant with our observations and those of Howes (1983a, 1983b). In an attempt to match the results of Diogo et al. (2006) with our observations, we could more confidently infer a correspondence among only two of their sections: their "A2" seems to be equivalent to our A2", and their "A3"” to our also termed A3" (Fig. 36B). Based on an overall positional correspondence, the "A1-ost" of Diogo et al. (2006) may, perhaps, correspond to our A2' plus the A3', although the typical distinct fiber orientation of these sections in lateral view was not represented in their illustration (compare Figs. 1 and 36A with Fig. 36B). Diogo's et al. (2006) sections “A3'-d" and “A3'$v$ " are even more problematic since they were not illustrated and do not confidently match none of the sections identified by us or by Howes (1983a, 1983b).

\section{Trichomycteridae}

The monophyly of Trichomycteridae is strongly supported by several unambiguous synapomorphies: "body" of the interopercle compact, not laminar (Figs. 3, 7, 9, 11, 15, $20,22,28,38$ ); interopercle with posteroventral odontodebearing expansion (Figs. 3, 7, 9, 10, 11, 16, 18, 20, 22, 23, 28, 29, 38); anteroventral part of opercle compact, not laminar, forming an elongate stem (Figs. 3, 7, 9, 10, 15, 16, 22, 38); opercle and interopercle linked by strong ligament(s) (Figs. 3, 7, 9, 11, 14, $18,20,22,38 \mathrm{~B}$ ); crest and posterior spine of the parietosupraoccipital absent (Fig. 10); rictal barbels with internal core inserting on the maxilla (Figs. 3, 7, 9, 10, 15, 16, 18, 20, 22, 23,28 ); first pectoral-fin ray not forming a spine; and scapulocoracoids not running in parallel at midline (Baskin, 1973; de Pinna, 1992, 1998). Since the lacking of an opercular patch of odontodes in most copionodontines was recently demonstrated as being a reversal (Bichuette et al., 2008; see "Discussion: Copionodontinae and Trichogeninae" below), the presence of that patch on the region just posterior to the medial crest of the opercle (Figs. 7, 9, 10, 16, 18, 20, 22, 27, 28, 29,38 ) is considered to be an additional synapomorphy for the family (Baskin, 1973: 39-40). In this study, we have discovered two additional myological synapomorphies for the family: the presence of secondary-dorsal (Character 29) and secondary-ventral (Character 32) sections of the dilatator operculi. Since these sections correspond to subdivisions of a single section that may be poorly divided in the basal 
most trichomycterids, one could argue that these characters should be merged into a single character, i.e., the presence of secondary section of the dilatator operculi. This would, indeed, be the most appropriate approach if we are comparing trichomycterids with other catfishes. That is, trichomycterids may be diagnosed from other Siluriformes by the possession of a secondary section of the dilatator operculi. However, since each of these subdivisions of the secondary section may be independently absent (see Character 29) or modified in several ways (see Characters $30,31,33$ ) within the Trichomycteridae, the better approach for the purposes of an intrafamilial comparative study is that herein adopted, the recognition of two sections and the codification of two distinct characters concerning their presence.

The presence of a secondary section of the dilatator operculi has been indirectly reported for the Trichomycteridae in the previous literature. Howes (1983b: 329), Diogo (2005: Character 245, state 2), and Adriaens et al. (2010: 348) pointed out that the dilatator operculi of trichomycterids was divided into two parts. They do not recognize, however, that only one of these parts, the primary section, corresponds to the dilatator operculi of other siluriforms (see Character 25) and that only the acquisition of an additional portion, the secondary section, is unique to trichomycterids (see Characters 29 and 32). Diogo (2005: Character 242, state 1) still cites a dilatator operculi originating from the dorsal surface of the neurocranium as an additional synapomorphy for the Trichomycteridae. This reported origin is, however, characteristic of only the secondary-dorsal section of the dilatator operculi. Since the presence of this section is already a synapomorphy for the Trichomycteridae, that character of Diogo (2005) is redundant in our analysis.

\section{Internal relationships of the Trichomycteridae}

The currently most accepted hypothesis on the higherlevel phylogenetic relationships within the Trichomycteridae was supported primarily on skeletal traits, plus some few features from the soft anatomy and behavior ( $c f$. de Pinna, 1998). The single myological character utilized in the previous morphological phylogenies is the presence of the protractor operculi muscle, which was proposed as a synapomorphy for the non-copionodontine, non-trichogenine trichomycterid clade (de Pinna, 1992). Taking into account this scenario, our main purpose in generating a cladogram of the Trichomycteridae using characters exclusively gathered from observations of dorsolateral muscles of head, is to test that hypothesis (basically the same summarized by de Pinna, 1998) utilizing a new source of cladistic information. To undertake an overall cladistic analysis of the Trichomycteridae, encompassing all previously employed characters from the literature and those herein proposed (morphological total evidence), is beyond the scope of this study. Such achievement would demand two time consuming procedures. First, a complete and rigorous review of all published data, not its mere incorporation into a data matrix, since many of these characters seem not be valid for the level in which they were initially proposed in face to the subsequent discovery of new taxa and/or when considered within a more encompassing comparative context (see, for example, the discussion about monophyly of the Trichomycterinae below). Secondly, an increase in the number of taxa studied for myology in order to include representatives of subgroups of Trichomycteridae poorly sampled and rarely available for dissections such as some tridentines and glanapterygines.

Notwithstanding those limitations, we compare our hypothesis of phylogenetic relationships within the Trichomycteridae with those of other authors, discussing the agreements and discrepancies between them. The cladogram of the relationships among the subfamilies of the Trichomycteridae based solely on the myological dataset herein gathered is contrasted in Fig. 37 with the correspondent combined phylogenetic tree based on other morphological and behavioral data from literature (basically that summarized by de Pinna, 1998: fig. 10). The synapomorphies from literature which are not related to the muscles herein surveyed but that corroborate the clades that we obtained in our analysis are merely enumerated (unless stated otherwise) in the sections below. Characters that contradict our results and support different topologies were revised and discussed whenever possible.

\section{Copionodontinae and Trichogeninae}

According to our scheme of relationships, the subfamilies Copionodontinae and Trichogeninae form a monophyletic assemblage (Clade B) that is the sister-group of all other remaining trichomycterids (Clade $\mathrm{C}$ ). In the present analysis, the monophyly of Clade B is supported by a single unreversed

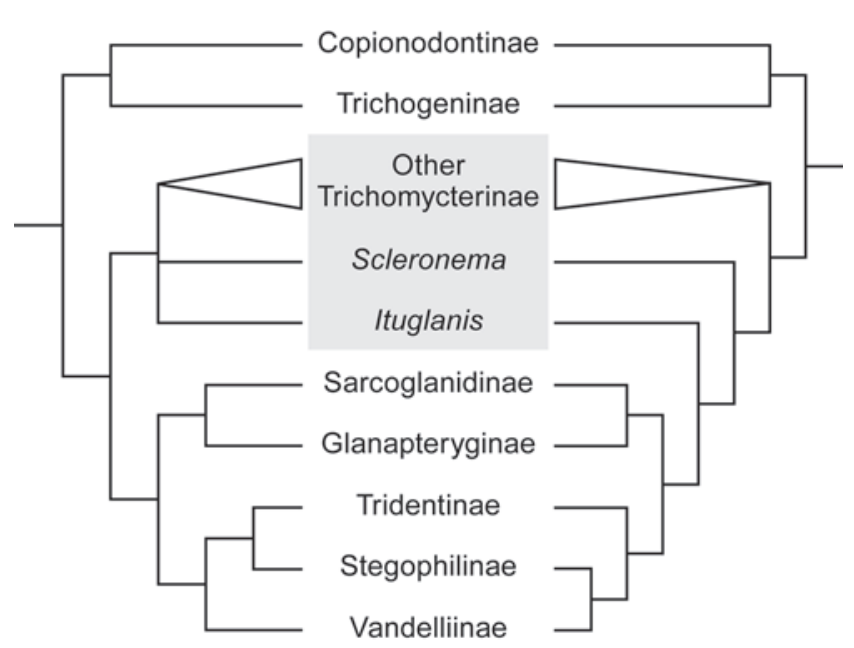

Fig. 37. Diagram comparing phylogenetic relationships of subfamilies of Trichomycteridae according to the present analysis of dorsolateral head muscles (left) and to the literature based on other morphological and behavioral characters (right). Tree from literature is compilation of hypotheses of Baskin (1973); Britski \& Ortega (1983); Arratia (1990); de Pinna \& Britski (1991); de Pinna (1992, 1998); Costa \& Bockmann (1993, 1994); Bockmann et al. (2004); and Bichuette et al. (2008). Gray area represents subfamily Trichomycterinae. 
myological synapomorphy: the presence of the adductor hyomandibulae muscle (Character 17). This new data from myology reinforces the hypothesis of sister-group relationship among these subfamilies as suggested by de Pinna (1998) and subsequently corroborated by Bichuette $e t$ al. (2008) (Fig. 37), and rejects the previous proposal that the Copionodontinae and Trichogeninae are successive sistergroups of the remaining trichomycterids (de Pinna, 1992). In supporting the monophyly of the Clade B, de Pinna (1998) suggested the following synapomorphies: possession of a "peculiar" process at the anterolateral corner of the first hypobranchial (see Bichuette et al., 2008: fig. 6); enlarged subtemporal fossa rendering the pterotic hollow in ventral view; endopterygoid ankylosed to the ventral surface of the autopalatine; and elongated hypurapophysis.

One myological autapomorphy for the examined member of the Copionodontinae was found, the A3" section of the adductor mandibulae inserting primarily onto the maxilla, thereby forming a so-called retractor tentaculi muscle (Character 7, state 1). In addition, the insertion of the extensor tentaculi on both the autopalatine and metapterygoid is considered to be an autapomorphy for the Trichogeninae (Character 13). Additional autapomorphies for the Copionodontinae and Trichogeninae are provided by de Pinna (1992) and Britski \& Ortega (1983), respectively.

\section{The "Clade C"}

The group composed of all non-copionodontine, nontrichogenine trichomycterids (Clade C) is well supported in the previous literature (Fig. 37) on the basis of sharing the following derived characters: sphenotic, prootic, and pterosphenoid fused (Figs. 9, 10, 13, 16, 18, 20, 22, 23, 28, 29); incomplete infraorbital branch of the of the latero-sensory canal system; Weberian capsule with a small opening, much smaller than its lateral profile (Fig. 22); interhyal absent; anterior cranial fontanel partially or completely closed (Figs. $10,16,18,23,26,29$ ); five or fewer pelvic-fin rays; dorsal caudal-fin plate with six or fewer rays; ventral caudal-fin plate with eight or fewer rays; dorsal caudal-fin lobe with five or fewer branched rays; and ventral caudal-fin lobe with six or fewer branched rays (de Pinna, 1992, 1998; Bockmann et al., 2004). The Clade $C$ is further diagnosed by the hitherto single known myological synapomorphy for an internal clade of Trichomycteridae: the presence of the protractor operculi muscle (de Pinna, 1992). Our study corroborates the validity of this character (Character 19), recovering this clade and establishing an additional synapomorphy for the lineage, the fibers of the levator operculi being posterodorsally directed towards its origin (Character 34).

\section{Trichomycterinae}

In the previous literature, the adductor mandibulae of trichomycterines was described by Howes (1983b), Schaefer \& Lauder (1986), and Adriaens et al. (2010). The description of Schaefer \& Lauder (1986: 493) is somewhat obscure, especially for the identification of an "A1" section.
Unfortunately, the absence of illustrations and a more detailed description of the muscle prevented us of confidently compare their results with ours.

Adriaens et al. (2010) described the adductor mandibulae of Trichomycterus guianensis as having a portion lateral and another medial to the levator arcus palatini. Howes (1983b) also referred to an "outer portion" and a "medial section". These descriptions are mostly in agreement with our observations. In the outer portion, Adriaens et al. (2010) recognized three subdivisions: "A1-OST", “A2A3' $\alpha$ ” and "A2A3' $\beta$ ". Their "A1-OST” seems to correspond to a ventral bundle of our A2' (Fig. 11: arrow). In some trichomycterines we examined the fibers of the A2' originating just below the tendon shared with the protractor operculi are slightly more prominent, forming a bundle that is, sometimes, only posteriorly separated from the remaining dorsal fibers by a delicate fascia (Fig. 11). Anteriorly, this ventral bundle completely fuses with the remaining fibers of the A2'. Among the material we examined, that ventral bundle is identifiable only in Ituglanis cf. gracilior, Scleronema angustirostris, Trichomycterus cf. iheringi, and some individuals of $T$. davisi. In all remaining examined trichomycterines, as well as in most other trichomycterids, the A2' lacks any kind of subdivision (Figs. 3, 7, 9, 14, 15, 20, 22). An apparently undivided outer portion of the adductor mandibulae in the Trichomycteridae was also briefly reported and illustrated by Howes (1983b). That implies that the "A1-OST" of Adriaens et al. (2010) is completely fused to their "A2A3'” in most other trichomycterids, being also subject of some intraspecific variation. Note that the "A1-OST" of Adriaens et al. (2010) corresponds to only a ventral bundle of the A2' in Trichomycterus guianensis, whereas the "A1-ost” of Diogo et al. (2006) apparently corresponds to the entire A2' plus part of the A3' in Nematogenys inermis (see "Discussion: Nematogenyidae"; Fig. 36B). This type of ambiguity in discriminating and identifying the sections of the adductor mandibulae according to the terminology of Diogo \& Chardon (2000) seems to occur in many other catfish groups (pers. obs.). That is one of the main reasons that lead us to avoid their nomenclature until a more detailed and comprehensible revisionary study of the adductor mandibulae in Teleostei is available.

Adriaens et al. (2010) reported the absence of an evident subdivision between their A3' and the remaining outer part of the adductor mandibulae (A2) in Trichomycterus guianensis. For that reason, they adopted the compound name "A2A3'”. An obvious separation by fascia between the $\mathrm{A} 2$ and the A3' is also absent in all trichomycterines examined by us (Fig. 10). Nevertheless, the group of fibers corresponding to the A3' may be clearly recognizable from a medial view in many trichomycterines examined by us (see Fig. 12). In contrast to the description of Adriaens et al. (2010: 344), the A3' of all the trichomycterines we examined is anterior rather than lateral to the levator arcus palatini (see Fig. 12).

A bipennate A2 as reported for Trichomycterus guianensis (Adriaens et al., 2010) was not found in any trichomycterine 
that we examined. The most similar condition encountered was that of Trichomycterus cf. iheringi, which has a superficially tripennate A2' (Fig. 11).

Howes (1983b) reported a medial section of the adductor mandibulae for trichomycterines (his “? $\mathrm{A}_{2}$ ”). Adriaens et al. (2010) also refers to such a section (A3") passing medial to the levator arcus palatini in Trichomycterus guianensis. Those descriptions permit us to confidently homologize that part with our A3". However, an A3" passing medial to the levator arcus palatini was encountered in some trichomycterines only (Scleronema angustirostris, Ituglanis proops, I. cf. gracilior, Trichomycterus brasiliensis, $T$. candidus, T. corduvensis, $T$. cf. iheringi, and T. maracaya) and should not to be taken as a universal landmark for distinguishing this muscle section. An A3" is undoubtedly present in all the remaining trichomycterines, but it lies anterior to the levator arcus palatini, as in trichogenines and the sarcoglanidines Microcambeva and Stauroglanis.

Within Clade C, all examined specimens of Bullockia, Hatcheria, Ituglanis, Scleronema and Trichomycterus were united into a monophyletic group (Clade D) in sharing one unique homoplasy-free apomorphy: the posterior portion of the levator internus 4 originating from the dorsal face of the posttemporo-supracleithrum (Character 35). This clade would correspond to the composition of the Trichomycterinae of Arratia (1990), which also includes Eremophilus, Rhizosomichthys, and Silvinichthys (none available for dissection by us). The Arratia's (1990) Trichomycterinae would also comprise Ituglanis, a genus that was described later by Costa \& Bockmann (1993) to include some species previously assigned to Trichomycterus.

Arratia (1990) proposed four putative synapomorphies for the Trichomycterinae. Three of them were found in all trichomycterines examined in this study (including the species of Ituglanis and Scleronema). The only exception is "Trichomycterus" hasemani (de Pinna, 1998; pers. obs.), which is retained in Trichomycterinae by default only due the absence of a formal subfamilial assignment for it, being known to be closely related to the Tridentinae (de Pinna, 1989b; see paragraph below). All these three characters of Arratia (1990), however, are also encountered in many other nontrichomycterine trichomycterids, as discussed below. The vomer with only one long posterior process (Arratia, 1990) is found at least in the copionodontine Copionodon pecten (pers. obs.; Fig. 6), the Trichogeninae (pers. obs.), the sarcoglanidines Microcambeva ribeirae (pers. obs.) and Sarcoglanis simplex (pers. obs.; Claeson et al., 2008), the glanapterygine Glanapteryx anguilla (pers. obs.; de Pinna, 1989b: fig. 5b), the tridentine Tridentopsis (pers. obs.), and the stegophilines Parastegophilus paulensis (pers. obs.), Pseudostegophilus nemurus (pers. obs.) and Pareiodon microps (pers. obs.). The enarthrodial articulation ("ball-andsocket” joint) between the preopercle and opercle in adults (Arratia, 1990) is present at least in the sarcoglanidines Ammoglanis pulex (pers. obs.), Microcambeva barbata (pers. obs.), Microcambeva ribeirae (pers. obs.), and, in a less- developed condition, in the Trichogeninae (pers. obs.; Fig. 7). Finally, the pronounced notch on the posteromedial (= "posteroventral" of Arratia, 1990: 396-397) margin of the third ceratobranchial is also present at least in the following nontrichomycterines: the glanapterygines Listrura camposi (pers. obs.) and Pygidianops eigenmanni (Baskin, 1973: fig. 84), the sarcoglanidines Microcambeva ribeirae (pers. obs.), Stauroglanis (de Pinna, 1989a: fig. 9), Malacoglanis (pers. obs.), and Sarcoglanis (pers. obs.), and the tridentine Tridentopsis pearsoni (pers. obs.). The fourth purported synapomorphy for the Trichomycterinae of Arratia (1990), the presence of a well-developed anterior membranous process of the basioccipital lying ventrolateral to the parasphenoid and prootic, was found in most, but not all, trichomycterines examined by us. Such a process is absent in Trichomycterus punctulatus (Adriaens et al., 2010: 341), T. guianensis (Adriaens et al., 2010: 341), Ituglanis gracilior (pers. obs.), and I. macunaima (pers. obs.; Datovo \& Landim, 2005: fig. 2B). It is unclear what Arratia (1990) meant by “a well-developed" membranous process because we have found a series of intermediate states ranging from a vestigial eminence to a very pronounced structure among the trichomycterines studied. Trichomycterus maracaya bears the relatively smallest process on only one side of the basioccipital, while on the other side the process is completely absent (pers. obs.). A similarly small process is also present on both sides of the basioccipital of trichogenines (pers. obs.). Outside the Trichomycterinae, a large laminar process comparable to that found in most trichomycterines was encountered in one specimen of the glanapterygine Glanapteryx anguilla examined by us ( $59.4 \mathrm{~mm}$ SL specimen of MZUSP 36530), although such a process is apparently absent in the specimen illustrated by de Pinna (1989b: fig. 5b). Because all four characters provided by Arratia (1990) to support the monophyly of Trichomycterinae have obvious broader distributions across the Trichomycteridae, we refute them as valid synapomorphies for that level.

In contrast to the conclusion of Arratia $(1990,1998)$, other studies in the recent years proposed that some members of the Trichomycterinae are more closely related to other lineages of the family than to other trichomycterines (e.g. de Pinna, 1989a; Costa \& Bockmann, 1993). De Pinna (1989a) proposed the removal of Trichomycterus hasemani and T.johnsoni from Trichomycterus suggesting that they were more closely related to the Tridentinae than to any other member of the Trichomycterinae. This hypothesis of relationships was based mainly on the retention of an obvious juvenile feature in these taxa, the single enormously expanded cranial fontanel (Fig. 20; de Pinna, 1989a). This character has apparently evolved several times during trichomycterid radiation, being also found in the sarcoglanidine Ammoglanis and the vandelliines Paravandellia and Paracanthopoma (pers. obs.; Baskin, 1973; de Pinna, 1989a). Nonetheless, the material of "Trichomycterus" hasemani we studied seems to confirm de Pinna's (1989a) suggestion (we have not obtained material of "T." johnsoni for our analysis). Since the placement of " $T$." 
hasemani and "T." johnsoni in a subfamily other than the Trichomycterinae is already underway by M. C. C. de Pinna and W. Wosiacki (pers. comm.), we do not herein discuss additional evidences for such a reassignment. The only feature that we will mention is that " $T$." hasemani lacks the posterior part of levator internus 4 muscle originating from the dorsal face of the posttemporo-supracleithrum; the character that unites all other members of the Trichomycterinae in our analysis (Clade D). For the sake of convenience, whenever we thenceforth refer to Trichomycterinae, we are not including " $T$ ". hasemani and " $T$ ". johnsoni in this subfamily.

Myers \& Weitzman (1966) first suggested that Scleronema could be more closely related to the Sarcoglanidinae based on a shared enlargement of the maxilla (Fig. 16). De Pinna (1989a) further advanced this proposal and suggested that Trichomycterus boylei and, perhaps, T. santaeritae might also be included in this group because they similarly exhibit relatively enlarged maxillae and share a convex anterior mesial border of the mesethmoid, although these features are less conspicuous in the referred trichomycterines than in the Sarcoglanidinae. Several later studies, however, rejected this concept of affinity. Enlargement of the maxilla is also found in Bullockia and Hatcheria (Arratia, 1990), Trichomycterus aguarague, T. alterus, T. belensis, and T. ramosus (Fernández \& Osinaga, 2006). The same situation applies to the convexity of the anterior border of mesethmoid that seems to be a highly intraspecifically variable trait found in many other trichomycterines including Hatcheria, Bullockia, and some species of Trichomycterus (Arratia, 1990), Trichomycterus davisi and Ituglanis gracilior (pers. obs.), along with many other trichomycterids and Nematogenys (pers. obs.; de Pinna, 1989a). Arratia (1990) also highlights that a convex anterior mesial border of the mesethmoid was absent in most individuals of Trichomycterus boylei examined by her (13 of 14). All specimens of Scleronema angustirostris examined by us also lack that feature. Furthermore, the subsequent discovery that the Sarcoglanidinae composes a monophyletic group with the Glanapteryginae (Clade H) (Costa \& Bockmann, 1993, 1994; de Pinna, 1998; current work) unequivocally rejects a closer affinity of these trichomycterines with the Sarcoglanidinae.

Costa \& Bockmann (1993) erected Ituglanis, a new genus of the Trichomycterinae, to encompass several species previously assigned to Trichomycterus. In this same publication, the authors postulated that Ituglanis and Scleronema were closely related to the TSVSG clade, with Scleronema being the sister-group of Ituglanis plus TSVSG (Fig. 37). Two synapomorphies were proposed as evidence for the most inclusive clade. One of them was the reduction of the interopercular patch of odontodes (Costa \& Bockmann, 1993; de Pinna, 1998). According to that hypothesis, the interopercular patch of odontodes in Scleronema and Ituglanis are of an intermediate size, and thus an intermediate state in an ordered transformation series, between the elongated patch present in the Copionodontinae (Fig. 3), Trichogeninae (Fig. 7), and the remaining Trichomycterinae (Fig. 9), versus the reduced odontode patch characteristic of
TSVSG members (Figs. 15, 20, 22, 28). In fact, the interopercular patch of odontodes of TSVSG members is distinctly shorter than those of other trichomycterids, and as a result their condition was expressed in quantitative terms: "with 15 or fewer odontodes" by Costa \& Bockmann (1994) and "nearly as long as deep" by de Pinna (1998). The supposed intermediate state, however, has never been defined with precisely quantified terms, as noted by Fernández \& de Pinna (2005), rendering the distinction between "reduced" and "elongate" interopercular patch of odontodes somewhat vague, if not arbitrary. Regardless, the interopercular patch of odontodes of at least one Ituglanis species, I. proops, is clearly more elongate than those of many other trichomycterines (Fig. 38A). Furthermore, an "intermediately reduced" interopercular patch is also present in other trichomycterines such as Trichomycterus stawiarski (Fig. 38B) and Silvinichthys bortayro (Fernández \& de Pinna, 2005). Thus, under the originally proposed phylogenetic scheme (Costa \& Bockmann, 1993; Pinna, 1998) (Fig. 37, right side), the reduction of the interopercular patch of odontodes independently occurred several times with, at least, one reversion in I. proops. This hypothesis, notwithstanding, is still only tangential to a major problem with this purported feature: the continuous gradation of size of the interopercular patch of odontodes between "large" and the "intermediately reduced" such as is observed throughout different trichomycterine taxa (pers. obs.). Following our examination of a broad sampling of taxa across the Trichomycteridae, we confirm the surmise of Fernández \& de Pinna (2005) and reject this character as evidence for the monophyly of the group formed by Scleronema, Ituglanis, and TSVSG.

The second character provided by Costa \& Bockmann (1993) to support the clade Scleronema + Ituglanis + TSVSG was the tips of lateral process of parurohyal (= "urohyal"; see "Material and Methods: Anatomical nomenclature") being thin and elongated. Although many trichomycterines exhibit parurohyals with stout and rounded lateral processes (Fig. 39A; Bockmann et al., 2004: fig. 8), others, such as Trichomycterus alternatus, $T$. maracaya, $T$. pauciradiatus, $T$. reinhardti, and $T$. stawiarski (pers. obs.), along with Silvinichthys mendozensis (Arratia, 1998: fig. 9), have parurohyals with thin and elongated lateral processes that are very similar to those found in Ituglanis and Scleronema. Trichomycterus cf. itatiayae has a more extreme condition with its parurohyal bearing lateral processes even thinner and more elongate that those of many species of Ituglanis (Fig. 39B). Alternatively, an undescribed Ituglanis from the Rio Tocantins and upper Rio Paraná basins (Ituglanis sp. 1) has its parurohyal much less thin and elongate than those of several species of Trichomycterus (Fig. 39C). As is the case with the reduction of the interopercular patch of odontodes discussed in the preceding paragraph, the thinness and elongation of parurohyal lateral processes seem to be developed to varying degrees across Trichomycterus and Ituglanis, with a continuum of intermediate states between the more extreme conditions. These results raise doubts as to the phylogenetic utility of this character for delimiting the clade Scleronema + Ituglanis + TSVSG. 
A third final character proposed to corroborating the clade consisting of Scleronema + Ituglanis + TSVSG was the possession of three or fewer abdominal vertebrae (de Pinna, 1998). The term "abdominal vertebrae" was used by de Pinna (1998) to refer to those free vertebrae (not involved to Webberian apparatus) lacking both haemal arches and spines (de Pinna, pers. comm.). Our findings disagree with this purported synapomorphy. The large majority of the Ituglanis examined in the course of our study have more than three abdominal vertebrae, with some species having up to nine and most species six; the sarcoglanidine Ammoglanis
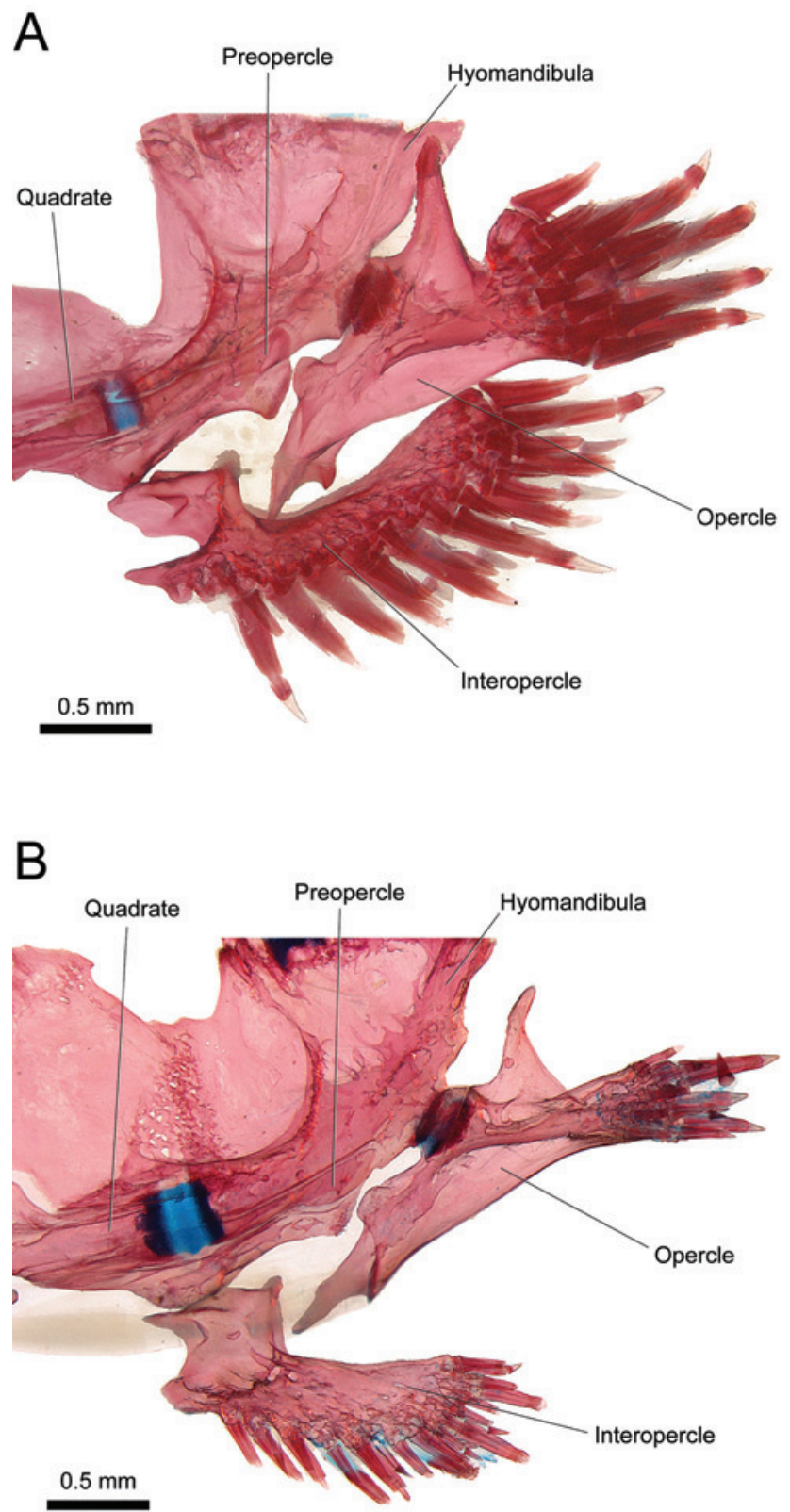

Fig. 38. Lateral view of posteroventral region of suspensorium and opercular series of (A) Ituglanis proops, MZUSP 60255 (77.0 mm SL), right side, image flipped horizontally to facilitate comparisons; (B) Trichomycterus stawiarski, LIRP 5088 (50.1 mm SL), left side. diaphanus has four; the stegophilines Ochmacanthus flabelliferus, Pareiodon microps and Haemomaster venezuelae, respectively, five, seven, and eight. Additionally, at least one member of the Trichomycterinae sensu stricto has three of fewer abdominal vertebrae: Trichomycterus alterus, which, according to Fernández \& Vari (2002), has from three to five precaudal vertebrae (all abdominal vertebrae are necessarily precaudal too). These observations lead us to reject the character proposed by de Pinna (1998) as
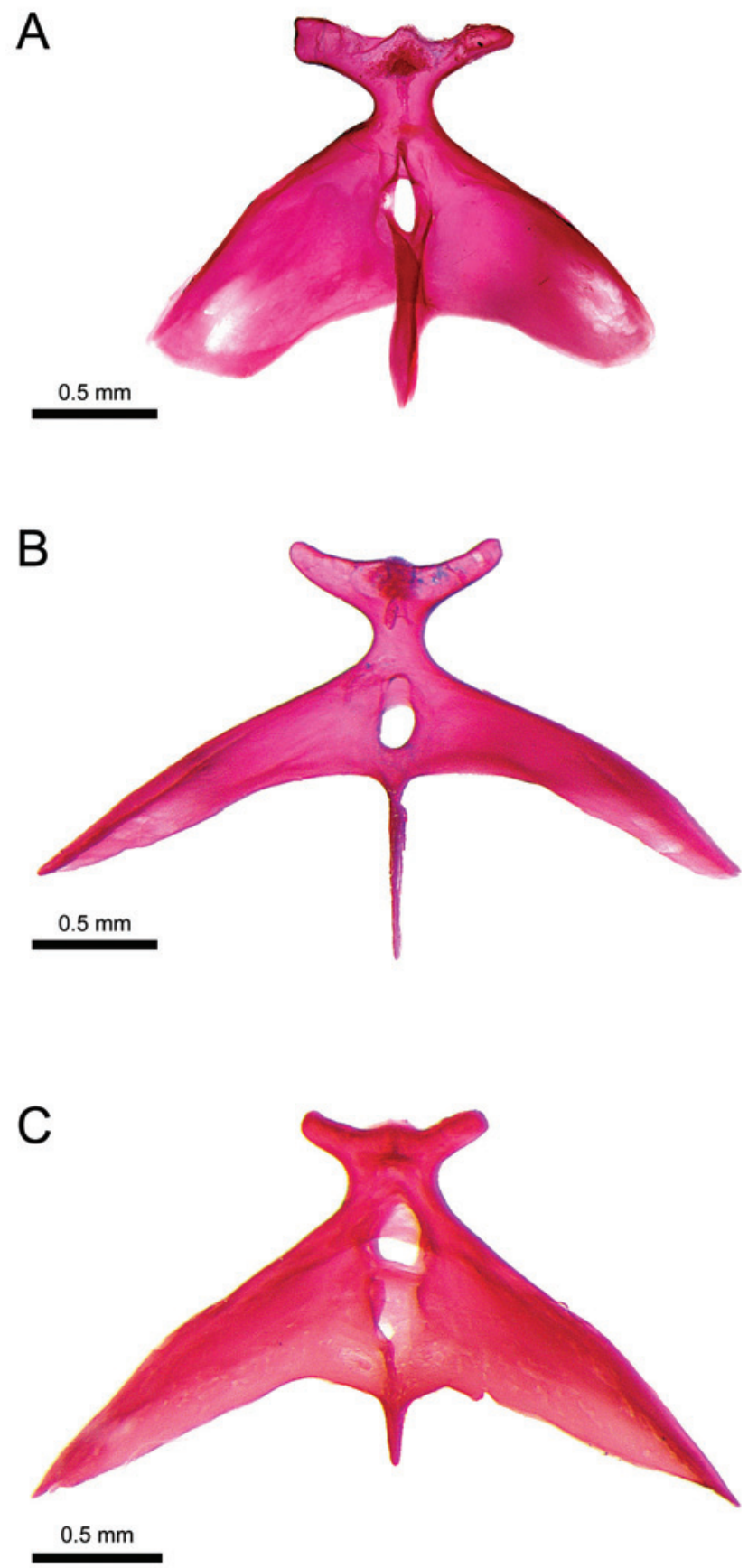

Fig. 39. Ventral view of parurohyal of (A) Trichomycterus davisi, LIRP 2798 (56.7 mm SL); (B) Trichomycterus cf. itatiayae, LIRP 5086 (43.3 mm SL) and (C) Ituglanis sp. 1, MCP 15930 (53.3 mm SL). 
evidence for the monophyly of the group formed by Scleronema, Ituglanis, and TSVSG.

As previously noted, it was hypothesized that Ituglanis is the sister-group of the TSVSG clade (Costa \& Bockmann, 1993; de Pinna, 1998). In supporting this arrangement, Costa \& Bockmann (1993) proposed that these taxa shared a reduced number of ribs (= "pleural ribs"; see "Material and methods: Anatomical nomenclature") which, according to de Pinna (1998: 309), ranged from one to six pairs. However, Ituglanis passensis, described subsequently to that analysis, exhibits seven ribs (Fernández \& Bichuette, 2002). Other members of the TSVSG clade also have more than six ribs, such as the stegophilines Haemomaster venezuelae and Pareiodon microps (seven and six or seven, respectively; pers. obs.). Costa \& Bockmann (1994) furthermore explicitly point out that within the TSVSG clade the number of ribs varies from one to eight pairs. Thus, a modification of this character might be suggested to be eight or fewer pairs of ribs. Nonetheless, other non-Ituglanis trichomycterines exhibit fewer or overlapping rib counts. Trichomycterus guianensis has six pairs of ribs (pers. obs. of radiograph of type; Morris et al., 2006); T. conradi, seven pairs (pers. obs. of radiograph of type; Morris et al., 2006); Bullockia, from seven to 10 pairs (Arratia et al., 1978); T. latidens, eight pairs (pers. obs. of radiograph of type; California Academy of Sciences, 2007); T. gorgona, eight or nine pairs (Fernández \& Schaefer, 2005). Therefore, a reduction in the number of ribs seems to have occurred independently several times during trichomycterid evolution, and its utility in supporting the Ituglanis + TSVSG clade is feeble, at best.

Given these evidences, it seems clear that the only taxa that must be certainly excluded from the Trichomycterinae is "Trichomycterus" hasemani and, possibly, "T." johnsoni (de Pinna, 1989a). All remaining hypotheses attempting to demonstrate closer affinities of certain trichomycterines to other trichomycterid subfamilies (de Pinna, 1989a, 1998; Costa \& Bockmann, 1993) are based on invalid or, at best, doubtful characters. On the other hand, none of the previously proposed synapomorphies for the Trichomycterinae are valid (Arratia, 1990). The only character that may potentially indicate the monophyly of the subfamily is the posterior part of the levator internus 4 originating from the dorsal face of the posttemporo-supracleithrum (Character 35). This character was found in all trichomycterines examined in the current study, being absent in all remaining trichomycterids and nematogenyids. Notwithstanding, we do not want to overestimate the phylogenetic value of this character. The previous paragraphs illustrate how various morphological traits in the Trichomycteridae show a high degree of interand intraspecific variation. This fact, in addition to the enormous diversity of the Trichomycterinae, demands a more encompassing investigation of the distribution of that myological character across the Trichomycterinae. Only such a broad investigation can more confidently assess its phylogenetic reliance and confirm whether the character is synapomorphic for the whole subfamily or for a less inclusive group of the Trichomycterinae.

\section{Monophyletic groups within the Trichomycterinae}

Two monophyletic groups within Trichomycterinae were identified in our analysis. One of them unites four trichomycterines from Chile and Argentina - Hatcheria macraei, Bullockia maldonadoi, Trichomycterus areolatus, and T. chiltoni - with two species from Atlantic Coastal drainages of Brazil - T. immaculatus and T. zonatus - into a monophyletic group (Clade E). This clade is diagnosed by the possession of a secondary-ventral section of the dilatator operculi significantly expanded anteriorly at the region of its insertion, rendering a triangular shape to that section in lateral view (Character 33). Costa (1992) suggested that many species of Trichomycterus from Atlantic Coastal drainages from Brazil might be more closely related to each other than to other Trichomycterus from central Brazil. It would be interesting to determine whether these other species also exhibit the triangular secondary-ventral section that herein unites the members of the Clade $\mathrm{E}$.

The other clade obtained within Trichomycterinae is formed by Trichomycterus davisi and T. stawiarski (Clade F) on the basis of one unique shared apomorphy, the extensor tentaculi originating from both the neurocranium and suspensorium (Character 12). These species inhabit similar geographic areas, with Trichomycterus davisi occurring in the Brazilian drainages of the rio Paranapanema and rio Iguaçu, and T. stawiarski only occurring in the rio Iguaçu basin (de Pinna \& Wosiacki, 2003; pers. obs.). A survey on the presence of this character in Trichomycterus igobi and $T$. crassicaudatus, both recently described from the Rio Iguaçu basin and though to be closely allied to $T$. stawiarski (Wosiacki \& de Pinna, 2008a, 2008b), would be useful to determine whether all these four species form a monophyletic group.

The cladogram arrived at herein has the examined species of Trichomycterus distributed across the tree for the Trichomycterinae, with some species appearing more closely related to species belonging to other genera (within Clade E) than to other species of Trichomycterus (Clade F). This result is not surprising given that the genus, as currently conceived, is strongly suspected to be non-monophyletic (Baskin, 1973; de Pinna, 1989a, 1998), being diagnosed by the lack of the synapomorphies that characterize the other genera of the subfamily. Nonetheless, the taxonomic reallocation of the species of Trichomycterus phylogenetically allied to other genera is premature at this moment. Nomenclatural changes would require a detailed and, above all, more encompassing analysis within the Trichomycterinae in order to avoid the proliferation of ambiguous taxonomic categories.

\section{The Clade TSVSG}

The TSVSG clade (Clade G) is a large intrafamilial monophyletic group in the Trichomycteridae formed by the subfamilies Tridentinae, Stegophilinae, Vandelliinae, Sarcoglanidinae, and Glanapteryginae. This assemblage was first recognized by Costa \& Bockmann (1993) and is currently supported by three shared derived osteological characters: 
the absence of a posterior process of the parasphenoid; the extreme reduction or absence of the metapterygoid (Figs. 16, 18); and the reduction of the interopercular patch of odontodes that renders that patch nearly as long as deep (Figs. 15, 20, 22, 28) (Costa \& Bockmann, 1993; de Pinna, 1998). Relationships among these subfamilies also have strong support in the molecular analyses of the Trichomycteridae by Fernández \& Schaefer (2009). The monophyly of the TSVSG clade is herein corroborated (Clade $\mathrm{G}$ ) by the discovery of one homoplasy-free synapomorphy: the primary section of the dilatator operculi passing dorsolateral to the levator arcus palatini (Character 26). Since all the proposed skeletal synapomorphies for the TSVSG clade are presumably reductive, it might be argued that they are more prone to be homoplastic, throwing doubts on the monophyly of that group. The discovery of one non-reductive myological synapomorphy is particularly interesting because it corroborates those skeletal features as valid synapomorphies at the level to which were proposed, notwithstanding their putative paedomorphic natures.

\section{Sarcoglanidinae and Glanapteryginae}

Our study supports the hypothesis of a sister-group relationship between the Sarcoglanidinae and Glanapteryginae (Clade $\mathrm{H}$ ), thereby corroborating the previous proposals of Costa \& Bockmann (1994), Fernández \& Schaefer (2009), and, in part, that of Baskin (1973). Members of these two subfamilies were united in our analysis based on sharing one homoplasy-free myological synapomorphy: the insertion of the A3" section of the adductor mandibulae onto the buccopalatal membrane (Character 7, state 2). The following characters were proposed as additional synapomorphies for the Clade H: reduced vomer; reduced number of premaxillary teeth; quadrate with a posteriorly-directed anterodorsal process; anterior portion of the hyomandibula modified into a long process (Figs. 16, 18); and seven or fewer anal-fin rays (Baskin, 1973; Costa \& Bockmann, 1994; de Pinna, 1998). Nevertheless, many of these putative synapomorphies are of difficult polarization and known to exhibit a considerable degree of homoplasy (de Pinna 1989a, 1998; Costa \& Bockmann, 1994; de Pinna \& Winemiller, 2000) thus requiring a more comprehensive study in order to confirm their phylogenetic signals.

The Glanapteryginae was represented in our analysis by only two species of Listrura, the basal most genus of the subfamily (de Pinna, 1988, 1989b). The monophyly of the Glanapteryginae was not recovered and, as a consequence, neither was that of Listrura, which is nonetheless a readily identifiable and well-diagnosed genus (de Pinna, 1988, 1989b; Landim \& Costa, 2002). The unresolved phyletic status of the Glanapteryginae (or Listrura) in this study was due to the lack of informative myological characters instead of incongruent information.

The monophyly of the Sarcoglanidinae has been reexamined during the last two decades, as a consequence of the successive discovery of new taxa (e.g. de Pinna, 1989a; de Pinna \& Starnes, 1990; Costa \& Bockmann, 1994; Costa, 1994; de Pinna \& Winemiller, 2000). According to Costa (1994) three skeletal synapomorphies support the monophyly of the Sarcoglanidinae: lateral process of premaxilla pointed; enlarged maxilla (Fig. 16); and premaxilla with a ventral expansion. Costa (1994) also postulated Ammoglanis and Microcambeva respectively as successive close relatives to the group composed of the remaining members of the subfamily. Despite provisionally maintaining Ammoglanis in Sarcoglanidinae, de Pinna \& Winemiller (2000) cast some doubts on the proper phylogenetic placement of the genus, suggesting that it might represent a new subfamily which would be the sister-group of the TSVSG clade. Unfortunately, we were unable to exam the cranial muscles of Ammoglanis. Two specimens of Ammoglanis diaphanus underwent the same process of skeleton staining applied to all other terminaltaxa in this study. However, the soft tissues of these individuals became strangely fully translucent, despite not being processed for digestion of muscle. This prevented the examination of the myology of the genus. Our sample of the Sarcoglanidinae consequently was limited to Microcambeva, Sarcoglanis, and Stauroglanis, and these genera formed a monophyletic group (Clade I) supported by the following three homoplasy-free synapomorphies: fibers of main axis of the protractor operculi posteroventrally oriented towards its insertion (Character 23); an extremely reduced primary section of the dilatator operculi (Character 25, state 1); and a secondary-dorsal section of the dilatator operculi with the central axis posteromedially oriented towards its origin (Character 30). Additional osteological synapomorphies for the Clade I are: lateral process of the premaxilla elongate and presence of a separate ossification on the anterior cartilage of the autopalatine (Costa, 1994).

In our analysis, Microcambeva is the sister-group of the clade formed by Sarcoglanis and Stauroglanis (Clade J), with these two genera sharing one homoplasy-free synapomorphy, the primary section of the dilatator operculi lacking (Character 25, state 2). That scheme is fully congruent with previous hypotheses in which the Stauroglanis is considered to be the sister-group of the clade consisting of Sarcoglanis and Malacoglanis (de Pinna, 1989a; Costa, 1994). According to Costa (1994), a group equivalent to our Clade J is diagnosed by the common possession of: convex medial border of the mesethmoid (de Pinna, 1989a); reduced number of interopercular odontodes (up to four) (Figs. 15, 16); and widened dorsal process of the quadrate.

One myological autapomorphy for Microcambeva ribeirae was also discovered in our analysis: the protractor operculi and secondary-ventral section of the dilatator operculi continuous with each other and forming a compound muscle (Character 20).

\section{The Vandelliinae-group}

Inside the TSVSG clade, the subfamilies Stegophilinae, Tridentinae, and Vandelliinae appears as a well-supported monophyletic unit (Clade K) based on the common possession 
of five unique synapomorphies: A2 and A3 sections of the adductor mandibulae completely separated from each other (Character 5); A3 section of the adductor mandibulae originating from the anterior region of the suspensorium, but not reaching the autopalatine (Character 8, state 1); insertion of the A3 section of the adductor mandibulae onto the lower jaw extending anteriorly beyond the Meckel's cartilage (Character 11; reversed in the Tridentinae); origin of the levator arcus palatini broader than its insertion (Character 18); and origin of the primary section of the dilatator operculi anteriorly expanded beyond the olfactory foramen (Character 27). These are more than the four characters accepted by the Pinna (1998) as diagnostic for the Vandelliinae-group: absence of the antorbital (= "lacrimal" of some studies); lateral opening of the Weberian capsule at the end of a neck-like constriction; jaw teeth "S-shaped" (Figs. 20, 22, 24, 25, 28); and mesethmoid cornu with a ventral process (Figs. 22, 23, 28).

\section{Tridentinae and Stegophilinae}

In our cladogram the Tridentinae and Stegophilinae appears as sister-groups to each other (Clade L), while the Vandelliinae is closely akin to the clade formed by these two subfamilies. This proposition is at variance with to the most commonly accepted hypothesis which postulates that the Stegophilinae and Vandelliinae are more closely than either is to the Tridentinae (Baskin, 1973; de Pinna \& Britski, 1991; de Pinna, 1998; Fernández \& Schaefer, 2009) (Fig. 37). In our study, we discovered one character that is shared only by stegophilines and vandelliines: the A3 section of the adductor mandibulae with insertion onto the lower jaw extending anteriorly beyond the Meckel's cartilage (Character 11). On the other hand, two other derived characters were uniquely found in the Stegophilinae and Tridentinae: the origin of the A3 section of the adductor mandibulae distinctly narrow, being less than one quarter of the width of its insertion (Character 9); and the A3 section of the adductor mandibulae with origin both musculous and tendinous (Character 10, state 1). Therefore, in the parsimony analysis, the monophyly of the lineage formed by the Tridentinae plus Stegophilinae prevailed upon the alternative hypothesis, with the cited character shared by the Stegophilinae and Vandelliinae (Character 11) being optimized as a synapomorphy for the whole Vandelliinae-group with a reversion in the Tridentinae. We note, nevertheless, the relative lack of robustness of the arrangement herein obtained, especially considering the few samples of Tridentinae available for our study. However, as discussed below, the support for the standard hypothesis that postulates the monophyly of the lineage formed by the Stegophilinae plus Vandelliinae seems not to be much higher than the one we obtained.

According to de Pinna (1998), the supposed monophyly of the Stegophilinae and Vandelliinae is supported by three characters: the reduction of the maxillary (Figs. 22, 23) and rictal barbels (Figs. 22, 23, 28, 29); the presence of a median premaxilla (Figs. 22, 23, 28, 29); and the possession of semiparasitic feeding habits. However, as previously noted by
Baskin (1973) and we agree, the latter character cannot be taken as undisputable synapomorphy for this group. The feeding habits of the Tridentinae in nature are as yet unknown. However, the teeth of the Tridentinae and Stegophilinae have a very peculiar morphology and arrangement on the jaws which suggests that these subfamilies share a similar mode of feeding. Furthermore, as noticed by Weitzman (apud Baskin, 1973: 146), specimens of tridentine appear to chase characids in aquarium settings. A similar behavior also was recently registered for Tridentopsis in both aquarium (FAB, pers. obs.) and field observations (Stewart apud Adriaens et al., 2010: 352). This behavior may be indicative of lepidophagy and/or mucophagy, suggesting that the semi-parasitic feeding habits may be a synapomorphy for the whole Vandelliinae-group (Clade K). To further complicate the issue, Baskin (1973), although proposing the monophyly of the clade Stegophilinae plus Vandelliinae, pointed out four characters shared by many tridentines and stegophilines. These are: the premaxillary and dentary teeth very fine, numerous, and arranged in distinct rows (Figs. 20, 22, 24, 25); the presence of one or more premaxillary teeth rows implanted in the flesh of the upper lip (Fig. 22); a mouth width greater than the width of the neurocranium; and the "S-shaped" jaw teeth. While the last character is actually synapomorphic for the whole Vandelliinae-group (de Pinna, 1998) the other features might be informative at this level. It is noteworthy that all the above cited morphological characters purportedly synapomorphic for both the two alternative hypotheses of relationships among the subfamilies of the Vandelliinae-group (Fig. 37) are not homoplasy-free. Apparently, a well-supported hypothesis of the phylogenetic relationships among the Tridentinae, Stegophilinae, and Vandelliinae should be achieved only when accompanied by the elucidation of the internal relationships within each subfamily, especially the two former where most homoplasies occurs. Only such an approach seems to be able to confidently assert the phylogenetic signal and the proper optimization for the above cited characters. Unfortunately, such achievement is beyond the scope of this study and the more appropriate approach at present seems to represent the phylogenetic relationships among the subfamilies of Vandelliinae-group as an unresolved basal polytomy.

\section{Tridentinae}

One autapomorphy has been discovered for the single member of the Tridentinae examined in our study: the protractor operculi originating from both the suspensorium and the fascia of the levator arcus palatini (Character 24, state 2). Additional synapomorphies for the subfamily are provided by Baskin (1973).

\section{Stegophilinae}

The monophyly of the subfamily Stegophilinae currently has a weak morphological support inasmuch as four of the six synapomorphies proposed by Baskin (1973) were rejected by de Pinna \& Britski (1991). Only the presence of a mouth opening forming a wide crescent shape disc and, perhaps, 
the presence of a scapulo-coracoid ring were considered valid synapomorphies for the whole subfamily (de Pinna \& Britski, 1991). In the present study, the monophyly of the Stegophilinae (Clade M) was corroborated by one homoplasyfree synapomorphy: the possession of a protractor operculi much shorter than deep (Character 22).

Resolution of the relationships within Stegophilinae in our analysis is also largely compatible with the scheme proposed by Baskin (1973) and DoNascimiento \& Provenzano (2006) on the basis of morphological data, and especially the maximum parsimony tree by Fernández \& Schaefer (2009), on the basis of mitochondrial and nuclear gene sequences. The incongruences between our proposed scheme of relationships and the previous phylogenies of the Stegophilinae (Baskin, 1973; Fernández \& Schaefer, 2009) are minor, and they rest mainly on the interchangeable position of the three consensually accepted basal genera: Haemomaster, Homodiaetus, and Ochmacanthus. According to our analysis, Haemomaster is the sister-group of all other genera of the Stegophilinae. The non-Haemomaster stegophilines are united into a clade (Clade $\mathrm{N}$ ) based on the common possession of a primary section of the dilatator operculi meeting its counterpart along the mid-sagittal plane (Character 28). The basal position of Haemomaster is also recovered by molecular data of Fernández \& Schaefer (2009). Baskin (1973) also accepted a relative basal position of Haemomaster although he indicated Ochmacanthus as the most basal member of the subfamily. In the phylogeny of Fernández \& Schaefer (2009), Ochmacanthus is the sister-group of the nonHaemomaster stegophilines.

One of the most conspicuous features of the monotypic Haemomaster is its enormously enlarged lateral eye (Fig. 23). Some peculiar modifications of its cranial morphology are probably coupled with this feature. One of them is the origin of the wide secondary-ventral section of the dilatator operculi that, in this taxon, is strongly attached to eyeball capsule. Contrary to expectations, this attachment does not seem to serve to move the eyeball. Direct manipulation in preserved specimens and analysis of the attachment sites of this muscle seem to indicate that the contraction of the secondary-ventral section of the dilatator operculi is unable to rotate or otherwise move the eyeball. The contraction of this section in this case seems to play the same role as it does in most other trichomycterids, i.e., the abduction of the opercular patch of odontodes. Such a result is made possible by the stout eyeball capsule that has an anterior projection firmly anchored to the tip of the mesethmoid cornu (Fig. 23: arrow). The eyeball capsule, thus, should act simply as an intermediary that connects the secondary-ventral section of the dilatator operculi to the mesethmoid cornu. This mechanism might also explain the robust and posteriorly curved form of the mesethmoid cornua of Haemomaster (Fig. 23). These features seem to constitute adaptations to strengthen the cornu in order to deal with the intense forces that are applied to its tip during the contraction of the robust secondary-ventral section of the dilatator operculi. An eyeball capsule anteriorly anchored to the mesethmoid cornu and/or with attached fibers of the secondary-ventral section of the dilatator operculi is found also in some other stegophilines and vandelliines. However, their conditions are much less developed than that of Haemomaster. The eyeball capsule in these other stegophilines and vandelliines is extremely thin, with only a few fibers of the dilatator operculi weakly attached to it and the secondary-ventral section of the dilatator operculi itself being much atrophied. Thus, the mechanism described above for Haemomaster effectively does not occur in these other taxa. The condition found in these taxa may nonetheless represent the primitive condition that provides the elements necessary for the development of the derived mechanism present in Haemomaster.

In our analysis, Homodiaetus appears as the sister-groups of the non- Haemomaster stegophilines, as revealed by two homoplasy-free synapomorphies shared by Ochmacanthus, Pareiodon, Parastegophilus, and Pseudostegophilus (Clade $\mathrm{O})$ : the insertion of the anterodorsal fibers of the A2' section of the adductor mandibulae onto the buccopalatal membrane (Character 1); and the fully tendinous origin of the A3 section of the adductor mandibulae (Character 10, state 2). Baskin (1973) did not include Homodiaetus in his analysis (Parastegophilus was misidentified as such according to DoNascimiento \& Provenzano, 2006: 203). This genus appears as the sister-group of the non-Haemomaster, nonOchmacanthus stegophilines in the molecular analysis of Fernández \& Schaefer (2009).

Inside Clade O, the group composed of Parastegophilus, Pareiodon, and Pseudostegophilus (Clade P) is supported by one unique synapomorphy, the secondary-dorsal section of the dilatator operculi anteromedially expanded at its origin and contacting anteriorly its counterpart along the midsagittal plane (Character 31, state 1). This group may correspond at least to part of the well-corroborated Pareiodonclade (Baskin, 1973; DoNascimiento \& Provenzano, 2006; Fernández \& Schaefer, 2009), which also includes Acanthopoma, Henonemus, Megalocentor, and possibly Apomatoceros (DoNascimiento \& Provenzano, 2006; Fernández \& Schaefer, 2009), genera not included in this study. The Pareiodon-clade is diagnosed by the possession of a single medial epiphyseal pore (s6) in the supraorbital latero-sensory canal (Fig. 27) and of two rows of superficial neuromasts on the base of the caudal fin (Baskin, 1973; DoNascimiento \& Provenzano, 2006).

Pareiodon is nested within the Stegophilinae, as the sister-group of Pseudostegophilus (Clade Q), a relationship supported by two unique unreversed synapomorphies: the secondary-dorsal section of the dilatator operculi fully medially expanded at its origin and meeting its counterpart along the entire medial border at the mid-sagittal plane (Character 31, state 2); and the border of the anterodorsal trunk muscles on the posterodorsal region of the skull distinctly convex at the mid-sagittal plane (Character 36). This result differs from the position of Pareiodon in Baskin's (1973) phylogeny, as the most basal genus of the Pareiodon-clade, 
but it is fully congruent with molecular analysis of Fernández \& Schaefer (2009) after the exclusion of Acanthopoma, Apomatoceros, Henonemus, and Megalocentor, which were not examined by us. Our results reinforce the position of Pareiodon as a member of the Stegophilinae, corroborating the hypothesis that the absence of some subfamilial synapomorphies and other derived characters of higher universality related to the oral complex (e.g. wide crescentshaped mouth, median premaxillae, anterior tooth rows in the upper lips, several rows of teeth on the premaxilla) are secondary modifications, as first proposed by Baskin (1973).

\section{Vandelliinae}

In addition to the notable hematophagous habit in adults, the monophyly of the subfamily Vandelliinae is indicated by several skeletal synapomorphies: claw-like teeth on the distal end of the premaxilla (Figs. 28, 29) enclosed in a pocket of skin; dentaries well separated at midline; presence of a spine-like process on the posterolateral edge of the pterotic; absence of the mesocoracoid; plus several characters related to the reduction of the gill arches (Baskin, 1973; de Pinna, 1998). The clade formed by all vandelliines also has a strong support in the molecular phylogeny (Fernández \& Schaefer, 2009). In our analysis, the monophyly of the Vandelliinae (Clade R) was also well-supported by five homoplasy-free synapomorphies: A3 section of the adductor mandibulae originating exclusively from the autopalatine (Character 8, state 2); presence of the constrictor palatini muscle (Character 14); presence of the hyporostralis muscle (Character 15); presence of the epirostralis muscle (Character 16); and fibers of the protractor operculi inserting onto the base of some of the anteroventral most opercular odontodes (Character 21).

In the internal arrangement of the Vandelliinae of our analysis, Paracanthopoma appears as the basal most genus of the subfamily and Paravandellia and Vandellia are united (Clade $S$ ) based on two unique unreversed synapomorphies: the insertion of the medial part of the A2' section of the adductor mandibulae onto the premaxilla (Character 2); and the origin of the ventral portion of the A2' section of the adductor mandibulae from both the suspensorium and interopercle (Character 3). Such a scheme is fully congruent with the morphological and molecular phylogenies of Baskin (1973) and Fernández \& Schaefer (2009), respectively. However, our hypothesis differs from that of Schmidt (1993) in which Paravandellia is the basal most genus of the subfamily with Paracanthopoma as the sister-group to the remaining vandelliines. Interestingly, in none of these phylogenies, Paracanthopoma and Paravandellia are united into a monophyletic group, despite exhibiting several common paedomorphic features such as the extreme reduction of body size and the poor ossification of the cranial roof. In agreement with these hypotheses, an apparently "reductive" myological feature herein discovered for Paracanthopoma and Paravandellia also appears homoplastically in both genera, the loss of the secondary-dorsal section of the dilatator operculi (Character 29). The monophyly of Vandellia has been previously supported by only a single morphological character (Schmidt, 1993), although molecular data provides strong support to this hypothesis (Fernández \& Schaefer, 2009). We strongly corroborate the hypothesis of the monophyly of Vandellia with four myological synapomorphies: ventral portion of the A2' section of the adductor mandibulae subdivided into superior and inferior portions (Character 4); A3 section of the adductor mandibulae fully subdivided along vertical plane (Character 6); origin of the protractor operculi from both the suspensorium and interopercle (Character 24, state 1); and the primary section of the dilatator operculi meeting its counterpart along the mid-sagittal plane (Character 28).

\section{Acknowledgements}

This paper represents the major part of the Master Dissertation of AD at Universidade de São Paulo (Faculdade de Filosofia, Ciências e Letras de Ribeirão Preto, Dept. Biologia, PPG Biologia Comparada), completed under the supervision of FAB and supported by a scholarship from the Fundação de Amparo à Pesquisa do Estado de São Paulo (FAPESP: 04/05425-0). Marcelo R. Carvalho (Instituto de Biociências, Universidade de São Paulo) and Roberto E. Reis (MCP), members of the dissertation committee of $\mathrm{AD}$, provided valuable suggestions on an earlier version of this work. Special thanks are due to Richard P. Vari (USNM) who patiently reviewed the manuscript and corrected the English. This manuscript was greatly benefited from criticisms of Roberto E. Reis, an anonymous referee, and especially from a detailed and thorough review by Dominique Adriaens. We are very grateful to the following individuals and institutions for allowing us access to specimens under their care: Scott A. Schaefer (AMNH); Luiz R. Malabarba (UFRGS); Amalia Miquelarena (ILPLA and MLP); Lúcia R. Py-Daniel (INPA); Claudio de Oliveira (LBP); Fernando Apone and Júlio Garavello (LISDEBE); Roberto E. Reis, Zilda Margarete S. Lucena, and Carlos A. S. Lucena (MCP); Vinícius Abilhôa (MHNCI); Paulo A. Buckup, Marcelo R. Britto, Gustavo W. Nunan, and Leandro Villa-Verde (MNRJ); Mário C. C. de Pinna, Osvaldo T. Oyakawa, and José L. de Figueiredo (MZUSP); Weferson J. da Graça and Carla S. Pavanelli (NUP); Richard P. Vari (USNM); and Ivan Sazima (ZUEC). We sincerely thank Ricardo M. C. Castro for kindly allowed us to use the equipment for image capture and digital illustration under his care (FAPESP: 04/ 09219-6). Veronica Slobodian assisted us in editing some drawings. Fernando Apone helped with the cataloguing of specimens. Hertz F. dos Santos cleared and stained some specimens. Ivan Sazima provided the original drawing of Trichogenes longipinnis reproduced in Fig. 31. This article is a contribution of the All Catfish Species Inventory Project (NSF: DEB 0315963), which provided grants for the authors and made possible field trips that allowed us to collect some important catfishes used in this study. Research funding for this study came also from the Conselho Nacional de Desenvolvimento Científico e Tecnológico (CNPq: 309291/2007-0 to FAB). 


\section{Literature Cited}

Adriaens, D., J. N. Baskin \& H. Coppens. 2010. Evolutionary morphology of trichomycterid catfishes: about hanging on and digging in. Pp. 337-362. In: Nelson, J. S., H.-P. Schultze \& M. V. H. Wilson (Eds.). Origin and Phylogenetic Interrelationships of Teleosts. München, Verlag Dr. Friedrich Pfeil, 480p.

Adriaens, D. \& W. Verraes. 1996. Ontogeny of cranial musculature in Clarias gariepinus (Siluroidei: Clariidae): the aductor mandibulae complex. Journal of Morphology, 229(3): 255-259.

Adriaens, D. \& W. Verraes. 1997. Ontogeny of the maxillary barbel muscles in Clarias gariepinus (Siluroidei: Clariidae), with some notes on the palatine-maxillary mechanism. Journal of Zoology, London, 241(1): 117-133.

Agnarsson, I. \& J. A. Miller. 2008. Is ACCTRAN better than DELTRAN?. Cladistics, 24(6): 1-7.

Aguilera, O. 1986. La musculatura estriada em los peces gymnotiformes (Teleostei - Ostariophysi): musculatura facial. Acta Biologica Venezuelica, 12(2): 13-23.

Alexander, R. McN. 1964. Adaptation in the skulls and cranial muscles of South American characinoid fish. Zoological Journal of the Linnean Society, 45(305): 169-190.

Alexander, R. McN. 1965. Structure and function in the catfish. Journal of Zoology, London, 148(1): 88-152.

Allis, E. P. 1897. The cranial muscles and cranial and first spinal nerves of Amia calva. Journal of Morphology, 12(3): 486-809.

Amorim, D. S. 1997. Fundamentos de sistemática filogenética. 2a. ed. Ribeirão Preto, Holos Editora \& Sociedade Brasileira de Entomologia, 304p.

Arratia, G. 1983. Preferencias de habitat de peces siluriformes de aguas continentales de Chile (Fam. Diplomystidae y Trichomycteridae). Studies on Neotropical Fauna and Environment, 18(4): 217-237.

Arratia, G. 1987. Description of the primitive family Diplomystidae (Siluriformes, Teleostei, Pisces): morphology, taxonomy and phylogenetic implications. Bonner Zoologische Monographien, 24: 5-120.

Arratia, G. 1990. The South American Trichomycterinae (Teleostei: Siluriformes), a problematic group. Pp. 395-403. In: Peters, G. \& R. Hutterer (Eds.). Vertebrates in the Tropics: Proceedings of the International Symposium on Vertebrate Biogeography and Systematics in the Tropics, Bonn, June 5-8, 1989. Bonn, Alexander Koenig Zoological Research Institute and Zoological Museum.

Arratia, G. 1992. Development and variation of the suspensorium of primitive catfishes (Teleostei: Ostariophysi) and their phylogenetic relationships. Bonner Zoologische Monographien, 32: 1-149.

Arratia, G. 1998. Silvinichthys, a new genus of trichomycterid catfishes from the Argentinian Andes, with redescription of Trichomycterus nigricans. Ichthyological Exploration of Freshwaters, 9(4): 347-370.

Arratia, G., A. Chang, S. Menu-Marque \& G. Rojas. 1978. About Bullockia gen. nov., Trichomycterus mendozensis n. sp. and revision of the family Trichomycteridae (Pisces, Siluriformes). Studies on Neotropical Fauna and Environment, 13(3/4): 157-194.

Arratia, G. \& L. Huaquín. 1995. Morphology of the lateral line system and of the skin of diplomystids and certain primitive loricarioid catfishes and systematic and ecological considerations. Bonner Zoologische Monographien, 36: 1-110.

Arratia, G. \& H. -P. Schultze. 1990. The parurohyal: development and homology within osteichthyans. Journal of Morphology, 203(3): 247-282.
Baskin, J. N. 1973. Structure and relationship of the Trichomycteridae. Unpublished Ph.D. Dissertation, City University of New York, New York, 389p.

Baskin, J. N., T. M. Zaret \& F. Mago-Leccia. 1980. Feeding of reportedly parasitic catfishes (Trichomycteridae and Cetopsidae) in the Rio Portuguesa basin, Venezuela. Biotropica, 12(3): 182-186.

Benjamin, M. 1990. The cranial cartilages of teleosts and their classification. Journal of Anatomy, 169: 153-172.

Bichuette, M. E., M. C. C. de Pinna \& E. Trajano. 2008. A new species of Glaphyropoma: the first subterranean copionodontine catfish and the first occurrence of opercular odontodes in the subfamily (Siluriformes: Trichomycteridae). Neotropical Ichthyology, 6(3): 301-306.

Bockmann, F. A. 1998. Análise filogenética da família Heptapteridae (Teleostei, Ostariophysi, Siluriformes) e redefinição de seus gêneros. Unpublished Ph.D. Dissertation, Universidade de São Paulo, São Paulo, 599p.

Bockmann, F. A., L. Casatti \& M. C. C. de Pinna. 2004. A new species of trichomycterid catfish from the Rio Paranapanema, southeastern Brazil (Teleostei; Siluriformes), with comments on the phylogeny of the family. Ichthyological Exploration of Freshwaters, 15(3): 225-242.

Britski, H. A. \& H. Ortega. 1983. Trichogenes longipinnis, novo gênero e espécie de Trichomycterinae do sudeste do Brasil (Pisces, Siluriformes). Revista Brasileira de Zoologia, 1(3): 211-216.

Britz, R. \& P. Bartsch. 2003. The myth of dorsal ribs in gnathostome vertebrates. Proceedings of the Royal Society of London, Biological Sciences Series B, 270: S1-S4.

Britz, R., K. W. Conway \& L. Rüber. 2009. Spectacular morphological novelty in a miniature cyprinid fish, Danionella dracula n. sp. Proceedings of the Royal Society of London, Biological Sciences (Series B), 276: 2179-2186.

Britz, R. \& G. D. Johnson. 2010. Occipito-vertebral fusion in actinopterygians: conjecture, myth and reality. Part 1: Nonteleosts. Pp. 77-93. In Nelson, J. S., H. -P. Schultze \& M. V. H. Wilson (Eds.). Origin and phylogenetic interrelationships of teleosts. München, Verlag Dr. Friedrich Pfeil.

Burgess, W. E. 1989. An atlas of freshwater and marine catfishes: a preliminary survey of the Siluriformes. Neptune, Tropical Fish Hobbyist, 784p.

California Academy of Sciences. 2007. Dept. of Ichthyology Primary Types Imagebase. Available at: http://research.calacademy.org/ research/Ichthyology/Types/index.asp. Accessed February 1, 2007.

Claeson, K. M., J. W. Hagadorn, K. Luckenbill \& J. G. Lundberg. 2008. Anatomy of the very tiny: first description of the head skeleton of the rare South American catfish Sarcoglanis simplex (Siluriformes: Trichomycteridae). Palaeontologia Electronica, 11(2): 1-11.

Costa, W. J. E. M. 1992. Description de huit nouvelles espèces du genre Trichomycterus (Siluriformes: Trichomycteridae), du Brésil oriental. Revue Française d'Aquariologie et Herpetologie, 18(4), for 1991: 101-110.

Costa, W. J. E. M. 1994. A new genus and species of Sarcoglanidinae (Siluriformes: Trichomycteridae) from the Araguaia basin, central Brazil, with notes on subfamilial phylogeny. Ichthyological Exploration of Freshwaters, 5: 207-216.

Costa, W. J. E. M. \& F. A. Bockmann. 1993. Un nouveau genre Néotropical de la famille des Trichomycteridae (Siluriformes: Loricarioidei). Revue Française d'Aquariologie, 20(2): 43-46.

Costa, W. J. E. M. \& F. A. Bockmann. 1994. A new genus and species of Sarcoglanidinae (Siluriformes: Trichomycteridae) from southeastern Brazil, with a re-examination of subfamilial phylogeny. Journal of Natural History, 28(3): 715-730. 
Datovo, A. \& M. I. Landim. 2005. Ituglanis macunaima, a new catfish from the rio Araguaia basin, Brazil (Siluriformes: Trichomycteridae). Neotropical Ichthyology, 3(4): 455-464.

Datovo, A. \& R. P. Vari. in prep. Review and synonymy of the adductor mandibulae muscle complex in the major groups of the Teleostei.

Devincenzi, G. J. \& G. W. Teague. 1942. Ictiofauna del Río Uruguay Medio. Anales del Museo de Historia Natural de Montevideo, ser. 2, 5(4): 1-104.

Dingerkus, G. \& L. D. Uhler. 1977. Enzyme clearing of alcian blue stained whole small vertebrates for demonstration of cartilage. Biotechnic and Histochemistry. Stain Technology, 52(4): 229-232.

Diogo, R. 2005. Morphological evolution, aptations, homoplasies, constraints and evolutionary trends: catfishes as a case study on general phylogeny and macroevolution. Enfield, Science Publishers, Inc, 502p.

Diogo, R. 2007. Osteology and myology of the cephalic region and pectoral girdle of Heptapterus mustelinus, comparison with other heptapterins, and discussion on the synapomorphies and phylogenetic relationships of the Heptapterinae and the Pimelodidae (Teleostei: Siluriformes). International Journal of Morphology, 25(4): 735-748.

Diogo, R. \& D. Bills. 2006. Osteology and myology of the cephalic region and pectoral girdle of the South African catfish Austroglanis gilli, with comments on the autapomorphies and phylogenetic relationships of the Austroglanididae (Teleostei: Siluriformes). Animal Biology, 56(1): 39-62.

Diogo, R. \& M. Chardon. 2000. Homologies among different adductor mandibulae sections of teleostean fishes, with special regard to catfishes (Teleostei: Siluriformes). Journal of Morphology, 243(2): 193-208

Diogo, R., M. Chardon \& P. Vandewalle. 2004. Osteology and myology of the cephalic region and pectoral girdle of Batrochoglanis raninus, with a discussion on the synapomorphies and phylogenetic relationships of the Pseudopimelodinae and Pimelodidae (Teleostei: Siluriformes). Animal Biology, 54(3): 261-280.

Diogo, R., M. Chardon \& P. Vandewalle. 2006. On the osteology and myology of the cephalic region and pectoral girdle of Nematogenys inermis (Guichenot, 1848), with comments on the autapomorphies and phylogenetic relationships of the Nematogenyidae (Teleostei: Siluriformes). Belgian Journal of Zoology, 136(1): 15-24.

Diogo, R. \& P. Vandewalle. 2003. Review of superficial cranial musculature of catfishes, with comments on plesiomorphic states. Pp. 47-69. In: Arratia, G., B. G. Kapoor, M. Chardon \& R. Diogo (Eds.). Catfishes. Enfield, Science Publishers Inc, 812p.

DoNascimiento, C. \& F. Provenzano. 2006. The genus Henonemus (Siluriformes: Trichomycteridae) with a description of a new species from Venezuela. Copeia, 2006(2): 198-205.

Eigenmann, C. H. 1918. The Pygidiidae, a family of South American catfishes. Memoirs of the Carnegie Museum, 7(5): 259-398.

Eschmeyer, W. N. \& J. D. Fong. 2010. Species of Fishes by family/ subfamily. Available at: http://research.calacademy.org/ redirect?url=http://researcharchive.calacademy.org/research/ Ichthyology/catalog/fishcatmain.asp. Accessed May 6, 2010.

Fernández, L. \& M. E. Bichuette. 2002. A new cave dwelling species of Ituglanis from the São Domingos karst, central Brazil (Siluriformes: Trichomycteridae). Ichthyological Exploration of Freshwaters, 13(3): 273-278.
Fernández, L. \& K. Osinaga. 2006. A new Trichomycterus (Siluriformes: Trichomycteridae) from Aguarague National Park of the Bolivian preandean region, with comments on relationships within of the genus. Environmental Biology of Fishes, 75(4): 385-393.

Fernández, L. \& M. C. C. de Pinna. 2005. Phreatic catfish of the genus Silvinichthys from southern South America (Teleostei, Siluriformes, Trichomycteridae). Copeia, 2005(1): 100-108.

Fernández, L. \& S. A. Schaefer. 2005. New Trichomycterus (Siluriformes: Trichomycteridae) from an offshore island of Colombia. Copeia, 2005(1): 68-76.

Fernández, L. \& S. A. Schaefer. 2009. Relationships among the Neotropical Candirus (Trichomycteridae, Siluriformes) and the evolution of parasitism based on analysis of mitochondrial and nuclear gene sequences. Molecular Phylogenetics and Evolution, 52(2): 416-423.

Fernández, L. \& R. P. Vari. 2002. New Species of Trichomycterus from the Andes of Argentina with a redescription of Trichomycterus alterus (Siluriformes: Trichomycteridae). Copeia, 2002(3): 739-747.

Ferraris, C. Jr. 1991. Catfish in the aquarium. Morris Plains, Tetra Press, 199p.

Fink, S. \& W. Fink. 1981. Interrelationships of the ostariophysan fishes (Pisces, Teleostei). Zoological Journal of the Linnean Society, 72(4): 307-353.

Fricke, R. \& W. N. Eschmeyer. 2009. A guide to Fish Collections in the Catalog of Fishes database. Available at: http:// research.calacademy.org/research/ichthyology/catalog/ collections.asp. Accessed September 9, 2009.

Geerinckx, T. \& D. Adriaens. 2008. Ontogeny of the suspensorial and opercular musculature in the suckermouth armoured catfish Ancistrus cf. triradiatus (Loricariidae, Siluriformes). Zoomorphology, 127(2): 83-95.

Geerinckx, T., M. Brunain, A. Herrel, P. Aerts \& D. Adriaens. 2007. A head with a suckermouth: a functionalmorphological study of the head of the suckermouth armoured catfish Ancistrus cf. triradiatus (Loricariidae, Siluriformes). Belgian Journal of Zoology, 137(1): 47-66.

Geerinckx, T., F. Huysentruyt \& D. Adriaens. 2009. Ontogeny of the jaw and maxillary barbel musculature in the armoured catfish families Loricariidae and Callichthyidae (Loricarioidea, Siluriformes), with a discussion on muscle homologies. Zoological Journal of the Linnean Society, 155(1): 76-96.

Goloboff, P. A., J. S. Farris \& K. C. Nixon. 2008. TNT, a free program for phylogenetic analysis. Cladistics, 24(5): 774-786.

Gosline, W. A. 1975. The palatine-maxillary mechanism in catfishes, with comment on the evolution and zoogeography of modern Siluroids. Occasional Papers of the Californian Academy of Sciences, 120: 1-31

Gosline, W. A. 1989. Two patterns of differentiation in the jaw musculature of teleostean fishes. Journal of Zoology, London, 218(4): 649-661.

Goulding, M. 1979. Ecologia da pesca do rio Madeira. Manaus, Instituto Nacional de Pesquisas da Amazônia, 172p.

Goulding, M. 1980. The fishes and the forest, explorations in Amazonian natural history. Berkeley, University of California Press, 280p.

Grande, L. 1987. Redescription of ${ }^{\dagger}$ Hypsidoris farsonensis (Teleostei: Siluriformes), with a reassesment of its phylogenetic relationships. Journal of Vertebrate Paleontology, 7(1): 24-54.

Hadley, A. 2009. CombineZP. GNU public license software. Available at: http://www.hadleyweb.pwp.blueyonder.co.uk/. Accessed July 18, 2008. 
Haseman, J. D. 1911. Descriptions of some new species of fishes and miscellaneous notes on others obtained during the expedition of the Carnegie Museum to central South America. Annals of the Carnegie Museum, 7(3/4): 315-328.

Hertwig, S. T. 2008. Phylogeny of the Cyprinodontiformes (Teleostei, Atherinomorpha): the contribution of cranial soft tissue characters. Zoologica Scripta, 37(2): 141-174.

Howes, G. J. 1976. The cranial musculature and taxonomy of characoid fishes of the tribes Cynodontini and Characini. Bulletin of the British Museum, Natural History, Zoology, 30(4): 203-248.

Howes, G. J. 1978. The anatomy and relationships of the cyprinid fish Luciobrama macrocephalus (Lacepede). Bulletin of the British Museum, Natural History, Zoology, 34(1): 1-64.

Howes, G. J. 1981. Anatomy and phylogeny of the Chinese Major Carps Ctenopharyngodon Steind., 1866 and Hypophthalmichthys Blkr., 1860. Bulletin of the British Museum, Natural History, Zoology, 41(1): 1-52.

Howes, G. J. 1982. Anatomy and evolution of the jaws in the semiplotine carps with a review of the genus Cyprinion Heckel, 1843 (Teleostei: Cyprinidae). Bulletin of the British Museum, Natural History, Zoology, 42(4): 309-335.

Howes, G. J. 1983a. Problems in catfish anatomy and phylogeny as exemplified the Neotropical Hypophthalmidae (Teleostei: Siluroidei). Bulletin of the British Museum, Natural History, Zoology, 45(1): 1-39.

Howes, G. J. 1983b. The cranial muscles of loricarioid catfishes, their homologies and value as taxonomic characters (Teleostei: Siluroidei). Bulletin of the British Museum, Natural History, Zoology, 45(6): 309-345.

Howes, G. J. 1984. Phyletics and biogeography of the aspinine cyprinid fishes. Bulletin of the British Museum, Natural History, Zoology, 47(5): 283-303.

Howes, G. J. 1985a. Cranial muscles of gonorynchiform fishes, with comments on generic relationships. Bulletin of the British Museum, Natural History, Zoology, 49(2): 273-303.

Howes, G. J. 1985b. The phylogenetic relationships of the electric catfish family Malapteruridae (Teleostei: Siluroidei). Journal of Natural History, British Museum, 19(1): 37-67.

Huysentruyt, F., T. Geerinckx \& D. Adriaens. 2007. A descriptive myology of Corydoras aeneus (Gill, 1858) (Siluriformes: Callichthyidae), with a brief discussion on adductor mandibulae homologies. Animal Biology, 57(4): 433-452.

Kelley, W. E. \& J. Atz. 1964. A pygidiid catfish that can suck blood from goldfish. Copeia, 1964(4): 702-704.

Landim, M. I. \& W. J. E. M. Costa. 2002. Listrura tetraradiata (Siluriformes: Trichomycteridae): a new glanapterygine catfish from the southeastern Brazilian coastal plains. Copeia, 2002(1): 152-156.

Lüling, K. H. 1984. Über einige bemerkenswerte Welse Amazoniens. Natur und Museum, 114: 323-327.

Lundberg, J. G., J. P. Sullivan, R. Rodiles-Hernández \& D. A. Hendrickson. 2007. Discovery of African roots for the Mesoamerican Chiapas catfish, Lacantunia enigmatica, requires an ancient intercontinental passage. Proceedings of the Academy of Natural Sciences of Philadelphia, 156: 39-53.

Machado, F. A. \& I. Sazima. 1983. Comportamento alimentar do peixe hematófago Branchioica bertonii (Siluriformes, Trichomycteridae). Ciência e Cultura, 35(3): 344-348.

Maddison, W. P. \& D. R. Maddison. 2009. Mesquite: a modular system for evolutionary analysis, version 2.7. Available at: http://mesquiteproject.org. Accessed September 24, 2009.
Maslin, T. P. 1952. Morphological criteria of phyletic relationships. Systematic Zoology, 1(2): 49-70.

Mo, T. 1991. Anatomy, relationships and systematics of the Bagridae (Teleostei: Siluroidei) with a hypothesis of siluroid phylogeny. Köenigstein, Koeltz Scientific Books (Theses Zoologicae, 17), 217p.

Morris, P. J., H. M. Yager [programmers] \& M. H. Sabaj Pérez [editor]. 2006. ACSImagebase: a digital archive of catfish images compiled by participants in the All Catfish Species Inventory. [WWW image Database]. Available at: http://acsi.acnatsci.org/ base. Accessed October 17, 2008.

Myers, G. S. 1944. Two extraordinary new blind nematognath fishes from the Rio Negro, representing a new subfamily of Pygidiidae, with a rearrangement of the genera of the family, and illustrations of some previously described genera and species from Venezuela and Brazil. Proceedings of the California Academy of Sciences, Series 4, 23(40): 591-602.

Myers, G. S. \& S. H. Weitzman. 1966. Two remarkable new trichomycterid catfishes from the Amazon basin in Brazil and Colombia. Journal of Zoology, London, 149(3): 277-287.

Nico, L. G. \& M. C. C. de Pinna. 1996. Confirmation of Glanapteryx anguilla (Siluriformes, Trichomycteridae) in the Orinoco River basin, with notes on the distribution and habitats of the Glanapteryginae. Ichthyological Exploration of Freshwaters, 7(1): 27-32.

de Pinna, M. C. C. 1988. A new genus of trichomycterid catfish (Siluroidei, Glanapteryginae), with comments on its phylogenetic relationships. Revue Suisse de Zoologie, 95(1): 113-128.

de Pinna, M. C. C. 1989a. A new sarcoglanidine catfish, phylogeny of its subfamily, and an appraisal of the phyletic status of the Trichomycterinae (Teleostei, Trichomycteridae). American Museum Novitates, 3050: 1-39.

de Pinna, M. C. C. 1989b. Redescription of Glanapteryx anguilla, with notes on the phylogeny of Glanapteryginae (Siluriformes, Trichomycteridae). Proceedings of the Academy of Natural Sciences of Philadelphia, 141: 361-374.

de Pinna, M. C. C. 1991. Concepts and tests of homology in the cladistic paradigm. Cladistics, 7(4): 367-394.

de Pinna, M. C. C. 1992. A new subfamily of Trichomycteridae (Teleostei, Siluriformes), lower loricarioid relationships and a discussion on the impact of additional taxa for phylogenetic analysis. Zoological Journal of the Linnean Society, 106(3): 175-229.

de Pinna, M. C. C. 1993. Higher-level phylogeny of Siluriformes, with a new classification of the order. Unpublished Ph.D. Dissertation, City University of New York, New York, 528p. de Pinna, M. C. C. 1998. Phylogenetic relationships of Neotropical Siluriformes (Teleostei: Ostariophysi): historical overview and synthesis of hypotheses. Pp. 279-330. In: Malabarba, L. R., R. E. Reis, R. P. Vari, Z. M. S. Lucena \& C. A. S. Lucena (Eds.). Phylogeny and Classification of Neotropical Fishes. Porto Alegre, Edipucrs, 603p.

de Pinna, M. C. C. \& H. A. Britski. 1991. Megalocentor, a new genus of parasitic catfish from the Amazon basin: the sistergroup of Apomatoceros (Trichomycteridae: Stegophilinae). Ichthyological Exploration of Freshwaters, 2(2): 113-128.

de Pinna, M. C. C. \& W. C. Starnes, 1990. A new genus of Sarcoglanidinae from the Rio Mamore, Amazon basin, with comments on subfamiIial phylogeny (Teleostei, Trichomycteridae). Journal of Zoology, London, 222(1): 75-88. de Pinna, M. C. C. \& K. O. Winemiller. 2000. A new species of Ammoglanis (Siluriformes: Trichomycteridae) from Venezuela. Ichthyological Exploration of Freshwaters, 11(3): 255-264. 
de Pinna, M. C. C. \& W. B. Wosiacki. 2003. Family Trichomycteridae (Pencil or parasitic catfishes). Pp. 270-290. In: Reis, R. E., S. O. Kullander \& C. J. Ferraris, Jr. (Eds.). Check List of the Freshwater Fishes of South and central America. Porto Alegre, Edipucrs, 742p.

Roberts, T. R. 1972. Ecology of fishes of the Amazon and Congo basins. Bulletin of the Comparative Zoology, 143(2): 117-147.

Saxena, S. C. 1960. The cranial musculature of a hill-stream cyprinid fish Garra mullya (Sykes). Proceedings of the National Institute of Sciences of India, B, 26(4): 176-188.

Sazima, I. 2004. Natural history of Trichogenes longipinnis, a threatened trichomycterid catfish endemic to Atlantic forest streams in southeast Brazil. Ichthyological Exploration of Freshwaters, 15(1): 49-60.

Schaefer, S. A. 1990. Anatomy and relationships of the scoloplacid catfishes. Proceedings of the Academy of Natural Sciences of Philadelphia, 142: 167-210.

Schaefer, S. A. 1997. The neotropical cascudinhos: systematics and biogeography of the Otocinclus catfishes (Siluriformes: Loricariidae). Proceedings of the Academy of Natural Sciences of Philadelphia, 148: 1-120.

Schaefer, S. A. \& G. V. Lauder. 1986. Historical transformation of functional design: evolutionary morphology of feeding mechanism in loricarioid catfishes. Systematic Zoology, 35(4): 489-508.

Schaefer, S. A. \& G. V. Lauder. 1996. Testing historical hypotheses of morphological change: biomechanical decoupling in loricarioid catfishes. Evolution, 50(4): 1661-1675.

Schaefer, S. A. \& F. Provenzano. 2008. The Lithogeninae (Siluriformes, Loricariidae): anatomy, interrelationships, and description of a new species. American Museum Novitates, 3637: 1-49.

Schaefer, S. A., F. Provenzano, M. C. C. de Pinna \& J. N. Baskin. 2005. New and noteworthy Venezuelan glanapterygine catfishes (Siluriformes, Trichomycteridae), with discussion of their biogeography and psammophily. American Museum Novitates, 3496: 1-27.

Schmidt, R. E. 1993. Relationships and notes on the biology of Paracanthopoma parva (Pisces: Trichomycteridae). Ichthyological Exploration of Freshwaters, 4(2): 185-191.

Slowinski, J. B. 1993. “Unordered” versus “ordered” characters. Systematic Biology, 42: 155-165.

Spotte, S. 2002. Candiru: life and legend of the bloodsucking catfishes. Berkeley, Creative Arts Book Company, 322p.

Springer, V. G. \& G. D. Johnson. 2004. Study of the dorsal gill-arch musculature of teleostome fishes, with special reference to the Actinopterygii. Bulletin of the Biological Society of Washington, 11: 1-260.

Stiassny, M. L. J. 1990. Notes on the anatomy and relationships of the bedotiid fishes of Madagascar, with a taxonomic revision of the genus Rheocles (Atherinomorpha: Bedotiidae). American Museum Novitates, 3079: 1-33.

Sullivan, J. P., J. G. Lundberg \& M. Hardman. 2006. A phylogenetic analysis of the major groups of catfishes (Teleostei: Siluriformes) using rag1 and rag2 nuclear gene sequences. Molecular Phylogenetics and Evolution, 41(3): 636-62.

Swofford, D. L. \& W. P. Maddison. 1987. Reconstructing ancestral character states under Wagner parsimony. Mathematical Bioscience, 87(2): 199-229.

Takahasi, N. 1925. On the homology of the cranial muscles of the cypriniform fishes. Journal of Morphology, 40(1): 1-103.

Takashima, F. \& T. Hibiya. 1995. An atlas of fish histology: normal and pathological features. $2^{\text {nd }}$ ed.Tokyo, Kodansha Ltda/ Stuttgart, Gustav Fischer Verlag, 213p.
Taylor, W. R. \& G. C. van Dyke. 1985. Revised procedures for staining and clearing small fishes and other vertebrates for bone and cartilage study. Cybium, 9(2): 107-119.

Vari, R. P. 1979. Anatomy, relationships and classification of the families Citharinidae and Distichodontidae (Pisces, Characoidea). Bulletin British of the Museum, Natural History, Zoology, 36(5): 261-344.

Vetter, B. 1878. Untersuchungen zur vergleichenden Anatomie der Kiemen- und Kiefermuskulatur der Fische. II Theil. Jenaische Zeitschrift für Naturwissenschaft, 12(3): 431-550.

Wiens, J. J. 2001. Character analysis in morphological phylogenetics: problems and solutions. Systematic Biology, 50: 689-699.

Wilkinson, M. 1992. Ordered versus unordered characters. Cladistics, 8: 375-285.

Winemiller, K. O. \& H. Y. Yan. 1989. Obligate mucus-feeding in a South American trichomycterid catfish (Pisces: Ostariophysi). Copeia, 1989(4): 511-514.

Winterbottom, R. 1974a. A descriptive synonymy of the striated muscles of the Teleostei. Proceedings of the Academy of Natural Sciences of Philadelphia, 125(12): 225-317.

Winterbottom, R. 1974b. The familial phylogeny of the Tetraodontiformes (Acanthopterygii: Pisces) as evidenced by their comparative myology. Smithsonian Contributions to Zoology, 155: 1-201.

Winterbottom, R. 1993. Myological evidence for the phylogeny of recent genera of surgeonfishes (Percomorpha, Acanthuridae), with comments on the Acanthuroidei. Copeia, 1993(1): 21-39.

Wosiacki, W. B. \& M. C. C. de Pinna. 2008a. Trichomyctertus igobi, a new catfish species form the rio Iguaçu drainage: the largest head in Trichomycteridae (Siluriformes: Trichomycteridae). Neotropical Ichthyology, 6(1): 17-23.

Wosiacki, W. B. \& M. C. C. de Pinna. 2008b. A new species of the Neotropical catfish genus Trichomycterus (Siluriformes: Trichomycteridae) representing a new body shape for the family. Copeia, 2008(2): 273-278.

Wu, K.-Y. \& S.-C. Shen. 2004. Review of the teleostean adductor mandibulae and its significance to the systematic positions of the Polymixiiformes, Lampridiformes, and Triacanthoidei. Zoological Studies, 43(4): 712-736.

Yabe, M. 1985. Comparative osteology and myology of the superfamily Cottoidea (Pisces: Scorpaeniformes) and its phylogenetic classification. Memoirs of the Faculty of Fisheries, Hokkaido University, 32: 1-130.

Zuanon, J., F. A. Bockmann \& I. Sazima. 2006. A remarkable sanddwelling fish assemblage from central Amazonia, with comments on the evolution of psammophily in South American freshwater fishes. Neotropical Ichthyology, 4(1): 107-118.

Zuanon, J. \& I. Sazima. 2004a. Candiru, o peixe-vampiro. Ciência Hoje, 34(202): 64-67.

Zuanon, J. \& Sazima, I. 2004b. Natural history of Stauroglanis gouldingi (Silutiformes: Trichomycteridae), a miniature sanddwelling candiru from Central Amazonian streamlets. Ichthyological Exploration of Freshwaters, 15(3): 201-208.

Zuanon, J. \& I. Sazima. 2004c. Vampire catfishes seek the aorta not the jugular: candirus of the genus Vandellia (Trichomycteridae) feed on major gill arteries of host fishes. Aqua, Journal of Ichthyology and Aquatic Biology, 8(1): 31-36.

Accepted April 22, 2010 Published June 25, 2010 